Aus der Klinik für Kardiologie und Pneumologie

(Prof. Dr. med. G. Hasenfuß)

der Medizinischen Fakultät der Universität Göttingen

\title{
Der Effekt von CD16-positiven und CD16-negativen Monozyten auf die Arterio- und Angiogenese nach muriner Hinterlaufischämie
}

\author{
INAUGURAL-DISSERTATION \\ zur Erlangung des Doktorgrades \\ der Medizinischen Fakultät der \\ Georg-August-Universität zu Göttingen
}

vorgelegt von

Markus Bernhardt

aus

Lutherstadt Wittenberg

Göttingen 2018 
Dekan:

Referent/in:

Ko-Referent/in:
Prof. Dr. rer. nat. H. K. Kroemer

PD Dr. med. F. S. Czepluch

Prof. Dr. med. M. Oppermann

Datum der mündlichen Prüfung: 09. August 2018 
Hiermit erkläre ich, die Dissertation mit dem Titel "Der Effekt von CD16-positiven und CD16-negativen Monozyten auf die Arterio- und Angiogenese nach muriner Hinterlaufischämie" eigenständig angefertigt und keine anderen als die von mir angegebenen Quellen und Hilfsmittel verwendet zu haben.

Göttingen, den 


\section{Inhaltsverzeichnis}

Abbildungsverzeichnis ......................................................................................... III

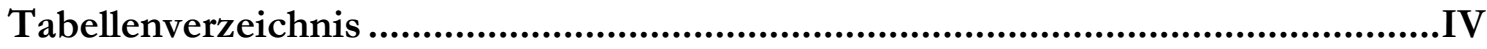

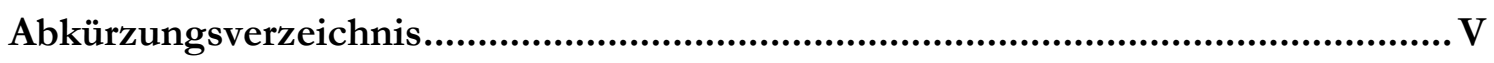

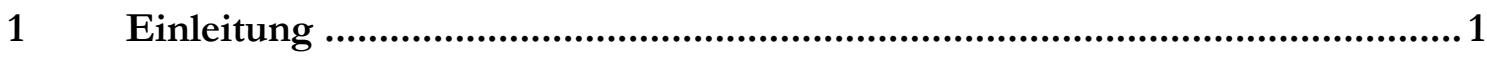

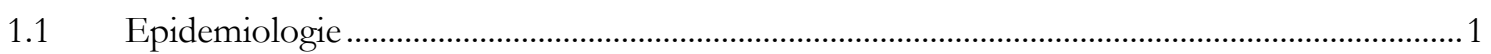

1.2 Kompensationsmechanismen ischämischer Erkrankungen ......................................................2

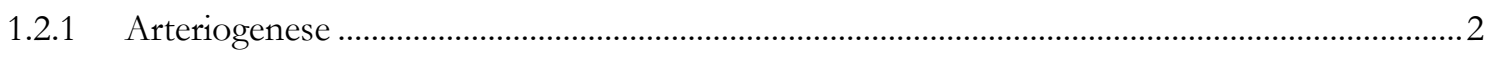

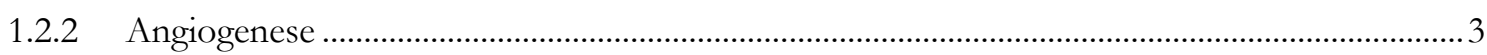

1.3 Beschreibung der Monozyten und Monozytensubpopulationen und ihre Bedeutung für die Angio- und Arteriogenese....................................................................................................

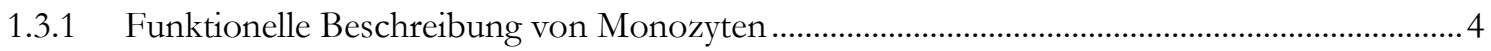

1.3.2 Klassifikation humaner Monozyten …………...............................................................

1.3.3 Beschreibung muriner Monozyten ..................................................................................

1.4 Monozyten und ihre Bedeutung in der Gefäßneubildung .........................................................5

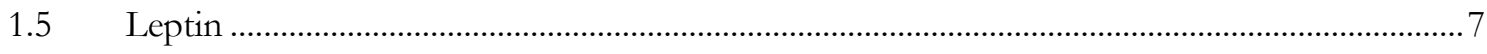

1.5.1 Leptininteraktionen im Adipositasstoffwechsel ...............................................................

1.5.2 Fettstoffwechsel-unabhängige Leptinwirkungen.................................................................. 8

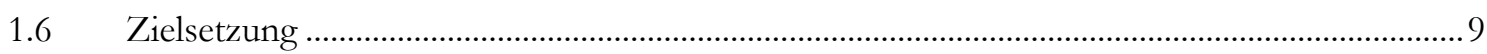

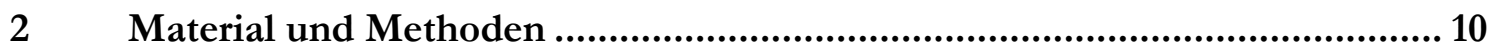

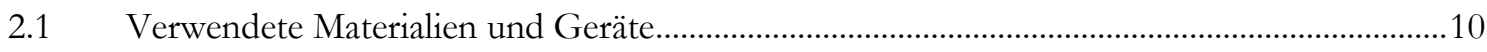

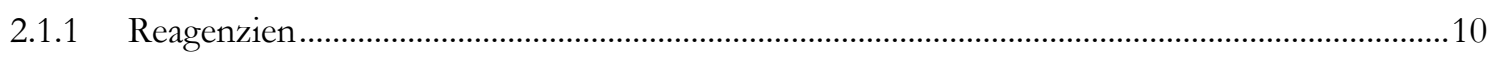

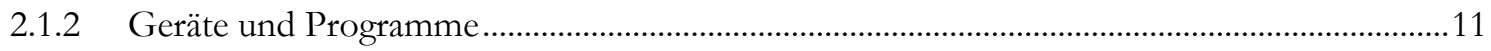

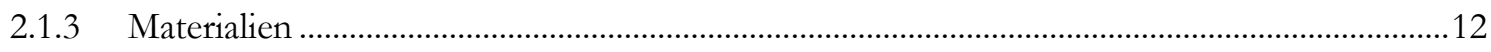

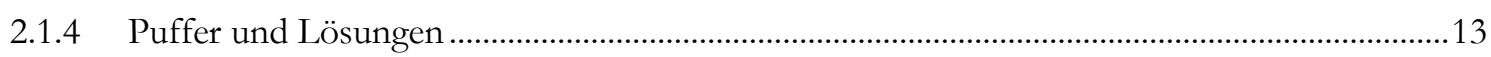

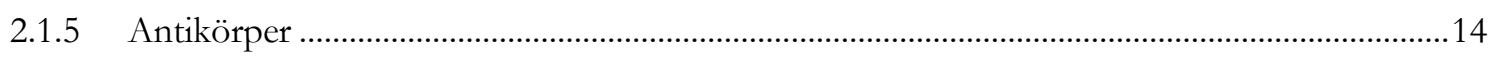

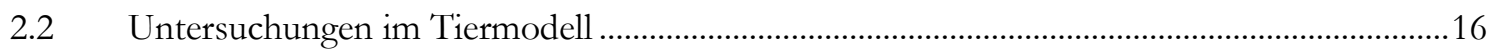

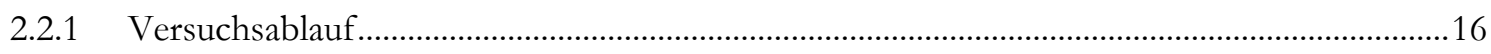

2.2.2 Induktion der Hinterlaufischämie.................................................................................18

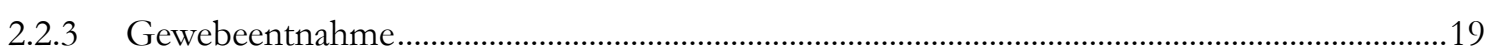

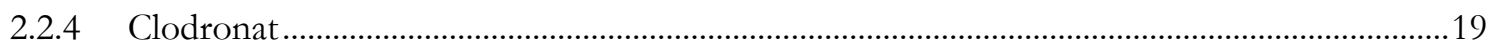

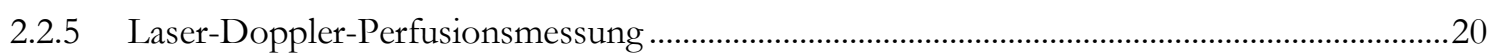

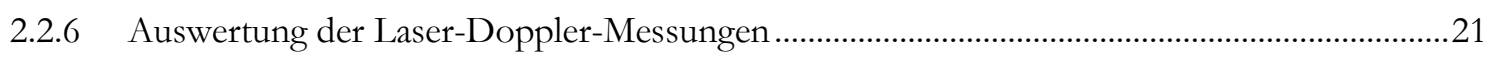

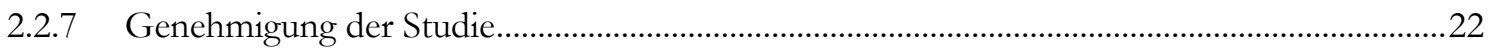

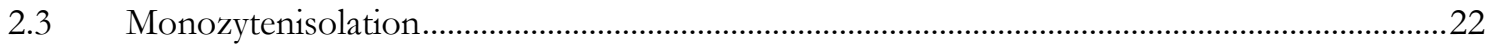

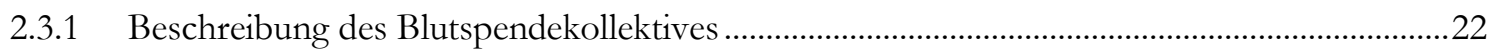

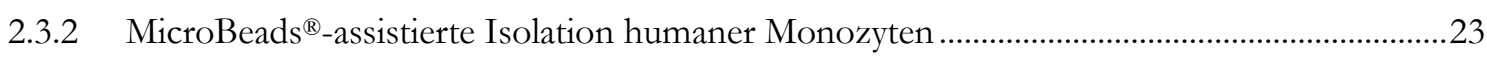

2.3.3 Durchflusszytometrische Qualitätskontrollen der Monozytenisolation...................................26 
2.3.4 Genehmigung der Studie.

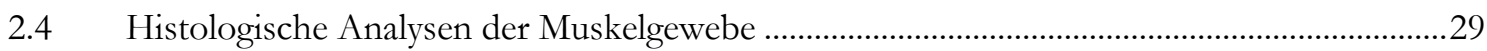

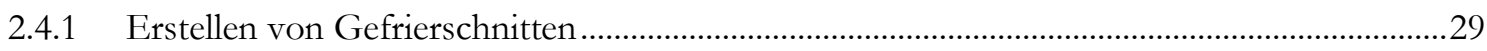

2.4.2 Beschreibung der unterschiedlichen Antikörper ...................................................................29

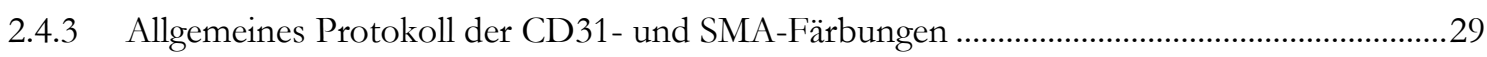

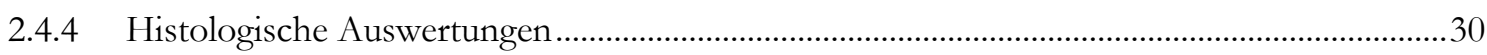

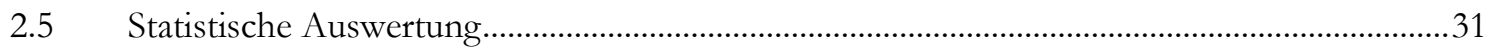

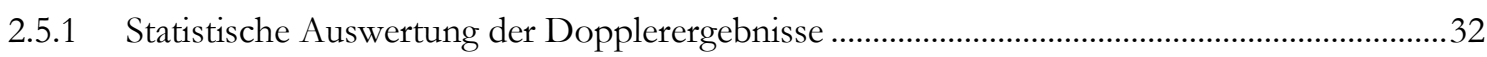

2.5.2 Statistische Auswertung der histologischen Untersuchungen ....................................................

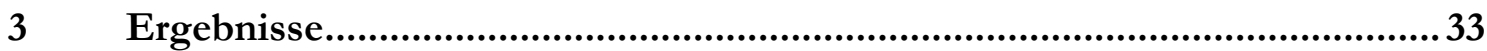

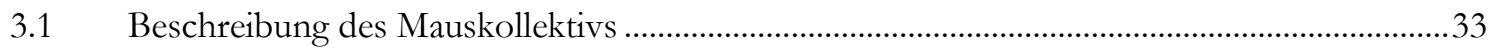

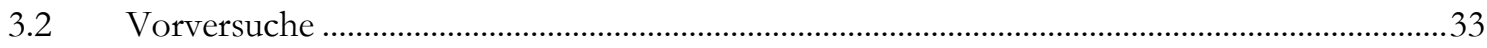

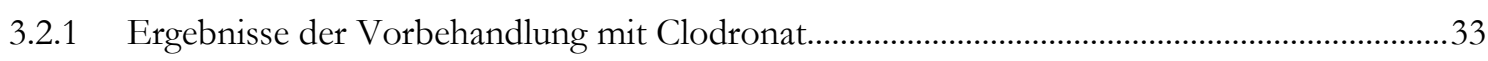

3.2.2 Qualitätskontrolle der Monozytenisolation..............................................................................3

3.3 Ergebnisse der Perfusionsmessungen nach Hinterlaufischämie...................................................

3.3.1 Reperfusion mit unstimulierten Monozyten behandelter Mäuse.................................................34

3.3.2 Evaluation der Perfusionsergebnisse nach Behandlung durch Leptin-stimulierte

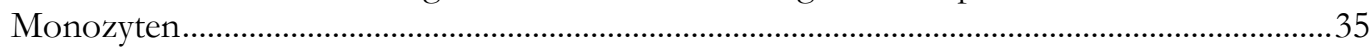

3.3.3 Unterschiede der Reperfusion mit unstimulierten und mit Leptin-stimulierten Monozyten

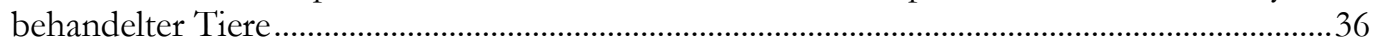

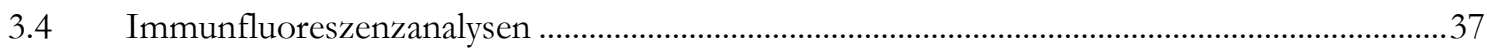

3.4.1 Ergebnisse der Untersuchungen zur Angiogenese ...................................................................

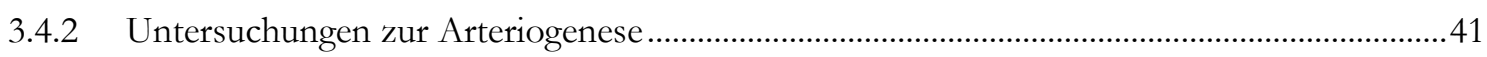

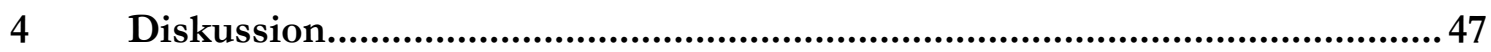

4.1 Monozyten und ihre Bedeutung in der Gefäßneubildung.......................................................4

4.2 Die Bedeutung der Gabe humaner Monozyten in der Reperfusion..........................................48

4.3 Die Rolle von humanen Monozyten in der Arteriogenese .........................................................49

4.4 Humane Monozyten und ihre Auswirkung auf die Angiogenese.................................................51

4.5 Limitationen der Arbeit...................................................................................................... 52

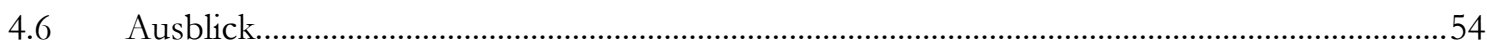

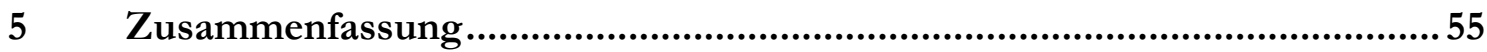

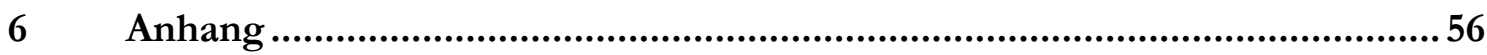

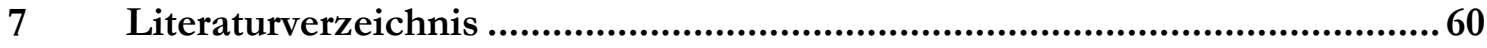




\section{Abbildungsverzeichnis}

Abbildung 1: Biphasische Monozytenantwort nach Myokardinfarkt in der Maus ....................................6

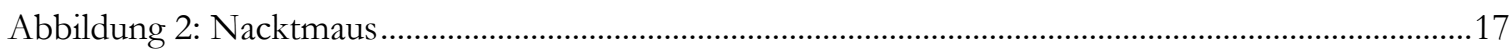

Abbildung 3: Darstellung des zeitlichen Ablaufs der Versuche.............................................................18

Abbildung 4: Schema der arteriellen Gefäßversorgung mit eingezeichneten Ligaturen ..........................19

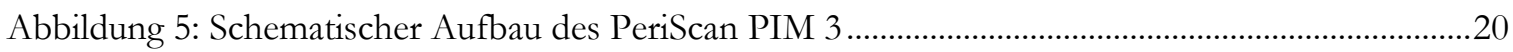

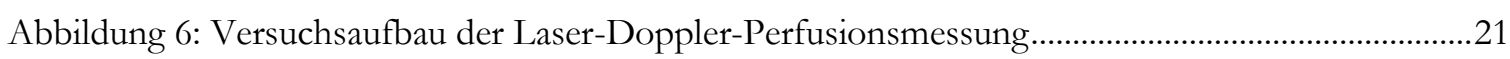

Abbildung 7: Beispielhafte Perfusionsdarstellung der Laser-Doppler-Messung.......................................22

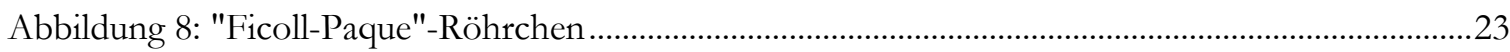

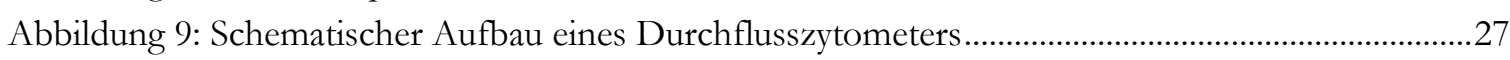

Abbildung 10: Exemplarische Darstellung der histologischen Färbungen ...............................................31

Abbildung 11: Repräsentative Dot-Plot-Darstellungen der einzelnen durchflusszytome-trischen Messungen

Abbildung 12: Darstellung der Laser-Doppler-Perfusionsmessung der Interventionsgruppen ohne

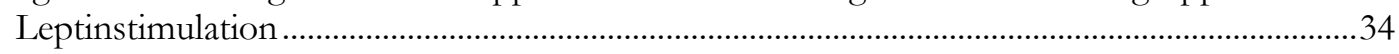

Abbildung 13: Darstellung der Laser-Doppler-Perfusionsmessung der Interventionsgruppen nach Leptinstimulation......................................................................... 35

Abbildung 14: Zusammenfassende Darstellung der Laser-Doppler-Perfusionsmessung aller Interventionsgruppen............................................................................................................ 36

Abbildung 15: Darstellung der Verhältnisse der Gesamtkapillaren der Gruppen ohne

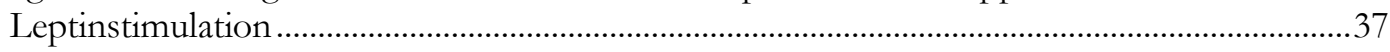

Abbildung 16: Darstellung der Verhältnisse der Gesamtkapillaren der Gruppen nach Leptinstimulation

Abbildung 17: Gesamtübersicht der Verhältnisse der Vaskularisierung einzelner Myofibrillen aller Interventionsgruppen .....................................................................................

Abbildung 18: Darstellung der Verhältnisse der kapillären Durchschnittsfläche der Gruppen ohne Leptinstimulation.

Abbildung 19: Darstellung der Verhältnisse der kapillären Durchschnittsfläche der Gruppen mit Leptinstimulation

Abbildung 20: Darstellung der Verhältnisse der Arteriolenzahl der Gruppen nach Gabe unstimulierter Monozyten..

Abbildung 21: Darstellung der Verhältnisse der Arteriolenzahl der Gruppen nach Gabe Leptinstimulierter Monozyten.

Abbildung 22: Gesamtübersicht der Verhältnisse der muskulären Gesamtquerschnittsfläche aller Interventionsgruppen.

Abbildung 23: Darstellung der Verhältnisse der muskulären Querschnittsfläche pro Arteriole der Gruppen nach Gabe unstimulierter Monozyten.

Abbildung 24: Darstellung der Verhältnisse der muskulären Querschnittsfläche pro Arteriole der Gruppen nach Gabe Leptin-stimulierter Monozyten 


\section{Tabellenverzeichnis}

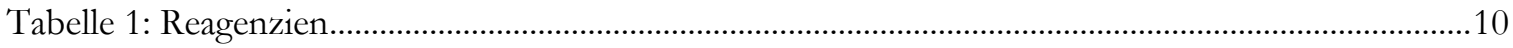

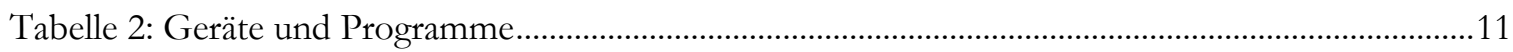

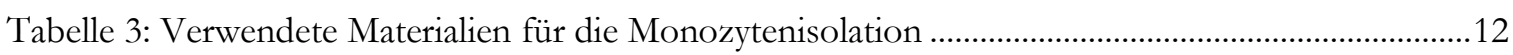

Tabelle 4: Verwendete Materialen für die Operation der Hinterlaufischämie..........................................12

Tabelle 5: Puffer und Lösungen der Monozytenisolation.........................................................................13

Tabelle 6: Puffer und Lösungen der Immunfluoreszenzfärbungen ........................................................13

Tabelle 7: Verwendete Puffer und Lösungen der Durchflusszytometrie .............................................13

Tabelle 8: Bestandteile des Monocyte Isolation Kit II .............................................................................14

Tabelle 9: Bestandteile des CD16+ Monocyte Isolation Kit...............................................................14

Tabelle 10: Zusammenstellung der Antikörper für die Isotypenkontrollen zur Reinheitskontrolle .....14

Tabelle 11: Zusammenstellung der Färbeantikörper zur Reinheitskontrolle...........................................15

Tabelle 12: Zusammenstellung der Isotypenkontrollantikörper zur ObR-Färbung..............................15

Tabelle 13: Zusammenstellung der Färbeantikörper der ObR-Färbung................................................15

Tabelle 14: Zusammensetzung der Primärantikörperlösung für die CD31-Färbung..............................16

Tabelle 15: Zusammensetzung der Sekundärantikörperlösung für die CD31-Färbung ........................16

Tabelle 16: Zusammensetzung der Sekundärantikörper für die SMA/CD31-Doppelfärbung .............16

Tabelle 17: Zusammensetzung der Sekundärantikörperlösung für die SMA/CD31-Doppelfärbung..16

Tabelle 18: Auflistung der Versuchsgruppen .........................................................................................17

Tabelle 19: Darstellung der Versuchsgruppen zum Clodronatversuch ..................................................20

Tabelle 20: Übersicht über die farblichen Eigenschaften und Wellenlängen der Fluorochrome..........27 


\section{Abkürzungsverzeichnis}

A. fem. Arteria femoralis

A. prof. fem. Arteria profunda femoris

$\mathrm{AB}$

Ang2

ANOVA

APC

BMI

BSA

CAC

CCL2

CCL5

CCR2

CD

CD16-mo

CD16-mo (s)

$\mathrm{CD} 16^{+}-\mathrm{mo}$

$\mathrm{CD} 16^{+}$-mo (s)

$\mathrm{CO}_{2}$

cvRF

$\mathrm{CX}_{3} \mathrm{CL} 1$

$\mathrm{CX}_{3} \mathrm{CR} 1$

CXCR4

DAPI

DPBS

EC

ECM

EDTA

FACS $^{\mathrm{TM}}$

$\mathrm{Fc}$
Antibody

Angiopoetin-2

analysis of variance

Allophycocyanin

Body-Mass-Index

Bovines Serumalbumin

circulating angiogenic cell

Chemokine-(C-C motif)-Ligand 2

Chemokine-(C-C motif)-Ligand 5

Chemokine-(C-C motif)-Receptor 2

Cluster of differentiation

CD16-negative Monozyten

stimulierte CD16-negative Monozyten

CD16-positive Monozyten

stimulierte CD16-positive Monozyten

Kohlenstoffdioxid

kardiovaskuläre Risikofaktoren

Chemokine-(C-X ${ }_{3}-C$ motif)-Ligand 1

Chemokine-(C-X ${ }_{3}-C$ motif)-Receptor 1

Chemokine-(C-X-C motif)-Receptor 4

4',6-Diamidin-2-phenylindol

Dulbecco's Phosphate Buffered Saline

Endothelzelle

extrazelluläre Matrix

Ethylendiamintetraessigsäure

Fluorescence-Activated Cell Sorting

fragment crystallisable 


\begin{tabular}{|c|c|}
\hline FcR & fragment crystallisable-Receptor \\
\hline FGF & Fibroblast Growth Factor \\
\hline FITC & Fluoresceinisothiocyanat \\
\hline FOXN1 & Forkhead box protein N1 \\
\hline FSC & Forward Scatter \\
\hline g & Gramm \\
\hline GM-CSF & Granulocyte-Monocyte Colony-stimulating Factor \\
\hline HIF-1 $\alpha$ & Hypoxia-inducable-factor $\alpha$ \\
\hline HUVECs & Human Umbilical Vein Endothelial Cells \\
\hline $\operatorname{IgG}$ & Immunglobulin $G$ \\
\hline IL & Interleukin \\
\hline JAK & Januskinase \\
\hline KHK & koronare Herzkrankheit \\
\hline KORA & Kooperative Gesundheitsforschung in der Region Augsburg \\
\hline Ly6-C high & stark-exprimiertes lymphocyte antigen 6 complex, locus $C 1$ \\
\hline Ly6-C low & schwach-exprimiertes lymphocyte antigen 6 complex, locus $C 1$ \\
\hline M-CSF & Monocyte-Colony stimulating Factor \\
\hline MACS $^{\mathrm{TM}}$ & Magnetic activated cell-sorting ${ }^{T M}$ \\
\hline MCP-1 & Monocyte Chemoattractant Protein-1 \\
\hline Mm. & Musculi \\
\hline MMP & Matrix-Metalloproteinase \\
\hline $\mathrm{MNC}$ & mononukleäre Zelle \\
\hline MONICA & Monitoring Trends and Determinants in Cardiovascular Disease \\
\hline mRNA & messenger Ribonukleinsäure \\
\hline $\mathrm{NaCl}$ & Natriumchlorid \\
\hline $\mathrm{nm}$ & Nanometer \\
\hline NMRI & Naval Medical Research Institute \\
\hline $\mathrm{NO}$ & Stickstoffmonoxid \\
\hline ObR & Leptinrezeptor \\
\hline OP & Operation \\
\hline
\end{tabular}


pAVK periphere arterielle Verschlusskrankheit

PBS

Phosphated Buffere Saline

PE

Phycoerythrin

PECAM-1

Platelet-Endothelial-Cell-Adhesion-molecule-1

PerCP-Cy ${ }^{\mathrm{TM}} 5.5 \quad$ Peridinin-Chlorophyll-Komplex + Cyanin5.5

PFA

Paraformaldehyd

PMN

Polymorphkerniger neutrophiler Granulozyt

PZN

Pharmazentralnummer

RPMI

Roswell Park Memorial Institute

SEM

Standard-Error of Mean

SMA

Smooth-Muscle-Actin

sObR

löslicher Leptinrezeptor

SSC

Side Scatter

STAT

signal-transducer-and-activator-of-transcription

TEMs

Tie2-expressing monocytes

TGF- $\beta$

Transforming growth factor $\beta$

Tie2

Tyrosine kinase with immunoglobulin-like and EGF-like domains 1

TNF

Tumornekrosefaktor

TNFAIP2

TNF- $\alpha$-induced protein 2

total-mo

Gesamtmonozyten

total-mo (s)

stimulierte Gesamtmonozyten

UMG

Universitätsmedizin Göttingen

VEGF

Vascular Endothelial Growth Factor

VEGFR-1

Vascular Endothelial Growth Factor-Receptor 1

WHO

World Health Organization

ZTE

Zentrale Tierexperimentelle Einrichtung 


\section{Einleitung}

\subsection{Epidemiologie}

Kardiovaskuläre Erkrankungen und ihre Folgeerscheinungen sind weltweit die häufigste zugrundeliegende Ursache für Morbidität und Mortalität (Lim et al. 2013). Diese sind in den allermeisten Fällen bedingt durch Arteriosklerose, welche im Wesentlichen zu einer Sauerstoffunterversorgung und Minderfunktion eines jeweils nachgeschalteten Organs führt. Die häufigste Manifestation der Arteriosklerose stellt die koronare Herzkrankheit (KHK) dar, welche im akut-ischämischen Ereignis den Myokardinfarkt zur Folge hat und hier bei rezidivierenden Infarkten in der chronischen-ischämischen Herzerkrankung enden kann. Weitere Ausprägungen kardiovaskulärer Erkrankungen sind z. B. die periphere arterielle Verschlusskrankheit (pAVK) oder der Schlaganfall.

Kardiovaskuläre Erkrankungen sind mit 39,7\% der Todesfälle im Jahr 2013 auch die Haupttodesursache in Deutschland (Statistisches Bundesamt 2014). Von diesen Todesfällen waren allein 20,6\% auf eine chronisch-ischämische Herzerkrankung zurückzuführen.

Die Sterblichkeit von Patienten mit KHK nimmt in Deutschland kontinuierlich ab. Seit Mitte der 1990er Jahre ist dies auch zunehmend in der älteren Bevölkerung zu beobachten hier vor allem in einer Steigerung der Prävalenz des überlebten Myokardinfarktes zu sehen (Gößwald et al. 2013). Dies ist insbesondere bei gleichbleibender Inzidenz des akuten Myokardinfarktes (Wiesner et al. 2002) auf eine bessere Akutbehandlung zurückzuführen (Kuch et al. 2008; Löwel et al. 2005) und zeigt sich vor allem in der stetig abnehmenden Zahl der Sterbefälle (Deutsche Herzstiftung e. V. [Hrsg.] 2015). Daten aus der kooperativen Gesundheitsforschung in der Region Augsburg (KORA) verglichen mit den Untersuchungen aus dem Projekt „Monitoring Trends and Determinants in Cardiovascular Disease" (MONICA) der Weltgesundheitsorganisation (WHO) belegen diese Entwicklung (Löwel 2006). Auch wenn diese Daten lediglich die Jahre 1985-1987 mit 2001-2003 vergleichen, ist auffällig, dass die um $40 \%$ reduzierte Reinfarktrate deutlich verbessert war. Dies ist zusätzlich darin begründet, dass in der Erforschung und Behandlung kardiovaskulärer Risikofaktoren (cvRF), wie z. B. arterielle Hypertonie und Fettstoffwechselstörungen innerhalb dieser Zeit deutliche Fortschritte erzielt werden 
konnten und somit die Sekundärprophylaxe verbessert wurde (Robert-KochInstitut [Hrsg.] 2014).

Den o.g. erfreulichen Entwicklungen bei Hypertonie und Hyperliproteinämie ist jedoch eine vermehrte Prävalenz von Adipositas und Diabetes mellitus gegenüberzustellen. Somit bleibt auch aufgrund der Veränderungen der demografischen Struktur in Deutschland mit einem immer größer werdenden Anteil der Älteren in der Gesellschaft die Prävalenz der Arteriosklerose und somit auch die Prävalenz der KHK gleich (Gößwald et al. 2013).

\subsection{Kompensationsmechanismen ischämischer Erkrankungen}

Zur Kompensation der chronisch-ischämischen Gewebeschädigung stehen dem menschlichen Körper im Wesentlichen zwei unterschiedliche Kompensationsmechanismen zur Verfügung. Hierbei spielen die Arteriogenese sowie auch die Angiogenese eine zentrale Rolle.

\subsubsection{Arteriogenese}

Die Arteriogenese beschreibt den Prozess der Entstehung von Arterien aus vorbestehenden kollateral verlaufenden Arteriolen. Hierbei werden durch eine Stenosierung des Ursprungsgefäßes und die dadurch erhöhte Flussgeschwindigkeit in den umliegenden Arteriolen die Scherkräfte erhöht (Galie et al. 2014). Dadurch kommt es zu einer Aktivierung des Endothels. Nachfolgend erhöhen Endothelzellen (ECs) die Ausschüttung von Zytokinen wie Monocyte Chemoattractant Protein-1 (MCP-1) und steigern die Expression von Adhäsionsmolekülen (Shyy et al. 1994). Hierunter kommt es zu einer vermehrten Einwanderung und Aktivierung von Monozyten in diesem Gebiet (Capoccia et al. 2008; Cowan und Langille 1996; Epelman et al. 2015). Diese wiederum produzieren weitere Wachstumsfaktoren, Chemokine und Zytokine, unter anderem auch Tumornekrosefaktor$\alpha($ TNF- $\alpha)$. Als Folge hiervon verwandeln sich Arteriolen in Arterien. Dies geschieht durch Endothelproliferation, der sich die Proliferation und Expansion glatter Muskelzellen anschließt. Für diesen Prozess wird zunächst die Lamina elastica interna über aktivierte Matrix-Metalloproteinasen (MMPs) enzymatisch gelockert. Im Weiteren erfolgt dann die Lyse des perivaskulären Gewebes, um dem wachsenden Gefäß den nötigen Raum zur Ausdehnung zu verschaffen (Schaper und Buschmann 1999). 


\subsubsection{Angiogenese}

Der Vorgang der Angiogenese beschreibt die Entstehung neuer Kapillaren aus bereits existierenden Kapillaren. Hierbei werden prinzipiell zwei verschiedene Arten der Angiogenese unterschieden: das Sprouting und die Intussuszeption (Risau 1997).

\subsubsection{Aussprossung (Sprouting)}

Sprouting beschreibt das Aussprossen neuer Kapillaräste aus einer bereits vorhandenen Kapillare. Hierbei kommen Stimuli multifaktorieller Genese zum Tragen. Zum einen wird durch mechanische Reize (z. B. erhöhte Muskelkontraktion (Hudlicka et al. 1992)) eine Aktivierung des Endothels herbeigeführt, was zu einer Induktion der StickstoffmonoxidSynthase (NO-Synthase) führt. Durch diese vermehrte NO-Freisetzung folgt eine Vasodilatation. Durch chemische Elemente (z. B. Anämie (Metivier et al. 2000)) kommt es unter anderem durch Induktion des Transkriptionsfaktors Hypoxia Inducible Factor $1 \alpha$ (HIF1 $\alpha$ ) zu einer vermehrten Expression von Vascular Endothelial Growth Factor (VEGF). Dies führt zur vermehrten Durchlässigkeit der vaskulären Wand, wodurch Plasmaproteine in den extravaskulären Raum gelangen. Diese nutzen die später hindurchtretenden Endothelzellen als Leitstrukturen (Ferrara 1995). Im Anschluss erfolgt die Angiopoetin-2vermittelte (Ang-2)-Auflockerung des Zellverbandes sowie das Lösen desselbigen durch MMPs, sodass nun wiederum VEGF- und Fibroblast Growth Factor (FGF)-vermittelt die ECs zum Wachsen und Migrieren angeregt werden und so die Gefäßsprosse ausbilden (Hanahan 1997).

\subsubsection{Intussuszeption}

Im Gegensatz zur Aussprossung bleibt bei der Intussuszeption die Basalmembran des Gefäßes erhalten. Hierbei werden zunächst auf gegenüberliegenden Seiten feine Pili (Djonov und Makanya 2005) ausgebildet, die aufeinander zuwachsen bis sie intraendotheliale Zell-Zell-Kontakte ausbilden können. Anschließend werden die endothelialen Zellverbindungen neu organisiert und im Folgenden diese Basis der endothelialen Anlagerung perforiert. Hierauf folgt eine Invasion von interstitiellem Gewebe, Perizyten und Myofibroblasten. Des Weiteren kommt es zur Anlagerung von Kollagenfibrillen und somit zur schrittweisen Ausdehnung der interkapillären Gewebebrücke und endgültigen Ausbildung des perivaskulären Gewebes (Makanya et al. 2009; Risau 1997). 


\subsection{Beschreibung der Monozyten und Monozytensubpopulationen und ihre Bedeutung für die Angio- und Arteriogenese}

\subsubsection{Funktionelle Beschreibung von Monozyten}

Monozyten sind Bestandteil der leukozytären Blutzellreihe und machen in dieser 2 - 10\% der im Blut zirkulierenden Zellen aus. Sie werden im Knochenmark aus der hämatopetischen Stammzelle über den Monoblasten unter dem Einfluss von zunächst Granulocyte Macrophage Colony-Stimulating Factor (GM-CSF) und später Macrophage ColonyStimulating Factor (M-CSF) gebildet und gehören zum angeborenen Immunsystem. Sie haben einen Durchmesser von ca. 5 - $20 \mu \mathrm{m}$ und sind somit die größten Leukozyten. Monozyten sind Vorläuferzellen von Makrophagen und dendritischen Zellen und bilden zusammen mit ihnen das Mononukleäre Phagozytensystem. Auf ihrer Zelloberfläche befinden sich verschiedene Rezeptoren, die es ihnen erlauben, pathogene Strukturen zu erkennen, diese mithilfe von Phagozytose zu eliminieren und im Folgenden Antigene zu präsentieren. Des Weiteren erlauben Chemokinrezeptoren die Migration der Monozyten aus dem Blut in Gebiete unterschiedlicher Gewebe (z. B. Lunge, Leber) und auch Pathologien (z. B. Ischämie oder Inflammation (Serbina et al. 2008; Venneri et al. 2007)). Hier bilden sie sich dann zu gewebstypischen Makrophagen (z. B. Alveolarmakrophagen in der Lunge oder Kupfferzellen in der Leber) aus.

\subsubsection{Klassifikation humaner Monozyten}

Humane Monozyten können anhand ihrer Oberflächenmarker in verschiedene Subpopulationen unterteilt werden. Hierzu wurde von Bernhard Passlick et al. 1989 neben der Expression des Lipopolysaccharidrezeptors (CD[Cluster of Differentiation]14) die differentielle Expression des Immunglobulin $G(\mathrm{Ig} G)$ bindenden kristallisierbaren Fragment gamma-Rezeptor (FcR/CD16) herangezogen (Passlick 1989). Entsprechend wurden Monozyten ohne Nachweis von CD16 als Oberflächenmarker (CD16-mo) als „klassische“ und CD16 ${ }^{+}$-Monozyten (CD16 ${ }^{+}$-mo) als „nicht-klassische“ Monozyten bezeichnet (Ziegler-Heitbrock et al. 2010).

Die CD $16^{+}$-mo bilden ca. 10\% der Gesamtmonozytenpopulation im peripheren Blut. Sie unterscheiden sich von den klassischen Monozyten nicht nur, wie oben erwähnt, in der Expression von CD16, sondern auch in der Funktion. Zum Beispiel ist die Migration gegenüber den Zytokinen VEGF und MCP-1 deutlich eingeschränkt (Czepluch et al. 2011). Zusätzlich zeigen die nicht-klassischen Monozyten eine höhere Expression des Interleukin8 (IL-8) -Rezeptors und migrieren demzufolge IL-8-abhängig ins Gewebe (Ancuta et al. 
2003). Auch Zytokine wie TNF- $\alpha$ oder Interleukin-1 $\beta$ (IL-1 $\beta$ ) werden durch CD16 ${ }^{+}$-mo produziert, vor allem nachdem sie am Toll-like Receptor-4 durch Lipopolysaccharid stimuliert, oder aber nachdem sie durch Leptin am Leptinrezeptor (ObR) aktiviert wurden (Fernandez-Riejos et al. 2010; Mukherjee et al. 2015). Antiinflammtorische Zytokine, wie z. B. Interleukin-10 (IL-10), spielen bei der Aktivierung und auch Zytokinausschüttung dieser Monozytensubpopulationen eher eine untergeordnete Rolle (Belge et al. 2002).

CD16-Monozyten (CD16-mo; ca. 90\% der Monozytenfraktion im Blut) zeigen mit der starken Expression des MCP-1-Rezeptors (Chemokine [C-C motif]-Receptor 2 [CCR2] (Weber et al. 2000)) und der Sezernierung von Myeloperoxidase (Grage-Griebenow et al. 2001a) im Gegensatz zu den $\mathrm{CD} 16^{+}$-mo eher inflammatorische Eigenschaften (Gordon und Taylor 2005).

\subsubsection{Beschreibung muriner Monozyten}

Analog zu den humanen Monozyten und ihren Subpopulationen wurden 2001 bei Mäusen ebenfalls verschiedene Monozytenuntergruppen beschrieben (Palframan et al. 2001). 2003 gelang es hier, eine differenziertere Beschreibung dieser Subpopulationen zu etablieren, die neben anderen Oberflächenantigenen hauptsächlich anhand unterschiedlicher Expressionsprofile des Lymphozytenantigens Lymphocyte Antigen 6 Complex, Locus C1 (Ly6C) getätigt wurde (Geissmann et al. 2003). Entsprechend wurden hier die Ly6-C high Monozyten im Mausmodell ebenfalls als „klassische“ Monozyten bezeichnet, obwohl zwischen humanen und murinen Monozyten deutliche Unterschiede in Anzahl und Funktion bestehen. Beispielhaft für solche Unterschiede sind z. B. die Einwanderung klassischer humaner Monozyten in ischämisches Gewebe mithilfe des MCP-1-Rezeptors CCR2 (Cochain et al. 2010) bzw. das unterschiedliche Migrationsverhalten der beiden Monozytenspezies gegenüber dem Fraktalkinrezeptor (Geissmann et al. 2003). Die Ly6$\mathrm{C}^{\text {low }}$-Monozyten hingegen exprimieren wiederum eher den Chemokine-(C-X $X_{3}-C$ Motif) Receptor 1 ( $\left.\mathrm{CX}_{3} \mathrm{CR} 1\right)$ in höherer Konzentration und finden sich in nicht-entzündlichem Gewebe. Sie werden auch als „residente“ oder „reparative“ Monozyten bezeichnet und sind somit eher den humanen $\mathrm{CD} 16^{+}$-mo zugeordnet (Cochain et al. 2010; Geissmann et al. 2003; Lim et al. 2013; Nahrendorf et al. 2007).

\subsection{Monozyten und ihre Bedeutung in der Gefäßneubildung}

Monozyten spielen eine bedeutende Rolle in der Gefäßneubildung, sowohl bei der Arterioals auch in der Angiogenese. So ist z. B. beschrieben, dass die Anzahl entstandener Kollateralen nach muriner Hinterlaufischämie von der Menge im Blut zirkulierender Leukozyten abhängig ist (Bergmann et al. 2006). Schon 1998 konnten Arras et al. zeigen, dass sich Monozyten nach muriner Hinterlaufischämie vermehrt an das Endothel von 
Kollateralen anlagern und auch vermehrt in der Muscularis von Ischämie ausgesetzten Arteriolen zu detektieren sind (Arras et al. 1998). Dies war in der Arteriogenese lediglich innerhalb der ersten beiden Tage nach Gefäßverschluss zu beobachten. Zusätzlich zeigte sich hier eine deutliche Zunahme an proliferativer Aktivität in der Gefäßmuskulatur. In der gleichen Untersuchung zeigte sich bei der Induktion der Angiogenese ebenfalls eine Adhärenz von Monozyten. Diese waren jedoch nicht vor dem siebten Tag nach Hinterlaufischämie zu detektieren. Histomorphologische Veränderungen im Sinne von Kapillarproliferation waren auch hier erst ab diesem Zeitpunkt zu sehen.

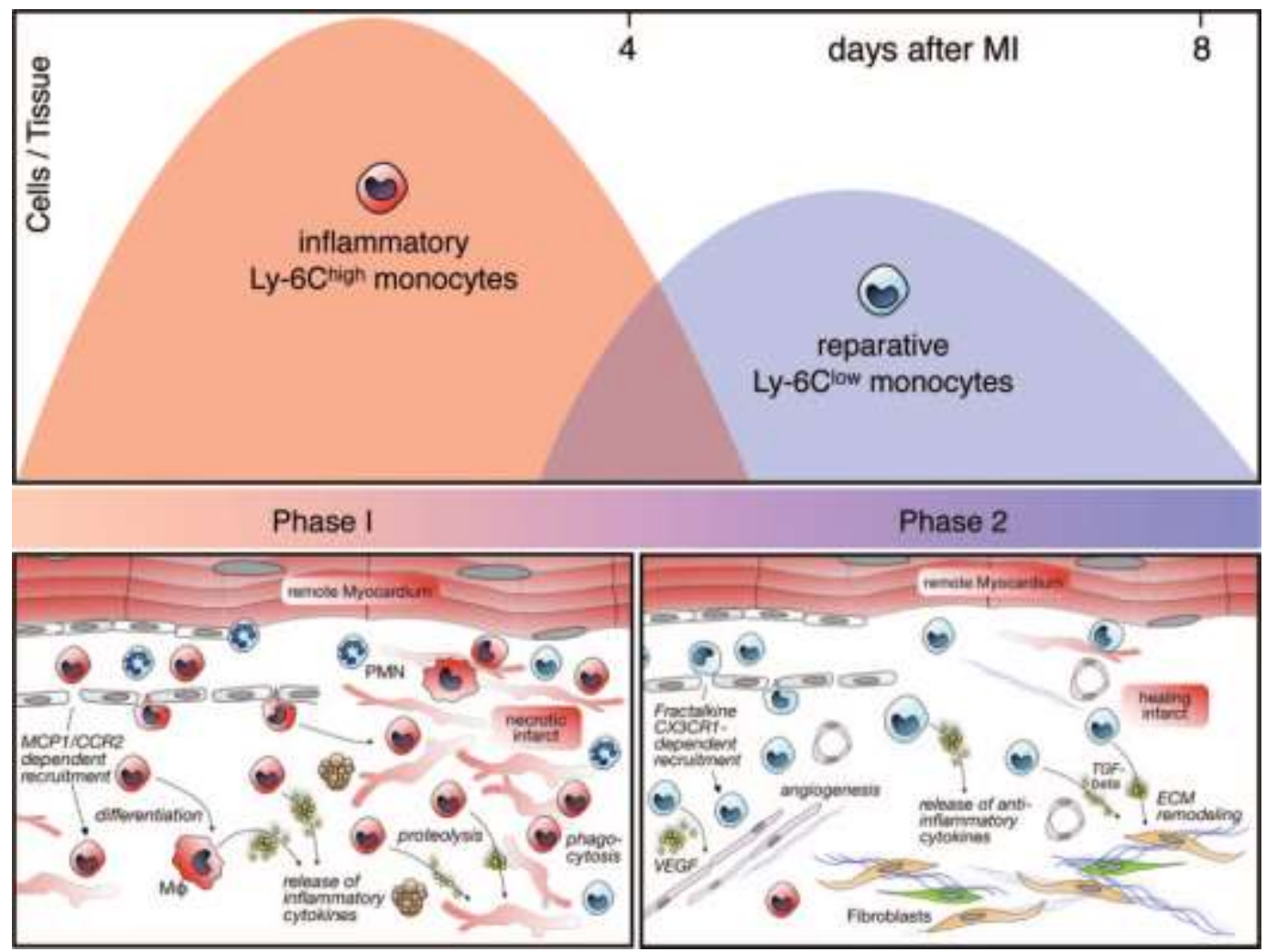

Abbildung 1: Biphasische Monozytenantwort nach Myokardinfarkt in der Maus: Gezeigt ist die Rekrutierung der Monozytensubpopulationen in Abhängigkeit der Zeit (in Tagen) nach Myokardinfarkt. Zusätzlich sind im unteren Abschnitt die wichtigsten Funktionen der verschiedenen Zellen beschrieben. PMN bedeutet polymorphkerniger neutrophiler Granulozyten; МФ, Makrophagen; ECM, extrazelluläre Matrix (Nahrendorf et al. 2010), mit freundlicher Genehmigung von Lippincott Williams \& Wilkins

Die zeitliche Abfolge der Monozyteninvasion und deren funktionelle Bedeutung im ischämischen Gewebe beschrieben auch Nahrendorf und Kollegen (Nahrendorf et al. 2010). Hierbei wurde in einem murinen Myokardinfarktmodell die unterschiedliche Invasion der funktionell verschiedenen Monozytensubpopulationen untersucht. Der zeitliche Verlauf ist auch in Abbildung 1 dargestellt (Nahrendorf et al. 2010; Nahrendorf et al. 2007). Innerhalb der ersten drei bis vier Tage nach ischämischem Ereignis wird in diesem Gewebe u. a. vermehrt MCP-1 freigesetzt, wodurch es zunächst zur Einwanderung von Ly6-C ${ }^{\text {high }}$-Monozyten kommt. Diese beseitigen nun im Wesentlichen durch Proteolyse und Phagozytose des nekrotischen Gewebes den Zelldetritus und zerstören durch 
Sezernierung von MMPs und Cathepsinen die vorbestehende Kollagenstruktur, sodass das Einwandern neuer Zellen vereinfacht wird.

Die zweite Phase (Tag vier bis sieben) ist gekennzeichnet durch die vermehrte endotheliale Expression des $\mathrm{CX}_{3} \mathrm{CR}$. Hierdurch wird eine verstärkte Adhärenz und somit erhöhte Leukodiapedese der Ly6-C ${ }^{\text {low }}$-Monozyten induziert (Allen et al. 2007). Diese produzieren und sezernieren wiederum eher antientzündliche Zytokine wie IL-10, Transforming Growth Factor $\beta$ (TGF- $\beta$ ) und VEGF und sorgen somit für die Unterstützung der Gefäßneubildung (s. o.).

Proangiogene Effekte von Monozyten sind nicht nur bei Ischämie beschrieben, sondern sind auch in der Tumorgenese essentiell, sodass es naheliegt, dass Monozyten auch bei der Gefäßneubildung Tumor-versorgender Gefäße eine bedeutende Rolle spielen. Diesen Punkt beleuchteten Venneri et al. näher und zeigten hierbei für bestimmte Tumorentitäten eine vermehrte Ansammlung von Monozyten, welche eine vermehrte Expression des Angiopoetinrezeptors (Tie2) aufwiesen (Venneri et al. 2007). Diese waren weder vollständig den klassischen noch den nicht-klassischen Monozyten zuzuordnen.

\subsection{Leptin}

Das Proteohormon Leptin ist einer der wichtigsten vom Fettgewebe produzierten Faktoren (Zhang et al. 1994). Es kommt physiologischerweise in einer freien und einer gebundenen Form vor (Sinha et al. 1996). Die freie Form gilt als aktiv und nimmt so vordringlich im Hypothalamus Einfluss auf die Entstehung von Hungergefühl und das Verlangen zur Nahrungsaufnahme (Li 2011). So führt bei Normalgewicht der Aufbau von Fettgewebe zur Synthese von Leptin und somit zu hohen freien Leptinspiegeln. Hierauf stellt sich ein Sättigungsgefühl ein. Sind die nutritiven Reserven nach Nahrungsaufnahme verbraucht (z. B. bei längerem Fasten), beginnt der Körper mit dem Abbau von Fettgewebe und senkt dadurch den Spiegel des freien Leptins. Es kommt zum Hungergefühl und der Körper wird zur Nahrungsaufnahme angehalten (Sinha et al. 1996).

Die Wirkung von Leptin ist Rezeptor-vermittelt. Der ObR existiert beim Menschen in verschiedenen Isoformen (Tartaglia 1997), von denen drei Klassen unterschieden werden: die lang gebundene, die kurz gebundene und die freie Klasse (Myers 2004). Eine dieser Klassen bildet das Gegenstück des im Plasma gebunden Leptins, während hingegen die anderen beiden weitestgehend die Leptinwirkung vermitteln. Diese befinden sich auf der Zelloberfläche und sind homolog zu den Zytokinrezeptoren der Klasse I zu sehen (Tartaglia 1997; Tartaglia et al. 1995). Diese vermitteln neben anderen Signalwegen ihre hauptsächliche Wirkung über den Januskinase/Signal-Transducer-and-Activator-of-Transcription(JAK/STAT)-Signalweg (Baumann et al. 1996; Myers 2004; Tartaglia 1997). 


\subsubsection{Leptininteraktionen im Adipositasstoffwechsel}

Nach oben beschriebener Leptinwirkung ließe sich annehmen, dass die Serum-LeptinSpiegel adipöser Menschen ausgesprochen niedrig seien. Dies konnten Sinha et al. 1996 widerlegen. Hierbei stellten sie fest, dass Menschen mit Adipositas stark erhöhte Spiegel freien Leptins aufweisen und somit vielmehr einer zentralen Leptin-Resistenz unterliegen (Myers 2004; Sinha et al. 1996). Des Weiteren wurde im Hungerversuch gezeigt, dass im Gegensatz zu normalgewichtigen Menschen die Blutkonzentration an gebundenem Leptin konstant bleibt und lediglich die Konzentration des freien Leptins sinkt. Im nicht-adipösen Stoffwechsel verändert sich eher die Konzentration des gebundenen Leptins und hält somit die Konzentration des freien Leptins annähernd gleich (jedoch weiterhin auf deutlich niedrigerem Niveau als im Adipositasstoffwechsel). Somit scheint eher das Verhältnis des freien zum gebundenen Leptin eine Rolle bei der Regulation des Hungergefühls eine Rolle zu spielen als die Absolutwerte beider Formen (Alshaker et al. 2015; Ge et al. 2002; Sinha et al. 1996).

\subsubsection{Fettstoffwechsel-unabhängige Leptinwirkungen}

Erste Erkenntnisse, dass Leptin nicht nur den Fettstoffwechsel beeinflusst, zeigten schon Sierra-Honigmann et al., die die Expression des ObR auch auf Human Umbilical Vein Endothelial Cells (HUVECs) und ECs untersuchten und nachfolgend das angiogene Potential von Leptin nachwiesen (Sierra-Honigmann et al. 1998). So wurde zusätzlich in Übereinstimmung mit diesen Ergebnissen gezeigt, dass Leptin in vitro auf o. g. Zellen ähnliche Effekte in puncto Zellproliferation und Zellwachstum aufweist wie VEGF (Bouloumie et al. 1998).

Weiterhin konnte im Tierexperiment nachgewiesen werden, dass durch Leptin eine Neovaskularisierung sowohl der Cornea (Sierra-Honigmann et al. 1998) als auch der Retina (Suganami et al. 2004) induziert wird.

Aufbauend auf diesen Erkenntnissen wurde weiterführend der Einfluss von Leptin auf die Angiogenese untersucht. Hierbei wurden zirkulierende angiogenetische Zellen (Circulating Angiogenic Cells [CACs]) aus dem peripheren Blut von Menschen isoliert und mit Leptin stimuliert. Anschließend wurde deren angiogenes Potenzial gegenüber nicht-stimulierten CACs mit HUVECs untersucht, und es konnte gezeigt werden, dass eine Leptinstimulation der CACs die Anzahl von Sprossen im Angiogenese-Experiment signifikant erhöht im Vergleich zu nicht stimulierten CACs (Heida et al. 2010). Interessanterweise zeigte sich diese Rekrutierung des angiogenen Potentials nur mit CACs aus dem Blut normalgewichtiger Menschen. Mit dem Blut adipöser Menschen war dies nicht möglich. 


\subsection{Zielsetzung}

Wie die o. g. Ausführungen belegen sind bisherige Untersuchungen bezüglich des Einflusses von Monozyten auf die Gefäßneubildung hauptsächlich an murinen Monozyten untersucht worden. Da jedoch zwischen murinen und humanen Monozyten ausgeprägte Unterschiede bestehen, ist die Bedeutung humaner Monozyten und ihrer Subpopulationen zur Neovaskularisierung nach Ischämie nicht direkt unkritisch zu übertragen. Des Weiteren ist noch nicht ausreichend herausgearbeitet, welche der Subpopulationsgruppe die proangiogenen Effekte am ehesten vermittelt und wodurch diese erzielt werden.

Daraus folgend ist es Ziel dieser Arbeit, die Unterschiede von $\mathrm{CD}_{16}{ }^{+}$-mo und $\mathrm{CD}_{16}{ }^{-}$-mo und ihr Zusammenspiel in der Arteriogenese und auch der Angiogenese zu untersuchen. Hierbei wird die Qualität der Entstehung neuer Gefäße über eine Messung der Reperfusion an verschiedenen Zeitpunkten nach Hinterlaufischämie untersucht. Die Quantität neu entstandener Gefäße wird histologisch ermittelt.

Frühere Arbeiten zur Neovaskularisierung zeigten, dass durch Leptin stimulierte CACs eine Verbesserung der Perfusion erzeugt werden konnte, sodass auch der Einfluss von Leptin auf Monozyten und ihre Subpopulationen im Rahmen der Angio- und Arteriogenese ebenfalls untersucht werden soll. 


\section{Material und Methoden}

\subsection{Verwendete Materialien und Geräte}

\subsubsection{Reagenzien}

Tabelle 1: Reagenzien

\begin{tabular}{|c|c|c|}
\hline Artikel & Art.-Nummer & Firma \\
\hline Aqua dest. & & hausintern \\
\hline Aceton & 8222511000 & Merck KGaA, Darmstadt, D \\
\hline Antibody (AB)-Diluent & $\mathrm{S} 3022$ & Dako Denmark A/S, Glostrup, DK \\
\hline Antikörper FACS ${ }^{\mathrm{TM}}$ & & s. FACS ${ }^{T M}$, Kap. 2.1.5.1 \\
\hline Antikörper Immunfluoreszenz & & s. Immunfluoreszenz, Kap. 2.1.5.1 \\
\hline $\begin{array}{l}\text { Bepanthen }^{\circledR} \quad \text { Augen- } \quad \text { und } \\
\text { Nasensalbe }\end{array}$ & PZN-01578675 & Bayer AG, Leverkusen, D \\
\hline Bovines Serum Albumin (BSA) & A7906 & Sigma-Aldrich, St. Louis, MO, USA \\
\hline CD $16^{+}$Monocyte Isolation Kit & 130-091-765 & $\begin{array}{l}\text { Miltenyi Biotec GmbH, Bergisch Gladbach, D, } \\
\text { s. Kap. 2.1.5.1 }\end{array}$ \\
\hline Clodronat-Liposomen & & $\begin{array}{l}\text { Vrije Universiteit, Faculty of Medicine, } \\
\text { Amsterdam, NL }\end{array}$ \\
\hline CM-DiI & V-22888 & Molecular Probes ${ }^{\circledR}$, Eugene, OR, USA \\
\hline $\begin{array}{l}4^{\prime}, 6-\text { Diamidin-2-phenylindol } \\
\text { (DAPI) }\end{array}$ & D9542 & Sigma-Aldrich, St. Louis, MO, USA \\
\hline Dinatriumhydrogenphosphat & 1063461000 & Merck KGaA, Darmstadt, D \\
\hline $\begin{array}{l}\text { Dulbecco's Phosphated-Buffered } \\
\text { Saline (DPBS) }\end{array}$ & 1362487 & $\begin{array}{l}\text { Gibco }^{\circledR} \text { by Life Technologies, Carlsbad, CA, } \\
\text { USA }\end{array}$ \\
\hline $\begin{array}{l}\text { Ethylendiamintetraessigsäure } \\
\text { (EDTA) } 0,5 \mathrm{M}\end{array}$ & AM9260G & AMBION GmbH, Kaufungen, D \\
\hline Ethanol & 1009831000 & Merck KGaA, Darmstadt, D \\
\hline Heparin & PZN-3029843 & Ratiopharm GmbH, Ulm, D \\
\hline Histopaque $^{\circledR}$ & 10771 & Sigma-Aldrich, St. Louis, MO, USA \\
\hline Isofluran & B506 & Abbott, GmbH+Co KG, Wiesbaden, D \\
\hline Kaliumchlorid & 1.049 .365 .000 & Merck KGaA, Darmstadt, D \\
\hline Kaliumdihydrogenphosphat & $420 \mathrm{~A} 877573$ & Merck KGaA, Darmstadt. D \\
\hline Leptin & 398-LP & R \& D Systems, Minneapolis, MN, USA \\
\hline Methanol & 106009 & Merck KGaA, Darmstadt, D \\
\hline Monocyte Isolation Kit II & 130-091-153 & $\begin{array}{l}\text { Miltenyi Biotec GmbH, Bergisch Gladbach, D, } \\
\text { s. Kap. 2.1.5.1 }\end{array}$ \\
\hline Novaminsulfon-ratiopharm & PZN-07387829 & Ratiopharm GmbH, Ulm, D \\
\hline Methylbutan & 106056 & Merck KGaA, Darmstadt, D \\
\hline
\end{tabular}




\begin{tabular}{lll}
\hline Nacktmausfutter & V1244-000 & Ssniff Spezialdiäten GmbH, Soest, D \\
\hline NaCl 0,9\% & $387028 \mathrm{R}$ & B. Braun Melsungen AG, Melsungen, D \\
\hline Natriumchlorid & 3957.2 & Carl Roth GmbH, Karlsruhe, D \\
\hline PAP PEN Mini & LP0002 & Zytomed Systems, Berlin, D \\
\hline $\begin{array}{l}\text { Phosphated-Buffered Saline (PBS), } \\
10 x\end{array}$ & $70011-036$ & $\begin{array}{l}\text { Gibco }{ }^{\circledR} \text { by Life Technologies, Carlsbad, CA, } \\
\text { USA }\end{array}$ \\
\hline Paraformaldehyd (PFA) & P6148 & Sigma-Aldrich, St. Louis, MO, USA \\
\hline Stickstoff, flüssig & & hausintern \\
\hline RPMI Media 1640 & $11835-063$ & $\begin{array}{l}\text { Gibco }{ }^{\circledR} \text { by Life Technologies, Carlsbad, CA, } \\
\text { USA }\end{array}$ \\
\hline Tissue Tec O.C.T. Compound & 4583 & Sakura Finetek Europe B.V.; Zoeterwoude, NL \\
\hline Triton X-100 & 93426 & Sigma-Aldrich, St. Louis, MO, USA \\
\hline Trypan Blau & L6323 & Merck KGaA, Darmstadt, D \\
\hline VectaShield Mounting Medium & H-1000 & Vector, Burlingame, CA, USA \\
\hline Xylazin, 2\% & 12095 & Serumwerk Bernburg AG, Bernburg, D \\
\hline
\end{tabular}

\subsubsection{Geräte und Programme}

Tabelle 2: Geräte und Programme

\begin{tabular}{|c|c|}
\hline Artikel & Firma \\
\hline Axio Vision 3.0 (Graphikprogramm) & Carl Zeiss AG, Oberkochen, D \\
\hline $\begin{array}{l}\text { Beckmann Coulter } \mathrm{A}^{\mathrm{C}} \mathrm{T} \text { 5diff Hematology } \\
\text { Analyzer }\end{array}$ & Beckman Coulter GmbH Deutschland, Krefeld, D \\
\hline Beleuchtung KL 1500 LCD & Schott AG, Mainz D \\
\hline Microsoft $^{\circledR}$ Excel für Mac 2011 & Microsoft Corp., Santa Rosa, CA, USA \\
\hline FACSCanto $^{\mathrm{TM}}$ II & BD Biosciences, San Jose, CA, USA \\
\hline FACSDiva $^{\mathrm{TM}}$ Software, Version 6.1 .3 & BD Biosciences, San Jose, CA, USA \\
\hline Fluoreszenzmikroskop (Zeiss Axiovert 200) & Carl Zeiss AG, Oberkochen, D \\
\hline GraphPad Prism (Statistikprogramm) & GraphPad Software, Inc., La Jolla, CA, USA \\
\hline Image Pro Plus (Graphikprogramm) & Media Cybernetics, Inc.; Bethesda, MD, USA \\
\hline Kryostat (Frigocut 2800N) & Leica Mikrosysteme GmbH, Wetzlar, D \\
\hline Mini Vent Mouse Ventilator Typ 845 & Hugo Sachs Elektronik GmbH, March-Hugstetten, D \\
\hline Mikroskop (Olympus CK40-F200) & Olympus Deutschland GmbH, Hamburg, D \\
\hline Mikroskop (Olympus SZ40-PT) & Olympus Deutschland GmbH, Hamburg, D \\
\hline PeriScan PIM 3 System & PERIMED, Järfälla, S \\
\hline PIMSoft & PERIMED, Järfälla, S \\
\hline STATISTICA (Version 12.0) & Stat Soft, Inc., Tulsa, OK, USA \\
\hline Vortex Genie ${ }^{\circledR} 2$ & Scientific Industries, Inc, Bohemia, N.Y., USA \\
\hline Wärmeplatte & MEDAX GmbH \& Co.KG \\
\hline Microsoft $^{\circledR}$ Word für Mac 2011 & Microsoft Corp., Santa Rosa, CA, USA \\
\hline Zentrifuge (5415 D) & Eppendorf AG, Hamburg, D \\
\hline
\end{tabular}




\begin{tabular}{ll}
\hline Zentrifuge $(5702 \mathrm{R})$ & Eppendorf AG, Hamburg, D \\
\hline Zentrifuge $(5810 \mathrm{R})$ & Eppendorf AG, Hamburg, D \\
\hline Zentrifuge (Rotanta/S) & Andreas Hettich GmbH \& Co.KG, Tuttlingen, D \\
\hline
\end{tabular}

\subsubsection{Materialien}

\subsubsection{Monozytenisolation}

Tabelle 3: Verwendete Materialien für die Monozytenisolation

\begin{tabular}{|c|c|c|}
\hline Artikel & $\begin{array}{l}\text { Art.- } \\
\text { Nummer }\end{array}$ & Firma \\
\hline Polystyrene-FACS-Röhrchen & 352058 & BD Biosciences, San Jose, CA, USA \\
\hline Magnet (QuadroMACS ${ }^{\mathrm{TM}}$ ) & $130-090-976$ & Miltenyi Biotec GmbH, Bergisch Gladbach, D \\
\hline MACS Separationssäule, LD & 130-042-901 & Miltenyi Biotec GmbH, Bergisch Gladbach, D \\
\hline MACS Separationssäule, LS & $130-042-401$ & Miltenyi Biotec GmbH, Bergisch Gladbach, D \\
\hline Neubauer Zählkammer & & Optik Labor Ltd., Lancing, E, UK \\
\hline Präseparationsfilter, $30 \mu \mathrm{m}$ & $130-041-407$ & Miltenyi Biotec GmbH, Bergisch Gladbach, D \\
\hline Spritze, Omnican ${ }^{\circledR} 50$ & 9151125 & B. Braun Melsungen AG, Melsungen, D \\
\hline Spritze, Omnifix ${ }^{\circledR} 40$ Solo & $9161309 \mathrm{~V}$ & B. Braun Melsungen AG, Melsungen, D \\
\hline Sterilfilter & 10462200 & Schleicher \& Schuell BioScience GmbH, Dassel, D \\
\hline $\begin{array}{l}\text { Quadruple Pack OptiPure RC, Top } \\
\& \text { Bottom Blutbeutelsystem mit } \\
\text { integriertem Erythrozytenfilter RC } \\
\text { Soft. PL146/PL1240 }\end{array}$ & NGR6428B & Fenwal, Inc., Lake Zurich, IL, USA \\
\hline
\end{tabular}

\subsubsection{Operation der Hinterlaufischämie}

Tabelle 4: Verwendete Materialen für die Operation der Hinterlaufischämie

\begin{tabular}{lll}
\hline Artikel & Art.-Nummer & Firma \\
\hline $\begin{array}{l}\text { Cohan-Vannas Spring } \\
\text { Schere-6mm Blades }\end{array}$ & $15000-02$ & Fine Science Tools ${ }^{\circledR}$ GmbH, Heidelberg, D \\
\hline Leukosilk ${ }^{\circledR}$ & 0102100 & BSN medical GmbH, Hamburg, D \\
\hline Naht 6-0 Ethilon P1 & ETH 697H & $\begin{array}{l}\text { Ethicon, Johnson \& Johnson medical GmbH, Norderstedt, } \\
\text { D }\end{array}$ \\
\hline $\begin{array}{l}\text { Naht 6-0 PH-Seide } \\
\text { Nadelhalter Mayo-Hegar }\end{array}$ & 0022915 & $\begin{array}{l}\text { Ethicon, Johnson \& Johnson medical GmbH, Norderstedt, } \\
\text { D }\end{array}$ \\
\hline $\begin{array}{l}\text { Pinzetten, fein, Dumont } \\
\text { \#5/45 }\end{array}$ & 1125135 & Fine Science Tools ${ }^{\circledR}$ GmbH, Heidelberg, D \\
\hline $\begin{array}{l}\text { Pinzette, gebogen, Extra } \\
\text { Graede Forceps }\end{array}$ & 115110 & Fine Science Tools ${ }^{\circledR}$ GmbH, Heidelberg, D \\
\hline $\begin{array}{l}\text { Pinzette, gerade, Extra } \\
\text { Graede Forceps }\end{array}$ & 115010 & Fine Science Tools ${ }^{\circledR}$ GmbH, Heidelberg, D \\
\hline \begin{tabular}{l} 
Wattestäbchen \\
\hline
\end{tabular} & PZN-6177225 & Karl Beese (GmbH \& Co.), Barsbüttel, D \\
\hline
\end{tabular}




\subsubsection{Puffer und Lösungen}

\subsubsection{Monozytenisolation}

Tabelle 5: Puffer und Lösungen der Monozytenisolation

\begin{tabular}{lll}
\hline Lösung & Menge & eingesetzte Stoffe \\
\hline PBS/EDTA: & $0,744 \mathrm{~g}$ & EDTA \\
& $100 \mathrm{ml}$ & PBS $10 \%$ \\
& $900 \mathrm{ml}$ & Aqua dest. \\
\hline Assay-Puffer: & $130 \mathrm{ml}$ & PBS/EDTA \\
& $0,65 \mathrm{~g}$ & BSA \\
\hline
\end{tabular}

\subsubsection{Immunfluoreszenzfärbungen}

Tabelle 6: Puffer und Lösungen der Immunfluoreszenzfärbungen

\begin{tabular}{lll}
\hline Lösung & Menge & eingesetzte Stoffe \\
\hline Permeabilisierungslösung: & $0,5 \mathrm{ml}$ & Triton X-100 \\
& auf 11 & PBS \\
\hline Phosphatgepufferte & $160 \mathrm{~g}$ & Natriumchlroid \\
Salzlösung: & $4 \mathrm{~g}$ & Kaliumchlroid \\
& $28,8 \mathrm{~g}$ & Dinatriumhydrogenphosphat \\
& $4,8 \mathrm{~g}$ & Kaliumdihydrogenphosphat \\
& auf $2000 \mathrm{ml}$ & Aqua dest. \\
\hline
\end{tabular}

\subsubsection{Durchflusszytometrie}

Tabelle 7: Verwendete Puffer und Lösungen der Durchflusszytometrie

\begin{tabular}{lll}
\hline Lösung & Menge & eingesetzte Stoffe \\
\hline FACSTM_Puffer: & $10 \mathrm{~g}$ & BSA \\
& auf $1 \mathrm{l}$ & PBS $(1 \mathrm{x})$ \\
\hline Fixierungslösung & $1 \mathrm{~g}$ & Paraformaldehyd \\
& auf $100 \mathrm{ml}$ & Aqua dest. \\
\hline Phosphatgepufferte & $160 \mathrm{~g}$ & Natriumchlorid \\
Salzlösung: & $4 \mathrm{~g}$ & Kaliumchlorid \\
& $28,8 \mathrm{~g}$ & Dinatriumhydrogenphosphat \\
& $4,8 \mathrm{~g}$ & Kaliumdihydrogenphosphat \\
& auf $2000 \mathrm{ml}$ & Aqua dest. \\
\hline
\end{tabular}




\subsubsection{Antikörper}

\subsubsection{Monozytenisolation}

Tabelle 8: Bestandteile des Monocyte Isolation Kit II

\begin{tabular}{lll}
\hline Artikel & Mat.-Nummer & Mischungsverhältnis \\
\hline Anti-Biotin MicroBeads & $120-001-478$ & $10 \mu \mathrm{l}$ auf $10^{7}$ Zellen \\
\hline $\begin{array}{l}\text { Monocyte Biotin- } \\
\text { Antibody Cocktail }\end{array}$ & $120-001-467$ & $5 \mu \mathrm{l}$ auf $10^{7}$ Zellen \\
\hline $\begin{array}{l}\text { FcR-Blocking Reagenz } \\
\text { M }\end{array}$ & $120-000-442$ & $5 \mu \mathrm{lauf} 10^{7}$ Zellen \\
\hline
\end{tabular}

Tabelle 9: Bestandteile des CD16+ Monocyte Isolation Kit

\begin{tabular}{lll}
\hline Artikel & Mat.-Nummer & Mischungsverhältnis \\
\hline CD16 MicroBeads & $120-000-249$ & $10 \mu \mathrm{l}$ auf $10^{7}$ Zellen \\
\hline FcR-Blocking Reagenz & $120-000-442$ & $5 \mu \mathrm{l}$ auf $10^{7}$ Zellen \\
\hline $\begin{array}{l}\text { Non-Monocyte Depletion } \\
\text { Cocktail }\end{array}$ & $120-002-033$ & $5 \mu \mathrm{l}$ auf $10^{7}$ Zellen \\
\hline
\end{tabular}

\subsubsection{Durchflusszytometrie}

\subsection{Durchflusszytometrie der Monozyten}

Tabelle 10: Zusammenstellung der Antikörper für die Isotypenkontrollen zur Reinheitskontrolle

\begin{tabular}{|c|c|c|c|}
\hline Antikörper & $\begin{array}{l}\text { Art.- } \\
\text { Nummer }\end{array}$ & Mischungsverhältnis & Firma \\
\hline $\begin{array}{l}\text { FITC Mouse IgG2b, } \\
\kappa \text { Isotype Control }\end{array}$ & 555742 & $5 \mu \mathrm{l}$ auf $10^{6}$ Zellen & $\begin{array}{l}\text { BD Biosciences, San Jose, CA, } \\
\text { USA }\end{array}$ \\
\hline $\begin{array}{l}\text { FITC Mouse IgG2b, } \\
\kappa \text { Isotype Control }\end{array}$ & 555749 & $5 \mu \mathrm{l}$ auf $10^{6}$ Zellen & $\begin{array}{l}\text { BD Biosciences, San Jose, CA, } \\
\text { USA }\end{array}$ \\
\hline $\begin{array}{l}\text { APC Mouse IgG2a, } \\
\kappa \text { Isotype Control }\end{array}$ & 555576 & $5 \mu \mathrm{l}$ auf $10^{6}$ Zellen & $\begin{array}{l}\text { BD Biosciences, San Jose, CA, } \\
\text { USA }\end{array}$ \\
\hline $\begin{array}{l}\text { PerCP-Cy } \\
\text { IgG2b, K Isotype } \\
\text { Control }\end{array}$ & 558304 & $5 \mu \mathrm{l}$ auf $10^{6}$ Zellen & $\begin{array}{l}\text { BD Biosciences, San Jose, CA, } \\
\text { USA }\end{array}$ \\
\hline
\end{tabular}


Tabelle 11: Zusammenstellung der Färbeantikörper zur Reinheitskontrolle

\begin{tabular}{|c|c|c|c|}
\hline Antikörper & Art.-Nummer & Mischungsverhältnis & Firma \\
\hline $\begin{array}{l}\text { FITC Mouse Anti- } \\
\text { Human CD } 14\end{array}$ & 345784 & $5 \mu \mathrm{l}$ auf $10^{6}$ Zellen & $\begin{array}{l}\text { BD Biosciences, San Jose, CA, } \\
\text { USA }\end{array}$ \\
\hline $\begin{array}{l}\text { PE Mouse Anti- } \\
\text { Human CD16 }\end{array}$ & 555407 & $5 \mu \mathrm{l}$ auf $10^{6}$ Zellen & $\begin{array}{l}\text { BD Biosciences, San Jose, CA, } \\
\text { USA }\end{array}$ \\
\hline $\begin{array}{l}\text { APC Mouse Anti- } \\
\text { Human CD195 }\end{array}$ & 556903 & $5 \mu \mathrm{l}$ auf $10^{6}$ Zellen & $\begin{array}{l}\text { BD Biosciences, San Jose, CA, } \\
\text { USA }\end{array}$ \\
\hline $\begin{array}{l}\text { PerCP-Cy } 5.5 \\
\text { Mouse Anti-Human } \\
\text { CD44 }\end{array}$ & 560531 & $1,25 \mu \mathrm{l}$ auf $10^{6}$ Zellen & $\begin{array}{l}\text { BD Biosciences, San Jose, CA, } \\
\text { USA }\end{array}$ \\
\hline
\end{tabular}

\subsection{Nachweis des Leptinrezeptors}

Tabelle 12: Zusammenstellung der Isotypenkontrollantikörper zur ObR-Färbung

\begin{tabular}{|c|c|c|c|}
\hline Antikörper & Art.-Nummer & Mischungsverhältnis & Firma \\
\hline $\begin{array}{l}\text { FITC Mouse IgG2b, } \\
\text { к Isotype Control }\end{array}$ & 555742 & $5 \mu \mathrm{l}$ auf $10^{6}$ Zellen & $\begin{array}{l}\text { BD Biosciences, San Jose, CA, } \\
\text { USA }\end{array}$ \\
\hline $\begin{array}{l}\text { PE Mouse IgG1, } \\
\kappa \text { Isotype Control }\end{array}$ & 555749 & $5 \mu \mathrm{l}$ auf $10^{6}$ Zellen & $\begin{array}{l}\text { BD Biosciences, San Jose, CA, } \\
\text { USA }\end{array}$ \\
\hline $\begin{array}{l}\text { APC-Mouse IgG2b, } \\
\text { к Isotype Control }\end{array}$ & IC0041A & $2,5 \mu \mathrm{l}$ auf $10^{6}$ Zellen & $\begin{array}{l}\text { R \& D Systems, Minneapolis, } \\
\text { MN, USA }\end{array}$ \\
\hline
\end{tabular}

Tabelle 13: Zusammenstellung der Färbeantikörper der ObR-Färbung

\begin{tabular}{llll}
\hline Antikörper & Art.-Nummer & Mischungsverhältnis & Firma \\
\hline $\begin{array}{l}\text { FITC Mouse Anti- } \\
\text { Human CD 14 }\end{array}$ & 345784 & $5 \mu$ l auf $10^{6}$ Zellen & $\begin{array}{l}\text { BD Biosciences, San Jose, CA, } \\
\text { USA }\end{array}$ \\
\hline $\begin{array}{l}\text { PE Mouse Anti- } \\
\text { Human CD16 }\end{array}$ & 55407 & $5 \mu \mathrm{l}$ auf $10^{6}$ Zellen & $\begin{array}{l}\text { BD Biosciences, San Jose, CA, } \\
\text { USA }\end{array}$ \\
$\begin{array}{l}\text { APC Mouse Anti- FAB867A } \\
\text { Human Leptin R }\end{array}$ & $2,5 \mu$ lauf $10^{6}$ Zellen & $\begin{array}{l}\text { R \& D Systems, Minneapolis, } \\
\text { MN, USA }\end{array}$ \\
\hline
\end{tabular}




\subsubsection{Immunfluoreszenz}

Tabelle 14: Zusammensetzung der Primärantikörperlösung für die CD31-Färbung

\begin{tabular}{lllll}
\hline & Antikörper & Art.-Nummer & $\begin{array}{l}\text { Mischungs- } \\
\text { verhältnis }\end{array}$ & Firma \\
\hline 1. AK & PECAM-1 (MEC 13.3) & sc-18916 & $1: 50$ & $\begin{array}{l}\text { SantaCruz Biotechnology Inc., } \\
\text { Dallas, TX, USA }\end{array}$ \\
\hline
\end{tabular}

Tabelle 15: Zusammensetzung der Sekundärantikörperlösung für die CD31-Färbung

\begin{tabular}{lllll}
\hline & Antikörper & $\begin{array}{l}\text { Art.- } \\
\text { Nummer }\end{array}$ & $\begin{array}{l}\text { Mischungs- } \\
\text { verhältnis }\end{array}$ & Firma \\
\hline 2. AK & goat anti-rat 555 & MFP-A2434 & $1: 400$ & MoBiTec GmbH, Göttingen, D \\
\hline Nuclei & DAPI & D9542 & $1: 100$ & $\begin{array}{l}\text { Sigma-Aldrich, St. Louis, MO, } \\
\text { USA }\end{array}$
\end{tabular}

Tabelle 16: Zusammensetzung der Sekundärantikörper für die SMA/CD31-Doppelfärbung

\begin{tabular}{lllll}
\hline & Antikörper & Art.-Nummer & $\begin{array}{l}\text { Mischungs- } \\
\text { verhältnis }\end{array}$ & Firma \\
\hline 1. AK & PECAM-1 (MEC 13.3) & sc-18916 & $1: 50$ & $\begin{array}{l}\text { SantaCruz Biotechnology Inc., } \\
\text { Dallas, TX, USA }\end{array}$ \\
\hline 1. AK & mouse anti-mouse & F-3777 & $1: 3000$ & $\begin{array}{l}\text { Sigma-Aldrich, St. Louis, MO, } \\
\text { USA }\end{array}$
\end{tabular}

Tabelle 17: Zusammensetzung der Sekundärantikörperlösung für die SMA/CD31-Doppelfärbung

\begin{tabular}{lllll}
\hline & Antikörper & $\begin{array}{l}\text { Art.- } \\
\text { Nummer }\end{array}$ & $\begin{array}{l}\text { Mischungs- } \\
\text { verhältnis }\end{array}$ & Firma \\
\hline 2. AK & goat anti-rat 555 & MFP-A2434 & $1: 400$ & $\begin{array}{l}\text { MoBiTec GmbH, Göttingen, } \\
\text { D }\end{array}$ \\
\hline Kernfärbung & DAPI & D9542 & $1: 100$ & $\begin{array}{l}\text { Sigma-Aldrich, St. Louis, } \\
\text { MO, USA }\end{array}$ \\
\hline
\end{tabular}

\subsection{Untersuchungen im Tiermodell}

\subsubsection{Versuchsablauf}

Die Versuchsgröße belief sich auf insgesamt 69 männliche Nacktmäuse mit einem homozygoten Knock-out des FOXN-1-Genes (NMRI-Foxn1 ${ }^{\text {nu/nu}}$, s. Abbildung 2). Sie wurden in der Zentralen Tierexperimentellen Einrichtung (ZTE) der Universitätsmedizin 
Göttingen (UMG) gehalten. Allen Tieren wurde während des gesamten Versuchsablaufes spezielles Nacktmausfutter (s. Tabelle 1) und Wasser ad libitum bereitgestellt.

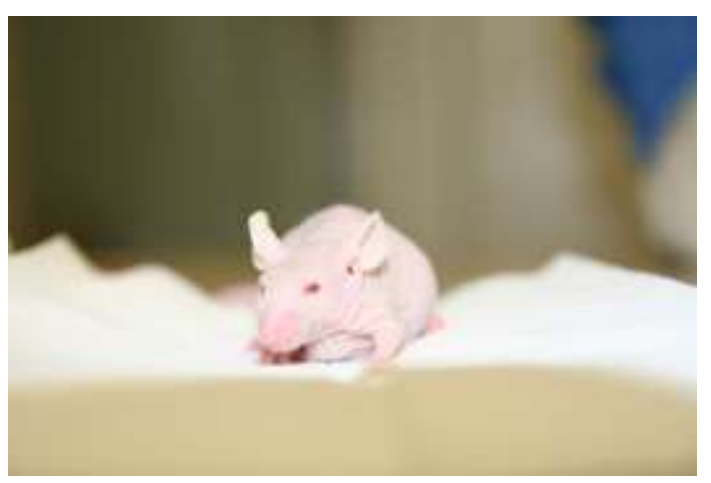

Abbildung 2: Nacktmaus

Nach präoperativer Ohrmarkierung zur eindeutigen Identifizierung wurde im Alter von 9 14 Wochen bei den Tieren die Operation der Hinterlaufischämie durchgeführt. Hierfür wurden die Mäuse mithilfe eines Laser-Dopplers untersucht und die Perfusion der Hinterläufe ermittelt. Dies geschah unmittelbar prä- und postoperativ, sowie erneut zur Verlaufsbeurteilung am 3., 7., 14., 21. und 28. postoperativen Tag.

Am ersten Tag nach Induktion der Hinterlaufischämie wurde den Tieren je nach Interventionsgruppe entweder Gesamtmonozyten (total-mo), CD16 ${ }^{+}$-mo, CD16-mo oder PBS intrakardial injiziert und folgend die Perfusionsänderung in Abhängigkeit der jeweiligen Monozytensubpopulation mittels Laser-Doppler-Perfusionsmessung an o. g. Zeitpunkten evaluiert. Um den Einfluss von Leptin auf Monozyten und deren Funktion weiter zu beleuchten, wurde die Versuchsreihe unter gleichem Versuchsaufbau noch einmal durchgeführt mit dem Unterschied, dass die Monozyten der unterschiedlichen Interventionsgruppen für 30 Minuten mit Leptin vorstimuliert wurden, sodass sich letztendlich folgende Untersuchungsgruppen ergaben:

Tabelle 18: Auflistung der Versuchsgruppen

\begin{tabular}{|l|l|l|l|l|}
\hline Gruppe & stimuliert & Injektion & Anzahl der Tiere & Bezeichnung \\
\hline $\mathbf{1}$ & nein & PBS & 10 & Kontrolle \\
\hline $\mathbf{2}$ & nein & CD16+-mo & 10 & CD16+-mo \\
\hline $\mathbf{3}$ & nein & CD16-mo & 10 & CD16-mo \\
\hline $\mathbf{4}$ & nein & Gesamtmonozyten & 10 & total-mo \\
\hline $\mathbf{5}$ & ja & CD16-mo & 10 & CD16 $6^{+}$-mo (s) \\
\hline $\mathbf{6}$ & ja & CD16-mo & 9 & CD16-mo (s) \\
\hline $\mathbf{7}$ & ja & Gesamtmonozyten & 10 & total-mo (s) \\
\hline
\end{tabular}


Nach der Laser-Doppler-Untersuchung am 28. postoperativen Tag wurden die Tiere finalisiert, die Musculi (Mm.) semimembranosi, semitendinosi et gastrocnemii dextri et sinistri entfernt und den unten aufgeführten histologischen Untersuchungen zugeführt. Hierbei wurden die $M m$. semimembranosi et semitendinosi für die Untersuchung der Arteriogenese und die $\mathrm{Mm}$. gastrocnemii für die Untersuchung der Angiogenese verwendet. Eine Übersicht über den gesamten Versuchsablauf zeigt Abbildung 3.

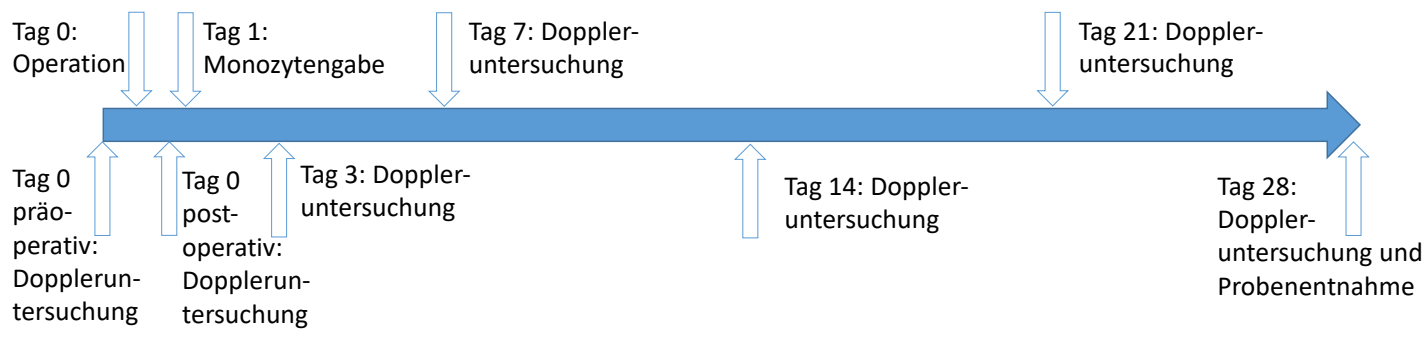

Abbildung 3: Darstellung des zeitlichen Ablaufs der Versuche

\subsubsection{Induktion der Hinterlaufischämie}

Die Operation zur Hinterlaufischämie erfolgte in Anlehnung an die Arbeiten der Arbeitsgruppe Limbourg aus Hannover (Limbourg et al. 2009). Die Tiere wurden gewogen und mit einer Peritonealanästhesie betäubt. Als Anästhetikum wurde ein NaCl-KetaminXylazin-Gemisch gewichtsadaptiert $(4,2 \mu \mathrm{l} / \mathrm{g})$ im Verhältnis 2:1:1 eingesetzt. Nach Einsetzen einer adäquaten Narkose und Dokumentation einer guten Perfusion (s. u.) beider Hinterläufe, wurden die Tiere auf einer Wärmeplatte $\left(36^{\circ} \mathrm{C}\right)$ positioniert, fixiert und in beiden Inguinalregionen mit 70\%-iger Ethanollösung desinfiziert. Nun erfolgte mit einer Schere eine $8 \mathrm{~mm}$ lange Inzision der rechten sowie linken Leiste. Als erstes wurde die shamOperation am linken Hinterlauf durchgeführt. Dies wurde durchgeführt, um sicherzustellen, dass die Effekte, welche gemessen wurden, auch auf die Ischämie und nicht auf eine ohnehin entstehende Entzündungsreaktion zurückzuführen sind. Hierzu wurde nach Einsetzen der Haken und der Präparation des subkutanen Fettgewebes die linke femorale Gefäß-Nerven-Straße dargestellt und proximal des Abgangs der Arteria profunda femoris (A. prof. fem.) aus ihrem Muskelbett präpariert. Auf die Separation der Arteria femoralis (A. fem.) von ihren Begleitstrukturen wurde bei der sham-Operation verzichtet. Nach Spülung der Operationswunde mit NaCl-Lösung $(0,9 \%)$ wurde diese bis zum endgültigen Wundverschluss belassen.

Für die eigentliche Ischämieinduktion am rechten Hinterlauf wurde nun ebenfalls das subkutane Fettgewebe präpariert und gleichermaßen auch die rechte femorale GefäßNerven-Straße dargestellt. Darauffolgend wurde diese proximal des Abganges der A. prof. fem. aus ihrem Muskelbett präpariert und dann die A. fem. von den begleitenden Strukturen (Vena femoralis und Nervus femoralis) separiert. Dabei entstandene venöse Blutungen wurden 
durch Kompression mit einem Wattestäbchen gestillt. Nach nochmaliger Darstellung der A. prof. fem. und Sicherstellung, dass der Abgang dieser sich distal befindet (s. Abbildung 4), wurde nun die A. fem. mittels 6-0 Seidefaden doppelt ligiert und zwischen den beiden Ligaturknoten durchtrennt. Nach Dokumentation der suffizienten Ischämie erfolgte der Wundverschluss mit einem 6-0 Ethilonfaden. Zur postoperativen Nachsorge wurden die Tiere bis zum Wiedererlangen des vollständigen Bewusstseins in einem sauberen Käfig bei $36^{\circ} \mathrm{C}$ auf einer Wärmeplatte belassen. Zur Schmerztherapie wurde das Trinkwasser der Mäuse schon am Vortag mit Metamizol versetzt. Die Schmerzmedikation wurde bis einschließlich 7 Tage post operationem durchgeführt.

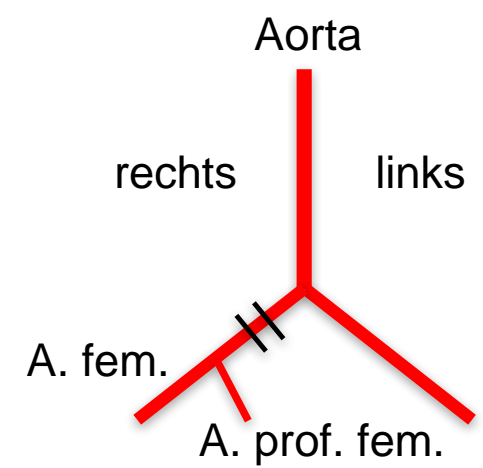

Abbildung 4: Schema der arteriellen Gefäßversorgung mit eingezeichneten Ligaturen A. fem., Arteria femoralis; A. prof. fem., Arteria profunda femoris

\subsubsection{Gewebeentnahme}

Nach der letzten Dopplermessung wurden die Tiere in noch betäubtem Zustand mittels zervikaler Dislokation getötet, die Mm. semimembranosi, semitendinosi et gastrocnemii dextri et sinistri entfernt und in physiologischer NaCl-Lösung auf Eis gelagert. Danach erfolgte die Einbettung in Tissue tec ${ }^{\circledR}$. Hierfür wurden die Proben auf einer vorbereiteten, beschrifteten Korkplatte befestigt, mit Tissue tec ${ }^{\circledR}$ in mit flüssigem Stickstoff gekühltes Methylbutan eingetaucht und bei $-80{ }^{\circ} \mathrm{C}$ eingefroren.

\subsubsection{Clodronat}

Da es zur in-vivo-Untersuchung humaner Monozyten im Mausmodell wünschenswert wäre, die Effekte der endogenen Monozyten weitestgehend zu minimieren, wurde versucht, diese mithilfe von Clodronat-Liposomen zu depletieren (Van Rooijen 1989; Van Rooijen und Sanders 1994). Hierzu wurde ein Vorversuch etabliert, bei dem 8 Tiere unter Isoflurannarkose (s. Kap. 2.2.5.2) mithilfe einer heparinisierten Glaskapillare ca. 50 - $100 \mu \mathrm{l}$ Blut aus dem retrobulbären Venenplexus entnommen und in einen mit $10 \mu \mathrm{l}$ 1,6\%iger EDTA-Lösung befüllten Eppendorfröhrchen geleitet wurde. Anschließend erfolgte die Applikation von Clodronat-Liposomen. Zur Evaluation der Menge und Applikationsart der Clodronat-Liposomen erfolgte die Gabe zweier unterschiedlicher Mengen jeweils intrakardial und intraperitoneal (s. Tabelle 19). 
Tabelle 19: Darstellung der Versuchsgruppen zum Clodronatversuch

\begin{tabular}{|c|c|c|c|}
\hline Gruppe & Injektionsort & Injektionsmenge & Anzahl der Tiere \\
\hline $\mathbf{1}$ & Herz & $150 \mu \mathrm{l}$ & 2 \\
\hline $\mathbf{2}$ & Peritoneum & $150 \mu \mathrm{l}$ & 2 \\
\hline 3 & Herz & $200 \mu \mathrm{l}$ & 2 \\
\hline 4 & Peritoneum & $200 \mu \mathrm{l}$ & 2 \\
\hline
\end{tabular}

Um die Wirkung der Clodronat-Liposomen auf das murine Monozyten-MakrophagenSystem zu überprüfen, erfolgte die retrobulbäre Blutabnahme nach oben beschriebenem Schema nochmals am erstem und dritten Tag nach der Injektion. Die Blutproben wurden unmittelbar nach der Entnahme gemischt und einer Blutbilduntersuchung am Beckmann Coulter $A^{C} T 5$ diff Hematology Analyžr zugeführt.

\subsubsection{Laser-Doppler-Perfusionsmessung}

\subsubsection{Prinzip der Laser-Doppler-Perfusionsmessung}

Die Technik der Laser-Doppler-Perfusionsmessung beruht auf der Emission eines Laserstrahls über eine faseroptische Sonde (https://www.perimed-instruments.com/de/LaserDoppler-Imaging 2016). Hierbei wird die gesamte Durchblutung des abgetasteten Areals inklusive der Mikrozirkulation untersucht, indem ein Laserstrahl nacheinander einzelne, dicht nebeneinander liegende Messpunkte analysiert.

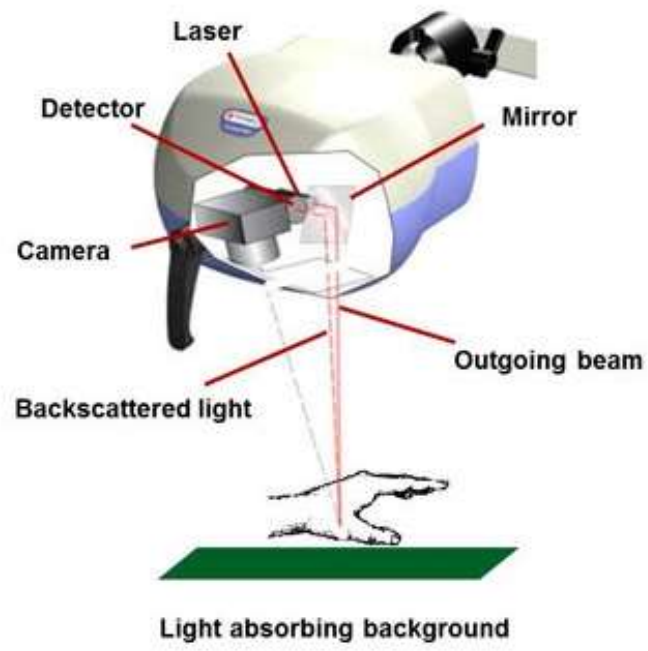

\section{Abbildung 5: Schematischer Aufbau des PeriScan PIM 3}

Mit freundlicher Genehmigung von Perimed AB

Trifft das Licht auf das zu untersuchende Gewebe, wird es verstreut und teilweise von diesem absorbiert. Wie bei akustischen Signalen, ändert sich auch bei Lichtwellen, die auf bewegte Teile treffen, die Wellenlänge. Lichtwellen, die dagegen auf unbewegtes Gewebe treffen, werden mit der gleichen Wellenläge reflektiert (Prinzip der Dopplerverschiebung). 
Dieses reflektierte Licht wird mithilfe eines integrierten Fotodetektors registriert (s. Abbildung 5) und somit der mikrozirkulatorische Blutfluss aus den unterschiedlichen Wellenlängen des reflektierten Lichtes errechnet.

\subsubsection{Durchführung der Perfusionsmessung}

Die Tiere wurden an o. g. Zeitpunkten am PeriScan PIM 3 System einer Laser-DopplerMessung unterzogen. Hierfür erfolgte die Narkoseeinleitung in einem mit Isofluran gefüllten, verschließbaren Glasgefäß. Nachdem die Mäuse betäubt waren, wurden sie auf einer Wärmeplatte platziert und mithilfe eines Beatmungsgeräts (Mini Vent Mouse Ventilator Typ 845) mit einem Isofluran-Luft-Gemisch weiterbeatmet und somit die Narkose aufrechterhalten (s. Abbildung 6). Bei der Fixierung wurde auf eine parallele und ausgestreckte Lagerung der Hinterläufe geachtet, um in der späteren DopplerPerfusionsmessung keine Überlagerungen zu sehen. Nach dem korrekten Platzieren der Maus auf der Wärmeplatte konnte das Gebiet, welches der Laser abfahren sollte, eingegrenzt werden. Anschließend wurde die Messung gestartet. Nachdem die jeweiligen Messungen beendet waren, wurden die Tiere in einen separaten Käfig verbracht und dort bis zum vollständigen Erwachen aufbewahrt.

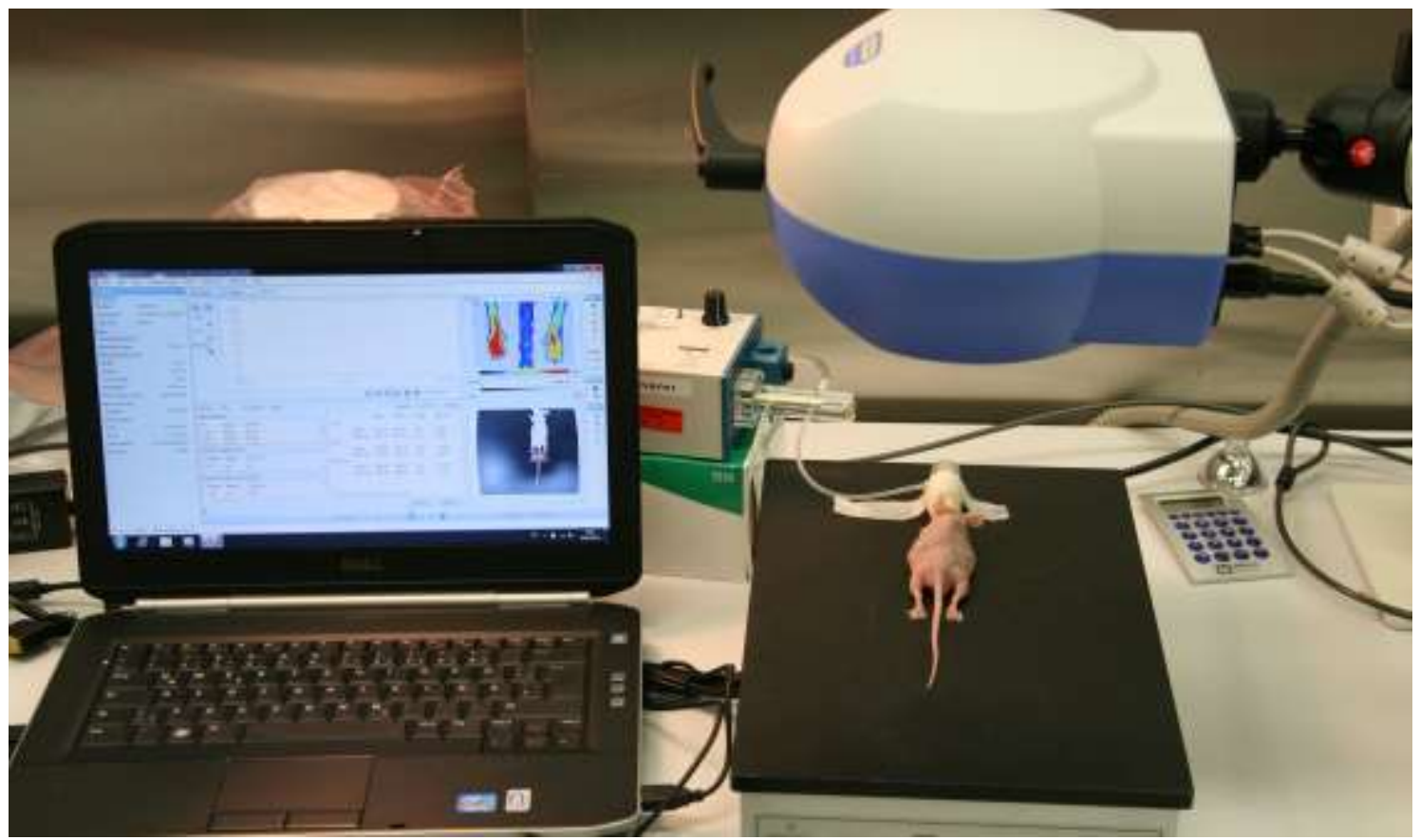

Abbildung 6: Versuchsaufbau der Laser-Doppler-Perfusionsmessung

\subsubsection{Auswertung der Laser-Doppler-Messungen}

Zur Durchführung und Auswertung der Laser-Doppler-Untersuchungen wurde das Programm PIMSoft ${ }^{\circledR}$ benutzt. Hierbei wurden die zu untersuchenden Areale markiert, wobei Areal 1 jeweils der sham-operierten Seite und Areal 2 der operierten Seite zugeteilt wurde. Um die Perfusion unabhängig von anderen Faktoren (Blutdruck etc.) beurteilen zu können, wurde nun jeweils der Quotient der mittleren Perfusionswerte von Areal 1 und Areal 
2 (im Folgenden Ratio genannt) gebildet und die Mittelwerte dieser Ratios in Abhängigkeit vom jeweiligen Untersuchungstag aufgetragen. Abbildung 7 zeigt eine exemplarische Darstellung der Perfusion mittels Laser-Doppler.
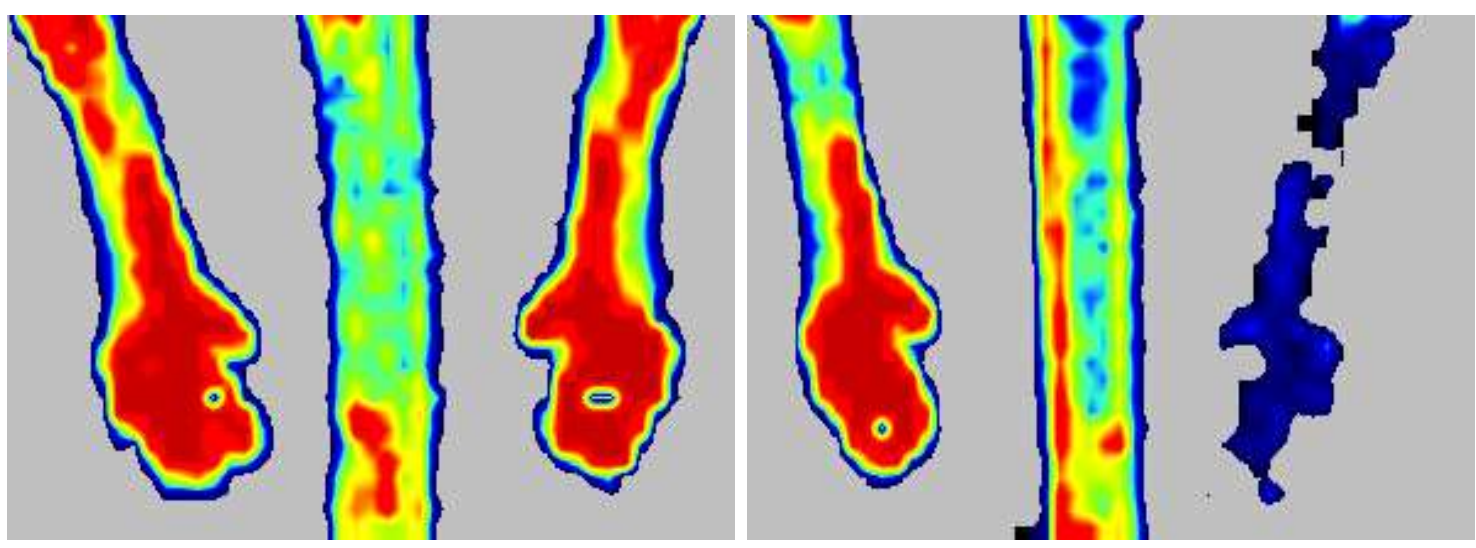

Abbildung 7: Beispielhafte Perfusionsdarstellung der Laser-Doppler-Messung links: Dopplermessung vor der Operation; rechts: Dopplermessung unmittelbar nach der Operation

\subsubsection{Genehmigung der Studie}

Der tierexperimentelle Teil dieser Studie wurde nach $\int 8$ Abs. 1 des Tierschutzgesetzes vom Niedersächsischen Landesamt für Verbraucherschutz und Lebensmittelsicherheit genehmigt (Az.: 33.9-42502-04-10/0320). Haltung und Versuche erfolgten gemäß nationalen Bestimmungen.

\subsection{Monozytenisolation}

\subsubsection{Beschreibung des Blutspendekollektives}

Die Monozyten und ihre Subpopulationen wurden aus Buffy Coats gewonnen, die in der Abteilung für Transfusionsmedizin der UMG (kommissarische Leitung: Priv.-Doz. Dr. J. Riggert) im Rahmen der täglichen Blutspende erstellt wurden. Die durchgeführten Versuche wurden ausschließlich an männlichen Tieren durchgeführt. Aus diesem Grund wurden für die Isolation der Monozyten ebenfalls ausschließlich männliche Probanden ausgewählt. Aus früheren Untersuchungen zur Monozytenfunktion geht hervor, dass z. B. isolierte Monozyten aus Patientenblut von Diabetikern ein schlechteres Migrationsvermögen aufweisen als Monozyten gesunder Probanden (Waltenberger et al. 2000). Zusätzlich zeigen auch Monozyten, isoliert aus Blut von Patienten mit Hypercholesterinämie, eine Migrationseinschränkung. Dies scheint verstärkt durch das gleichzeitige Vorhandensein einer KHK in diesen Patienten (Czepluch et al. 2007; Czepluch et al. 2011). Da diese Risikofaktoren für eine KHK weitestgehend in adipösen Menschen anzutreffen sind, wurden letztlich nur Blutspender in die Studie eingeschlossen, deren Body Mass Index (BMI) 18,5 - $30 \mathrm{~kg} / \mathrm{m}^{2}$ betrug. Spender mit den nachgewiesenen cvRF arterielle Hypertonie, Hypercholesterinämie, Diabetes mellitus sowie aktives Rauchen 
wurden ebenfalls nicht berücksichtigt, da z. B. weiterführende Untersuchungen zur Monozytenfunktion belegen, dass Monozyten aus Blut rauchender Probanden ebenfalls Einschränkungen in der Migrationsfähigkeit aufzeigen (Stadler et al. 2007). Zusätzlich wurden Probanden nicht berücksichtigt, die andere Krankheiten aufwiesen, bei denen die aktuelle Zahl der Monozyten beeinflusst sein könnte, wie z. B. Autoimmun- oder Tumorerkrankungen, aktive Allergien oder Infektionen. Diese Ausschlusskriterien wurden anhand eines Fragebogens (s. Anhang) vor Durchführung der Blutspende erfasst, sodass keiner der entstandenen Buffy Coats unnötig für wissenschaftliche Zwecke verbraucht wurde.

\subsubsection{MicroBeads ${ }^{\circledR}$-assistierte Isolation humaner Monozyten}

Die Isolation der humanen Monozyten wurde durchgeführt mithilfe einer MicroBeads ${ }^{\circledR}-$ assistierten magnetischen Selektion (Czepluch et al. 2011). Hierfür wurde zunächst nach Rekrutierung der Blutspender in der Abteilung für Transfusionsmedizin der UMG die Blutspende durchgeführt und die Blutkonserven im Anschluss für mindestens eine Stunde zum Ruhen aufbewahrt. Nach der anschließenden Zentrifugation und dem Abpressen der Erythrozyten zur weiteren Aufbereitung wurde der Buffy Coat ins Labor überführt und in Portionen von $20 \mathrm{ml}$ in mit Histopaque ${ }^{\circledR}$ vorbereitete „Ficoll-Paque“-Röhrchen (s. Abbildung 8) verteilt und für 20 min einer Dichtegradientenzentrifugation bei 400 rcf, $20{ }^{\circ} \mathrm{C}$ ohne Bremse zugeführt, sodass die entstandenen Banden nicht durch Bremsen wieder zerstört wurden.
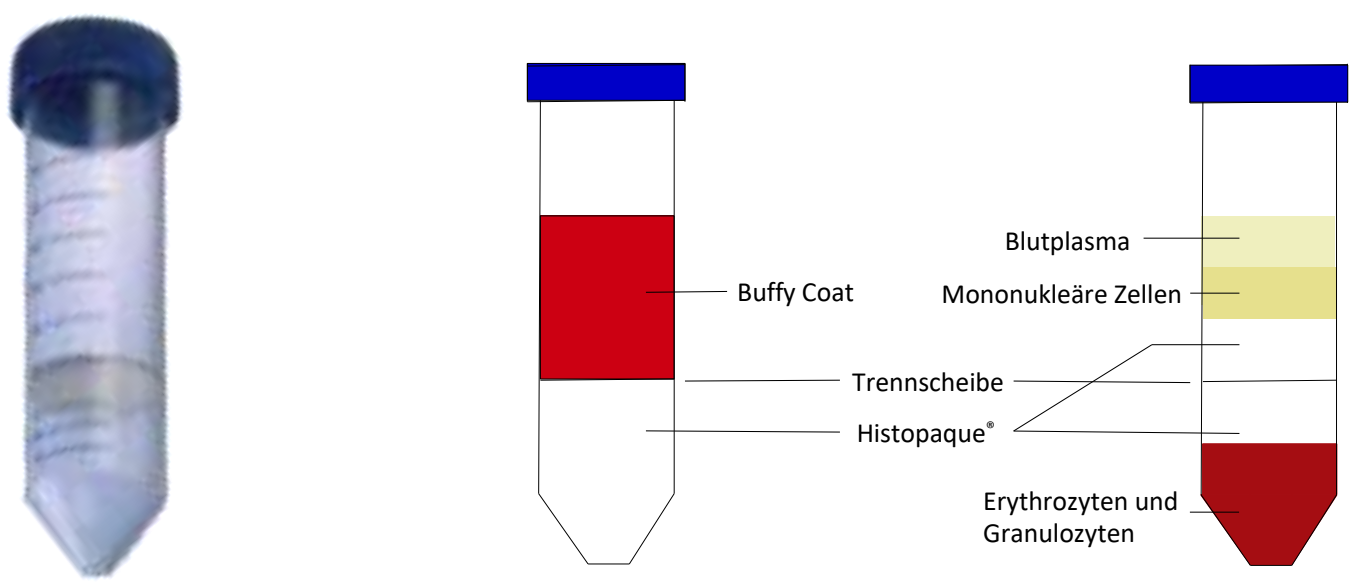

\footnotetext{
Abbildung 8: "Ficoll-Paque"-Röhrchen:

links: unbenutztes Röhrchen; Mitte: Schematische Darstellung vor Zentrifugation; rechts: schematische Darstellung nach Zentrifugation, mit freundlicher Genehmigung von Greiner Bio-One International GmbH
}

Nach der Zentrifugation wurde der Zellüberstand abgesaugt, die Bande der mononukleären Zellen (MNC)-Suspension in Falcon-Röhrchen überführt und nachfolgend mit 
PBS/EDTA gewaschen (250 rcf, $10 \mathrm{~min}, 20^{\circ} \mathrm{C}$ ). Nach dem Resuspendieren wurde die Lösung im Verhältnis 1:5 aufgeteilt. Ein Teil wurde für die Isolation der total-mo und CD16-mo, fünf Teile für die Herstellung der $\mathrm{CD}^{-} 16^{+}$-mo verwendet. Nach nochmaligem Waschen und anschließender Kühlung der Zentrifuge $\left(8^{\circ} \mathrm{C}\right)$ wurden die Suspensionen über einen Präseparationsfilter und gegeben und anschließend das genaue Volumen der Suspensionen, sowie deren Zellzahl mittels Neubauer-Zählkammer ermittelt. Aus diesen Parametern wurde die letztendliche Menge der Zellen bestimmt, die für die magnetische Konjugation eingesetzt werden sollte. Nach erneuter Zentrifugation (1000 rcf, 5 min, $8{ }^{\circ} \mathrm{C}$ ) und Absaugen des Überstandes wurden die Zellpellets mit jeweils $15 \mu \mathrm{l}$ Assay-Puffer pro $10^{7}$ Zellen resuspendiert und für die weitere Inkubation vorbereitet. Die folgenden zwei Abschnitte erfolgten im Wesentlichen parallel.

\subsubsection{Isolation von CD16- und Gesamtmonozyten}

Für die Isolation von CD16- und total-mo wurde das Monocyte Isolation Kit II (s. Tabelle 8) verwendet. Hierbei wurden zunächst mittels der aus humanem Immunglobulin bestehenden FcR-Blocking-Reagenz unspezifische Antigen-Antikörperbindungen geblockt. Gleichzeitig erfolgte als erster Schritt der Monoztyenisolation das Aussortieren von NichtMonozyten aus der MNC-Suspension. Hierfür wurde der Biotin-Antikörper Cocktail verwendet. Dieser enthält entsprechend verschiedene Biotin-konjugierte Antikörper (gegen CD3, CD7, CD16, CD19, CD56, CD123 und Glycophorin A). Entsprechend wurde den Zellen nach Resuspension zunächst die FcR-Blocking Reagenz und der Biotin-AntikörperCocktail hinzugegeben und die Suspension für 10 min im Kühlschrank inkubiert. Nach erneuter Zugabe von nochmals $15 \mu \mathrm{l}$ Assay-Puffer auf $10^{7}$ Zellen, wurden dann die AntiBiotin MicroBeads hinzugefügt und die Suspension nochmals für 15 min im Kühlschrank inkubiert. Für den anschließenden Waschschritt wurde dem Röhrchen nochmals $8 \mathrm{ml}$ Assay-Puffer zugeführt und anschließend für 5 min zentrifugiert (1000 rcf, $\left.8{ }^{\circ} \mathrm{C}\right)$. Während der Zentrifugation wurde die Separationssäule (LS-Säule) vorbereitet. Hierfür wurde diese in den Magneten eingespannt und mit $3 \mathrm{ml}$ Assay-Puffer vorgefüllt. Nach Absaugen des Überstandes und der anschließenden Resuspension mit $3 \mathrm{ml}$ Assay-Puffer wurde nun die Separationssäule mit der Zellsuspension befüllt und anschließend nochmals mit $6 \mathrm{ml}$ Assay Puffer gespült. Die hieraus resultierende Zelllösung wurde nun mit Assay-Puffer auf ein Gesamtvolumen von $10 \mathrm{ml}$ aufgefüllt, erneut die genaue Zellzahl bestimmt und $10^{7}$ Zellen (nun total-mo) entnommen und auf Eis gelagert. Die restliche Zellsuspension wurde zur Isolation der $\mathrm{CD}^{\circ} 6^{-}$-mo einer weiteren Zentrifugation zugeführt (1000 rcf, $\left.5 \mathrm{~min}, 8^{\circ} \mathrm{C}\right)$.

Nach erneutem Absaugen des Flüssigkeitsüberstandes wurden die Zellen erneut mit $40 \mu \mathrm{l}$ Assay-Puffer pro $10^{7}$ Zellen resuspendiert und anschließend $10 \mu \mathrm{l}$ an CD16 MicroBeads pro $10^{7}$ Zellen MicroBeads zugeführt. Es erfolgte wiederum die Inkubation für $15 \mathrm{~min}$ im Kühlschrank. Nach nochmaligem Auffüllen mit $8 \mathrm{ml}$ Assay-Puffer und anschließendem Zentrifugieren (1000 rcf, 5 min, $8{ }^{\circ} \mathrm{C}$ ) erfolgte die nachfolgende Resuspension des Pellets 
mit $50 \mu \mathrm{l}$ Assay-Puffer auf $10^{7}$ Zellen der initialen Zellzählung. Für die nun folgende zweite magnetische Separation wurde erneut eine LS-Separationssäule ausgewählt, welche im Magneten eingespannt mit $3 \mathrm{ml}$ Assay-Puffer vorgefüllt wurde. Nun erfolgte die erneute Hinzugabe der Zellsuspension. Nachfolgend wurden die Inkubationsröhrchen mit 3 x $3 \mathrm{ml}$ Assay-Puffer ausgespült. Nach erneuter Zentrifugation (1000 rcf, $5 \mathrm{~min}, 8{ }^{\circ} \mathrm{C}$ ) und dem Absaugen des Zellüberstandes wurden nun beide Zellpellets (inklusive den bis zu diesem Zeitpunkt auf Eis gelagerten total-mo) in $1 \mathrm{ml}$ PBS resuspendiert und die Zellzahl nochmals mittels Trypanblau und Neubauer-Zählkammer ermittelt. Das entsprechende Volumen für $10^{6}$ Zellen wurde abgenommen und bis auf $300 \mu \mathrm{l}$ aufgefüllt.

\subsubsection{Isolation von $\mathrm{CD} 16^{+}$-Monozyten}

Die Isolation der CD16 ${ }^{+}$-mo erfolgte unter der Verwendung des CD $16^{+}$Monocyte Isolation Kit (s. Tabelle 9). Hierbei wurde der Suspension zunächst die FcR-Blocking Reagenz (Funktion s. Kap 2.3.2.1) und der Non-Monocyte Depletion Cocktail (s. Kap. 2.1.5) hinzugefügt und diese im Anschluss für 15 min im Kühlschrank inkubiert. Hiernach erfolgte ein Waschschritt. Hierfür wurde die Suspension mit $8 \mathrm{ml}$ Assay-Puffer aufgefüllt und für 5 min zentrifugiert (1000 rcf, $8{ }^{\circ} \mathrm{C}$ ). Während der Zentrifugation wurde die Separationssäule (LD-Säule) vorbereitet. Diese wurde hierfür in den Magneten eingespannt und bereits mit $2 \mathrm{ml}$ Assay-Puffer vorgefüllt. Nach Beendigung der Zentrifugation wurde der Überstand abgesaugt und das Zellpellet erneut resuspendiert. Hierfür wurden $500 \mu \mathrm{l}$ Assay-Puffer pro 1,25 x $10^{8}$ Zellen benötigt. Nun wurde die LD-Säule mit der Zellsuspension befüllt und nachfolgend zweifach mit $1 \mathrm{ml}$ Assay-Puffer gespült. Anschließend wurde die Probe mit Assay-Puffer auf ein Gesamtvolumen von $10 \mathrm{ml}$ aufgefüllt und einer weiteren Zentrifugation zugeführt (1000 rcf, $5 \mathrm{~min}, 8^{\circ} \mathrm{C}$ ).

Der Zellüberstand wurde erneut abgesaugt und das Zellpellet nochmals mit $20 \mu \mathrm{l}$ AssayPuffer auf initial $10^{7}$ Zellen resuspendiert, nachfolgend die entsprechende Menge an CD16 MicroBeads zugeführt ( $5 \mu$ MicroBeads auf initial $10^{7}$ Zellen) und die Probe nochmals für 15 min im Kühlschrank inkubiert. Anschließend wurde nochmals gewaschen und die Suspension hierzu mit $8 \mathrm{ml}$ Assay-Puffer aufgefüllt. Nach Zentrifugation (1000 rcf, 5 min, 8 $\left.{ }^{\circ} \mathrm{C}\right)$ und Absaugen des Zellüberstandes erfolgte nun die Resuspension des Pellets mit $50 \mu \mathrm{l}$ Assay-Puffer auf $10^{7}$ Zellen der initialen Zellzählung. Wiederum wurde während dieses Waschschrittes die Separationssäule (LS-Säule) für die zweite magnetische Separation vorbereitet und diese hierzu in den Magneten eingespannt und mit $3 \mathrm{ml}$ Assay-Puffer vorgefüllt. Anschließend wurde die Zellsuspension hinzugegeben und das Inkubationsröhrchen mit $3 \times 3 \mathrm{ml}$ Assay-Puffer ausgespült. Da die isolierten CD16 ${ }^{+}$-mo sich nun innerhalb der Separationssäule befanden, wurde diese aus dem Magneten entfernt und über einem neuen Röhrchen mit $5 \mathrm{ml}$ Assay-Puffer vorsichtig herausgespült. Nach erneuter Zentrifugation (1000 rcf, $5 \mathrm{~min}, 8{ }^{\circ} \mathrm{C}$ ) und dem Absaugen des Zellüberstandes wurde in $1 \mathrm{ml}$ PBS resuspendiert und die Zellzahl nochmals mittels Trypanblau und 
Neubauer-Zählkammer ermittelt. Auch hier wurde das $10^{6}$ Zellen entsprechende Volumen abgenommen und bis auf $300 \mu \mathrm{l}$ aufgefüllt.

\subsubsection{Stimulation mit Leptin}

Im Falle der weiteren Stimulation mit Leptin wurden die Zelllösungen nochmals zentrifugiert (1000 rcf, $5 \mathrm{~min}, 8^{\circ} \mathrm{C}$ ), der Zellüberstand abgesaugt und die Pellets nun in $990 \mu \mathrm{l}$ RPMI-Medium aufgenommen. Hiernach wurde $10 \mu \mathrm{l}$ Leptin (c = $1 \mathrm{pg} / \mathrm{ml}$ ) hinzugefügt und die Suspension anschließend einer 30-minütigen Inkubation bei $37{ }^{\circ} \mathrm{C}$ unter 5\%-iger Kohlenstoffdioxid $\left(\mathrm{CO}_{2}\right)$-Begasung zugeführt. Nach Beenden der Inkubation wurden die Röhrchen unmittelbar mit PBS aufgefüllt, einer weiteren Zentrifugation zugeführt, und nach Absaugen des Zellüberstandes das Zellpellet anschließend in $300 \mu \mathrm{l}$ PBS aufgenommen.

\subsubsection{Applikation der Zellen}

Im Anschluss an die Aufnahme der Zellsuspensionen in Insulinspritzen (Kanülengröße 30 G) wurden die Zellen den mit Isofluran (Anästhesie s. S. 20) betäubten Mäusen intrakardial injiziert. Dies wurde regelhaft am ersten postoperativen Tag durchgeführt.

\subsubsection{Durchflusszytometrische Qualitätskontrollen der Monozytenisolation}

Qualitätskontrollen der bei der Monozytenisolation separierten Monozyten und ihrer Subpopulationen wurden durchflusszytometrisch anhand einzelner Stichproben der Isolationen durchgeführt. Zusätzlich wurde auch die Expression des ObR überprüft.

\subsubsection{Prinzip der Durchflusszytometrie}

Bei der Durchflusszytometrie werden mithilfe eines Laserstrahls unterschiedlichste Zellen und Partikel einer Probe untersucht und analysiert. Hierfür werden nach Aufnahme in das Durchflusszytometer die Zellen mithilfe eines starken Flüssigkeitsstroms dicht hintereinander aufgereiht und nacheinander an einem Messpunkt vorbeigeführt, an dem ein Laserstrahl jede Zelle des Materials einzeln erfasst. Hierbei können bei der Untersuchung bis zu 10000 Zellen pro Sekunde analysiert werden.

Nachdem der Laser eine Zelle getroffen hat, wird von dieser Vorwärtsstreulicht (engl. Forward Scatter [FSC]) und Seitwärtsstreulicht (engl. Side Scatter [SSC]) in zwei unterschiedliche Richtungen ausgesendet, welches von zwei unterschiedlichen Empfängern aufgefangen wird und dabei seine Wellenlänge nicht verändert (Leach et al. 2013; Macey 2007). Das Vorwärtsstreulicht klassifiziert hierbei die Zellgröße, wohingegen das SSC eher die Art und Beschaffenheit intrazellulärer Granula anzeigt. Abbildung 9 zeigt schematisch den prinzipiellen Aufbau eines Durchflusszytometers. 


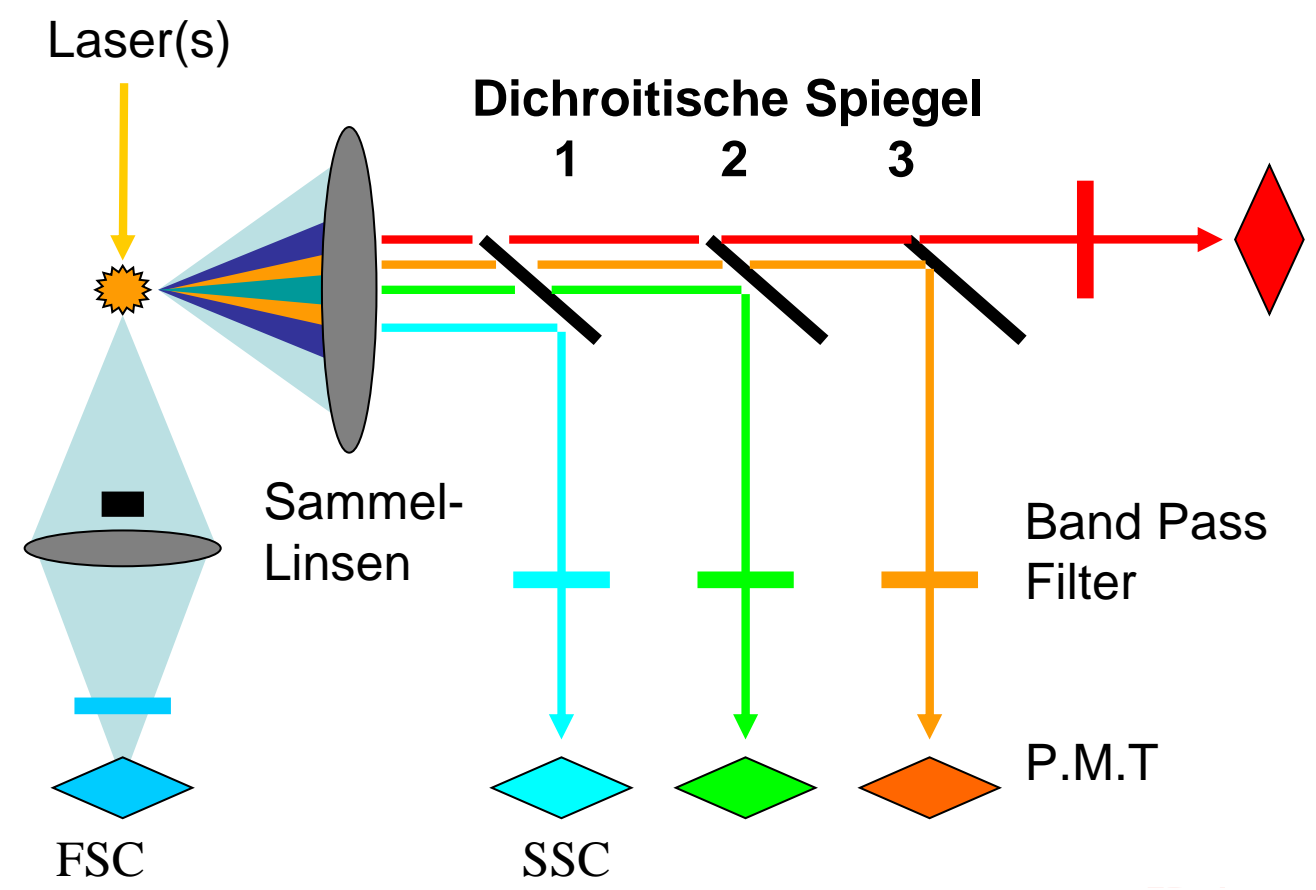

Abbildung 9: Schematischer Aufbau eines Durchflusszytometers

mit freundlicher Genehmigung von Dr. A. Böhmler, Beckmann Coulter

Über die vom Streulicht ausgehenden Aussagen hinaus können weitere Zelleigenschaften mittels eingesetzter Fluorochrome, welche nach Anregung durch Licht einer bestimmten Wellenlänge spezielle Emissionspektren abgeben, ermittelt werden. Diese können einerseits Bestandteil der Zelle sein, jedoch auch in vivo eingebracht (z. B. DAPI) oder über Antikörper in vitro an Oberflächenproteine von Zellen konjugiert werden.

Bei dem in der vorliegenden Arbeit benutzten Duchflusszytometer (BD FACSCanto ${ }^{\text {TM }}$ II) wurden Fluorochrome benutzt, welche bei $488 \mathrm{~nm}$ bzw. $633 \mathrm{~nm}$ ihr Exzitationsmaximum besitzen. Entsprechend wurde auch lediglich der blaue und rote Laser genutzt. Nachfolgende Tabelle zeigt die Eigenschaften der verschiedenen verwendeten Fluorochrome und der jeweils eingesetzten Laser. Die benutzten Antikörper finden sich in den Tabellen 9 bis 13 .

Tabelle 20: Übersicht über die farblichen Eigenschaften und Wellenlängen der Fluorochrome

\begin{tabular}{|c|c|c|c|c|}
\hline Fluorochrom & Exzitationsmaximum & Emissionsmaximum & Farbe & Laser \\
\hline FITC & $488 \mathrm{~nm}$ & $518 \mathrm{~nm}$ & grün & $\begin{array}{l}\text { blau } \\
\mathrm{nm})\end{array}$ \\
\hline PE & $488 \mathrm{~nm}$ & $578 \mathrm{~nm}$ & gelb & $\begin{array}{l}\text { blau } \\
\mathrm{nm})\end{array}$ \\
\hline APC & $633 \mathrm{~nm}$ & $660 \mathrm{~nm}$ & rot & $\operatorname{rot}(633 \mathrm{~nm})$ \\
\hline PerCP-Cy ${ }^{\mathrm{TM}} 5.5$ & $488 \mathrm{~nm}$ & $695 \mathrm{~nm}$ & tiefrot & $\begin{array}{l}\text { blau } \\
\mathrm{nm})\end{array}$ \\
\hline
\end{tabular}




\subsubsection{Aufbereitung der Monozyten zur FACS ${ }^{\mathrm{TM}}$-Färbung}

Nach der Bestimmung der endgültigen Zellzahl wurden jeweils $10^{6}$ Zellen aus den Probenröhrchen entnommen, in ein mit $400 \mu \mathrm{l}$ 1\%iger PFA-Lösung befülltes PolystyreneFACS ${ }^{\text {TM}}$-Röhrchen überführt, mit einer großlumigen Pipette gemischt und für 10 min bei Raumtemperatur inkubiert. Anschließend folgten zwei Waschschritte mit Zugabe von zunächst $2 \mathrm{ml}$ und anschließend $3 \mathrm{ml} \mathrm{PBS}(1 \mathrm{x}) / \mathrm{BSA}(1 \%)$ pro $\mathrm{FACS}^{\mathrm{TM}}$-Röhrchen und folgender Zentrifugation (1000 rcf, $5 \mathrm{~min}, 20^{\circ} \mathrm{C}$ ).

\subsubsection{Kontrolle der Reinheit der Isolation}

Die Reinheitskontrolle der total-mo und der Monozytensubpopulationsfraktionen wurde mithilfe von CD16- und CD14-Antikörpern geführt. Diesbezügliche folgte nach dem Absaugen des Zellüberstandes die vorsichtige Resuspension mit $\operatorname{PBS}(1 \mathrm{x}) / \mathrm{BSA}(1 \%)$. Hierfür wurden für die verschiedenen Teile der Färbung unterschiedliche Volumina benutzt. Die Negativkontrolle wurde mit $50 \mu \mathrm{l}$, die Isotypenkontrolle mit $30 \mu \mathrm{l}$ und die eigentliche Antikörperfärbung mit 33,75 $\mu \mathrm{l}$ resuspendiert. Hiernach wurden die jeweiligen Antikörperlösungen (s. Tabelle 10 und Tabelle 11) hinzupipettiert. Im Anschluss wurden die Lösungen für 30 min bei Raumtemperatur im Dunkeln inkubiert. Nach Zugabe von jeweils $2 \mathrm{ml} 4{ }^{\circ} \mathrm{C}$ kaltem PBS(1x)/BSA(1\%), Mischen und anschließender Zentrifugation (5 min, $4{ }^{\circ} \mathrm{C}, 1000 \mathrm{rcf}$ ) wurden die Zellpellets in $500 \mu \mathrm{l}$ 1\%igem PFA resuspendiert und bis zur Untersuchung am FACS ${ }^{\mathrm{TM}}$-Gerät bei $4{ }^{\circ} \mathrm{C}$ im Dunkeln gelagert.

\subsubsection{Kontrolle der Expression des Leptinrezeptors}

Für die Kontrolle der Expression des ObR erfolgte die Färbung ausgewählter Stichproben mit Fluorochromen gegen den ObR. Hierfür wurden den FACS ${ }^{\mathrm{TM}}$-Röhrchen nach Resuspension des Zellpellets in $100 \mu \mathrm{lPS}(1 \mathrm{x}) / \mathrm{BSA}(1 \%)$ für die Negativkontrolle und in jeweils 87,5 $\mu \mathrm{l}$ für die Färbung sowie auch die Isotypenkontrolle, 12,5 $\mu \mathrm{l}$ der Antikörperlösungen (Verteilung s. Tabelle 12 und Tabelle 13) zugeführt und die Proben im Anschluss gründlich mit dem Vortex ${ }^{\circledR}$ vermischt. Die anschließende Inkubation erfolgte für 30 min bei Raumtemperatur im Dunkeln. Die Inkubation wurde mit jeweils $2 \mathrm{ml} 4{ }^{\circ} \mathrm{C}$ kaltem $\operatorname{PBS}(1 \mathrm{x}) / \mathrm{BSA}(1 \%)$ unter gutem Vermischen gestoppt. Nach anschließender Zentrifugation (5 min, $4{ }^{\circ} \mathrm{C}, 1000 \mathrm{rcf}$ ) und Absaugen des Zellüberstandes folgte die Resuspension in $500 \mu \mathrm{l}$ 1\%igem PFA und die Lösung wurde bis zur Untersuchung am FACS $^{\text {TM}}-$ Gerät bei $4{ }^{\circ} \mathrm{C}$ im Dunkeln gelagert.

\subsubsection{Durchführung der FACS ${ }^{\mathrm{TM}}$-Untersuchung}

Die letztendliche durchflusszytometrische Untersuchung am FACSCanto $^{\text {TM }}$ II (BD Bioscience) sowie das Gating und die Auswertung wurden durch Herrn Dr. med. Hendrik Kuschicke, Doktorand in der Arbeitsgruppe (AG) „Vaskuläre Biologie und Arterioskleroseforschung“ der Abteilung für Kardiologie und Pneumologie der UMG, durchgeführt. 


\subsubsection{Auswertung der FACS ${ }^{\mathrm{TM}}$-Untersuchung}

Zum Auswerten der durchflusszytometrischen Daten wurde das Programm FACSDiva ${ }^{\text {TM }}$ benutzt. Hierbei wurden die aufgenommen Blots zuerst anhand ihres FSC und SSC gegatet und somit, da es sich ausschließlich um Zellen nach o. g. Zellisolationen handelte, nochmals die Reinheit der Isolationen überprüft. Anschließend erfolgte die Auftragung anhand der Fluorochromeigenschaften und die Zuordnung zu CD16 ${ }^{+}$-mo, CD 16-mo und total-mo bzw. $\mathrm{ObR}^{+}$und ObR: Die hieraus generierten Rohdaten wurden dann zur weiteren statistischen Berechnung und grafischen Darstellung in GraphPad Prism überführt. Auch diese Daten wurden mit freundlicher Unterstützung von Herrn Dr. Kuschicke erstellt.

\subsubsection{Genehmigung der Studie}

Der humane Teil dieser experimentellen Studie wurde durch die Ethik-Kommission der Georg-August-Universität Göttingen geprüft und unter der Antragsnummer 20/2/11 genehmigt.

\subsection{Histologische Analysen der Muskelgewebe}

\subsubsection{Erstellen von Gefrierschnitten}

Die eingefrorenen Muskelproben wurden in einem gekühlten Kryotom eingespannt und in 5 - $10 \mu \mathrm{m}$ dicke Scheiben geschnitten. Es wurden jeweils 3 Serienschnitte auf einen Objektträger aufgenommen, kurz angetrocknet und anschließend bis zur Weiterverarbeitung bei $-20{ }^{\circ} \mathrm{C}$ im Tiefkühlschrank gelagert.

\subsubsection{Beschreibung der unterschiedlichen Antikörper}

Für die unterschiedlichen histologischen Färbungen wurden spezifische Antikörper eingesetzt. So wurde für die Markierung des Endothels ein Antikörper gegen PlateletEndothelial-Cell-Adhesion-Molecule-1 (PECAM-1), oder auch CD31 genannt, eingesetzt. Zur Färbung der glatten Gefäßmuskelschicht wurde ein Antikörper gegen Smooth-Muscle-Actin (SMA) gewählt.

\subsubsection{Allgemeines Protokoll der CD31- und SMA-Färbungen}

Die eingefrorenen Muskelschnitte wurden nach dem Auftauen einem Wässerungsschritt mit PBS (5 min) unterzogen und hiernach für $10 \mathrm{~min}$ bei $-20{ }^{\circ} \mathrm{C}$ in Aceton fixiert. Nach einer kurzen Trocknungsphase der Objektträger unter einem Abzug wurden die einzelnen Schnitte mit einem PAP PEN ${ }^{\circledR}$ mini umrandet, um ein Zerfließen der Antikörperlösungen bei der späteren Inkubation zu verhindern. Nach einem weiteren Wässerungsschritt mit PBS (5 min) erfolgte die Permeabilisierung (10 min bei $37^{\circ} \mathrm{C}$ ) in einer vorgewärmten 
0,05\%-igen Triton-X-Lösung, welcher sich eine mehrmalige Spülung mit PBS (3 x 5 min) anschloss. Zur anschließenden Inkubation des ersten Antikörpers wurden unten stehende Antikörperkombinationen verwendet (s. Tabellen 14 und 15). Die jeweilige Negativkontrolle (statt Primärantikörperinkubation nur AB-Diluent) erfolgte auf jedem Objektträger an dem Schnitt, welcher sich am weitesten rechts befand. Zum Schutz vor Austrocknung wurden die Objektträger während aller Inkubationen in einer Feuchtkammer gelagert. Im Falle der CD31-Färbung wurde der Primärantikörper für $60 \mathrm{~min}$ bei Raumtemperatur, die Lösung der ersten Antikörper im SMA/CD31-Doppelfärbungsprotokoll jedoch für $60 \mathrm{~min}$ bei $37{ }^{\circ} \mathrm{C}$ im Inkubator inkubiert. Nach einem weiteren Waschschritt mit PBS (3 x 5 min) erfolgte die Inkubation der Sekundärantikörperlösung für 60 min im Dunkeln bei Raumtemperatur, welche wiederum durch eine weitere PBSWaschung ( 3 x 5 min) entfernt wurde. Nach der anschließenden Kernfärbung mit DAPI für 15 min bei Raumtemperatur konnten die Objektträger nach einem letzten Waschgang mit PBS (wiederum 3 x 5 min) mit dem Mounting Medium VectaShield ${ }^{\mathbb{B}}$ blasenfrei eingedeckt werden.

\subsubsection{Histologische Auswertungen}

Die Betrachtung der Färbungen unter dem Fluoreszenzmikroskop erfolgte innerhalb von 24 h, um einer Schwächung des Lichtsignals durch Lagerung entgegenzuwirken. Hierbei wurden alle Schnitte systematisch nach der visuell größten Dichte entsprechender Arteriolen (SMA/CD31-Doppelfärbung) bzw. Kapillaren (CD31-Färbung) durchsucht und jeweils fünf repräsentative Bilder (s. Abbildung 10) dieser Areale mithilfe des Programms Axio Vision in 200-facher Vergrößerung aufgenommen, wobei kontrolliert wurde, dass die Belichtungszeiten der jeweiligen Belichtungskanäle einer Färbung sich gleichen. Die entstandenen Bilder wurden mit dem Programm Image Pro Plus ${ }^{\circledR}$ ausgewertet. Um die Färbungen vor Austrocknung zu schützen, wurden die Deckgläschen mit Nagellack versiegelt, bevor die Lagerung bei $4{ }^{\circ} \mathrm{C}$ im Dunkeln erfolgte.

Im Einzelnen erfolgte bei der Untersuchung zur Angiogenese die Auszählung der mit CD31 positiv gefärbten Signale in Kolokalisation mit einem mit DAPI angefärbten Zellkern. Somit wurde sichergestellt, dass falsch-positiv gefärbte Signale in Rot (Farbe der CD31-Färbung) nicht versehentlich als Kapillare gewertet wurden. Um die verschiedenen Gruppen untereinander vergleichen $\mathrm{zu}$ können und interindividuelle Unterschiede zwischen den einzelnen Tieren zu minimieren, erfolgte die weitere Auswertung nachfolgend als Ratio der operierten gegen die sham- operierte Seite.

Zusätzlich wurde mithilfe des Programms Image Pro Plus ${ }^{\circledR}$ die mit Sekundärantikörper gefärbte Gesamtfläche des Bildausschnittes gemessen und im Anschluss durch die ermittelte Gesamtzahl an Kapillaren in diesem Bild dividiert. Dies gibt eine Aussage über die durchschnittliche Fläche einer einzelnen Kapillare im jeweiligen Bildausschnitt. Auch 
hier wurden analog zu den anderen Auswertungen das Verhältnis von operierter zu shamoperierter Seite ermittelt und diese Werte untereinander verglichen.
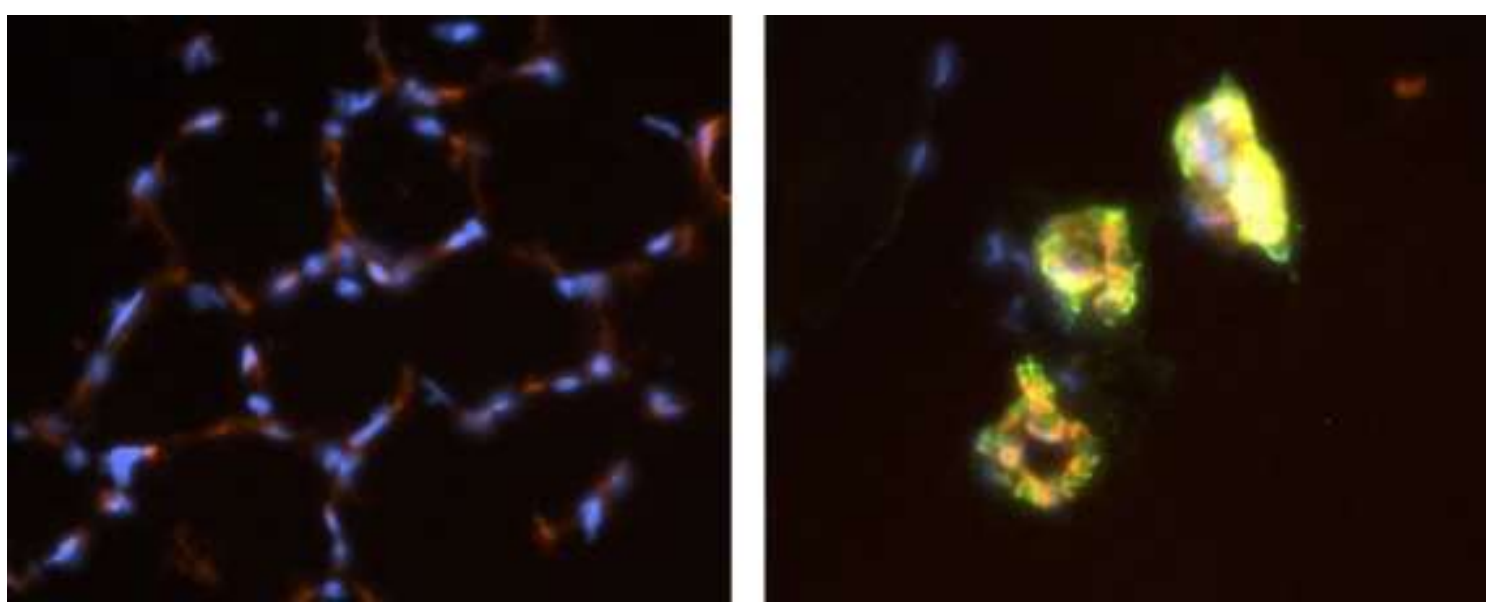

Abbildung 10: Exemplarische Darstellung der histologischen Färbungen links: Immunfluoreszenzbild der CD31-Färbung; rechts: Immunfluoreszenzbild der SMA-Färbung, Vergrößerung x200

Des Weiteren erfolgte zusätzlich die Untersuchung der Vaskularisation der einzelnen Myofibrillen. Hierfür wurden in jedem aufgenommenen Areal fünf repräsentative Fibrillen ausgewählt und die Anzahl der die jeweilige Fibrille versorgenden Kapillaren ermittelt. Auch hier erfolgte die weitere Auswertung als Ratio der operierten zur sham-operierten Seite.

Die Färbung wurde anhand „doppelt positiv“-gefärbter Areale ausgewertet, d. h. es wurden lediglich Zellen und Zellkerne zur Auswertung herangezogen, die ein positives Signal des zweiten Antikörpers und an gleicher Stelle auch ein positives DAPI-Signal zeigten. So konnten falsch positive Signale aus der Auswertung eliminiert werden. Es erfolgte die Auszählung der Zellen. Im Anschluss wurde die Anzahl der Zellen (pro Gesichtsfeld) mit dem entsprechenden Faktor (6,7 für 200x) multipliziert, um die Anzahl der doppelt positiven Zellen pro $\mathrm{mm}^{2}$ zu errechnen.

Weiterhin wurde bei der Analyse der Arteriogenese die Gesamtfläche der SMA-positiv gefärbten Areale pro Bild ermittelt, anschließend durch die Anzahl der auf dem Bild zu erkennenden Arteriolen dividiert und somit die durchschittliche Fläche als indirektes Maß für die Dicke der Arteriolenwand bestimmt. Hiernach erfolgte wiederum die Bildung des Quotienten vom operierten und sham-operierten Hinterlauf, um somit die Unterschiede in Abhängigkeit von der mit Leptin stimulierten sowie auch unstimulierten Monozytensubpopulationen darstellen zu können.

\subsection{Statistische Auswertung}

Sowohl die statistische Auswertung als auch die grafische Aufarbeitung und Darstellung der Daten wurde mithilfe des Programms GraphPad Prism (Version 6.01) durchgeführt. 


\subsubsection{Statistische Auswertung der Dopplerergebnisse}

Die statistische Analyse der Reperfusionsergebnisse nach Laser-Doppler-Untersuchung erfolgte jeweils zu den angegebenen Messzeitpunkten mittels one-way-Varianzanalyse (ANOVA)-Tests, gefolgt von dem Bonferroni Multiple Comparison Test (BonferroniKorrektur). Hierbei wurde auf statistische Unterschiede zwischen den Interventionsgruppen zur Kontrollgruppe, den unstimulierten sowie Leptin-stimulierten Interventionsgruppen untereinander und auch den jeweils zueinander gehörigen Gruppen in Abhängigkeit von der Leptin-Stimulation (z. B. total-mo gegen total-mo [s]) getestet.

\subsubsection{Statistische Auswertung der histologischen Untersuchungen}

Bei der Berechnung der statistischen Unterschiede der histologischen Daten erfolgte zunächst der Test der Daten auf eine Gauß'sche Normalverteilung. Sofern diese gegeben war, erfolgte die weitere Untersuchung der einzelnen Gruppen mithilfe des one-way ANOVA-Tests, gefolgt vom Bonferroni Multiple Comparison Test. Signifikanzen ergaben sich ab einem Wahrscheinlichkeitswert von $\mathrm{p}<0,05$. Dargestellt sind hier jeweils der Mittelwert \pm Standardfehler (SEM).

Bestätigte die initiale Testung keine Normalverteilung, erfolgte die weitere Berechnung mithilfe des nonparametrischen Kruskal Wallis Tests. Hier folgte daraufhin der Dunn's multiple Comparison Test. Auch hier waren Ergebnisse signifikant ab einem Wahrscheinlichkeitswert von $\mathrm{p}<0,05$. Bei nicht normalverteilten Daten erfolgte die Darstellung als Median; 25. Perzentile; 75. Perzentile. 


\section{Ergebnisse}

\subsection{Beschreibung des Mauskollektivs}

Zum Zeitpunkt der Operation der Hinterlaufischämie waren die Mäuse im Alter von $89 \pm$ 5 Tagen und zeigten ein Gewicht von 35,6 \pm 0,8 g.

\subsection{Vorversuche}

\subsubsection{Ergebnisse der Vorbehandlung mit Clodronat}

Um die ursprüngliche Vorstellung, die endogenen Monozyten der Versuchstiere depletieren zu können, zu verifizieren, wurde in einem Vorversuch nach oben beschriebenem Schema die Blutbildreaktionen der Tiere nach Clodronatgabe untersucht. Hier zeigte sich nach intrakardialer Gabe der Liposomen ein deutlicher Anstieg des prozentualen Anteils der Monozyten an der leukozytären Blutzellreihe. Dies lässt vermuten, dass die Clodronatliposomen neben einer Depletion der endogenen Monozyten sekundär auch zu einer reaktiven Bildung von Monozyten führen könnten. Dementsprechend wurde von einer Verwendung der Clodronatliposomen abgesehen.

\subsubsection{Qualitätskontrolle der Monozytenisolation}

Zur Überprüfung der Reinheit der einzelnen Proben der Monozytensubpopulationen sowie der Verteilung der Fraktionen in den total-mo nach Isolation wurden die einzelnen Subpopulationen anhand repräsentativer Proben $(n=4)$ durchflusszytometrisch analysiert. Hier zeigte sich eine durchschnittliche Reinheit für die $\mathrm{CD} 16^{+}$-mo von 85,4 \% und für die CD16-mo von 94,9\%. Auch die Verteilung der CD16 ${ }^{+}$-mo und CD16-mo in der totalmo-Population (total-mo) entsprach der in der Literatur angegebenen Verteilung von 10\% zu 90\% (Ziegler-Heitbrock et al. 2010). Abbildung 11 zeigt repräsentative Dot-PlotDarstellungen der Durchflusszytometrie (links: total-mo, Mitte: CD16-mo, rechts: CD16 ${ }^{+}-$ mo).

Wie bereits zuvor beschrieben, wurden zusätzlich auch durchflusszytometrische Untersuchungen zum Nachweis des Vorhandenseins des Leptinrezeptors durchgeführt. Dies erfolgte mithilfe eines ObR-Antikörpers (s. Tabelle 13). Hier zeigten lediglich ca. 20\% der CD16 ${ }^{+}$-mo eine Expression von ObR. Die CD16-mo und total-mo waren zu ca. 60\% $\mathrm{ObR}^{+}$. 
total-mo

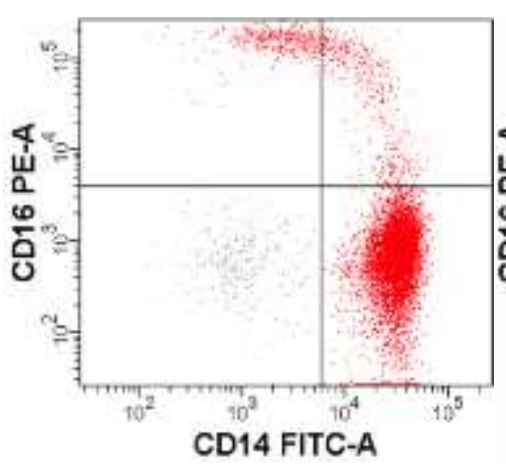

CD16-mo

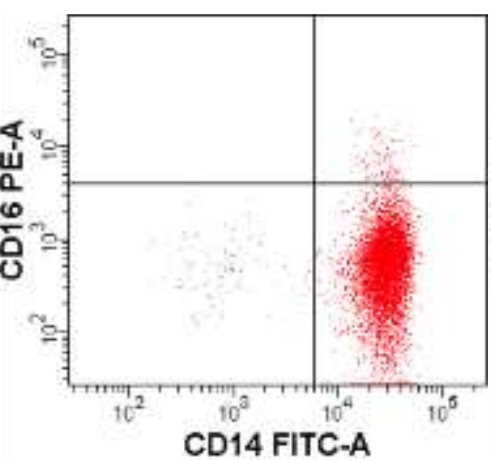

$\mathrm{CD} 16^{+}-\mathrm{mo}$

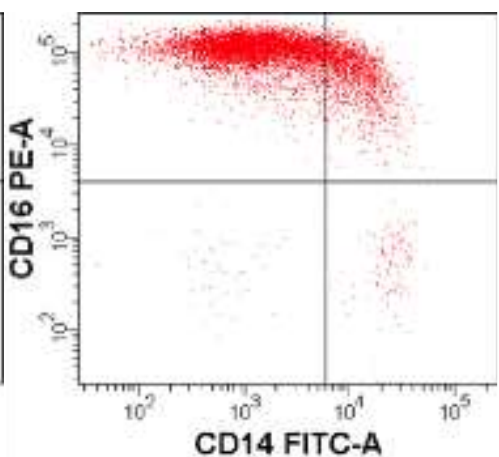

Abbildung 11: Repräsentative Dot-Plot-Darstellungen der einzelnen durchflusszytometrischen Messungen

CD16--mo, CD16-negative Monozyten; CD16+-mo, CD16-positive Monozyten; total-mo, Gesamtmonozyten; PE-A, Phycoerythrin; FITC-A, Fluoresceinisothiocyanat

\subsection{Ergebnisse der Perfusionsmessungen nach Hinterlaufischämie}

\subsubsection{Reperfusion mit unstimulierten Monozyten behandelter Mäuse}

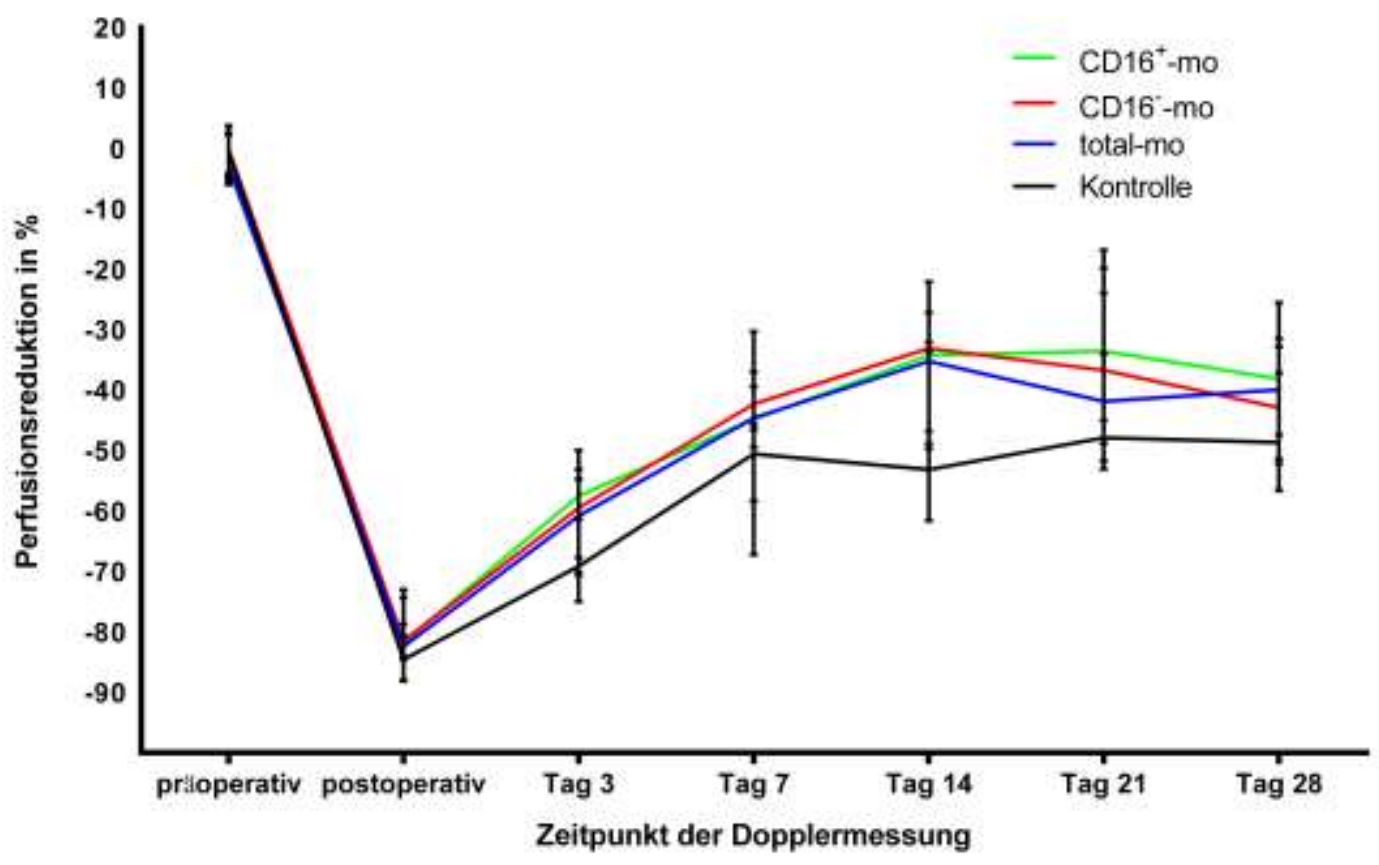

Abbildung 12: Darstellung der Laser-Doppler-Perfusionsmessung der Interventionsgruppen ohne Leptinstimulation

CD16--mo, CD16-negative Monozyten; CD16-mo, CD16-positive Monozyten; total-mo, Gesamtmonozyten 
Wie vorher beschrieben, wurden zur Evaluation der Reperfusion die Hinterläufe der Tiere an unterschiedlichen postoperativen Tagen mittels Laser-Doppler untersucht und im Anschluss der Quotient aus operierter und sham-operierter Seite aufgetragen. Hier zeigte sich rein optisch in den Interventionsgruppen der unstimulierten Monozyten und ihren Subpopulationen eine moderate Verbesserung der Reperfusion im Vergleich zu den Tieren der Kontrollgruppe. Diese erreichte in den drei Interventionsgruppen nach Gabe unstimulierter Monozyten ihr Maximum am 14. postoperativen Tag und fiel zum Ende der Untersuchungsperiode wieder ab (s. Abbildung 12). Die nachfolgende statistische Analyse zeigte jedoch keinen signifikanten Unterschied zwischen der Kontrollgruppe und den Interventionsgruppen.

\subsubsection{Evaluation der Perfusionsergebnisse nach Behandlung durch Leptin- stimulierte Monozyten}

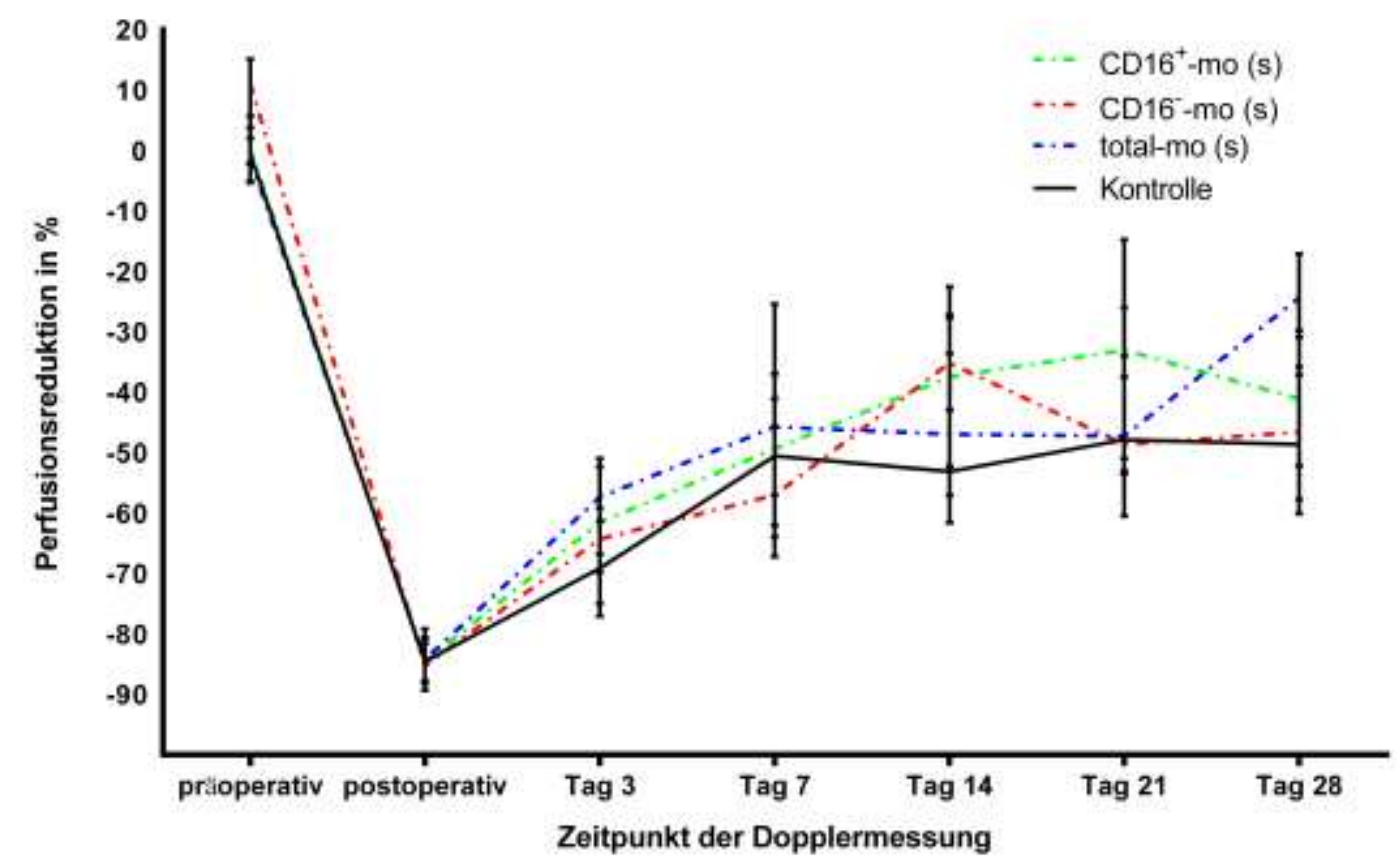

\footnotetext{
Abbildung 13: Darstellung der Laser-Doppler-Perfusionsmessung der Interventionsgruppen nach Leptinstimulation

CD16-mo (s), Leptin-stimulierte CD16-negative Monozyten; CD16+-mo (s), Leptin-stimulierte CD16positive Monozyten; total-mo (s), Leptin-stimulierte Gesamtmonozyten
}

Bei den Tieren, die mit Leptin-stimulierte Monozyten und -subpopulationen erhielten, stellte sich die Situation unübersichtlicher dar. Hier zeigte sich rein optisch die anfängliche Perfusionsverbesserung im Wesentlichen gleichverlaufend zur Kontrolle, allenfalls minimal verbessert. Ab dem 14. postoperativen Tag waren jedoch die Werte der Leptin-stimulierten Subpopulationen recht heterogen und teilweise rein optisch mit einer Verbesserung der Perfusion gegenüber der Kontrollgruppe vergesellschaftet, während dies jedoch bei den 
total-mo (s) erst ab Tag 28 der Fall war (s. Abbildung 13). Die statistische Untersuchung zeigte aber auch hier keine signifikanten Unterschiede.

\subsubsection{Unterschiede der Reperfusion mit unstimulierten und mit Leptin- stimulierten Monozyten behandelter Tiere}

Die Reperfusionsergebnisse zeigen auch innerhalb einer Monozyten-(subpopulations)gruppe keinen statisch signifikanten Unterschied zwischen Monozyten mit und ohne Leptinstimulation. (s. Abbildung 14).

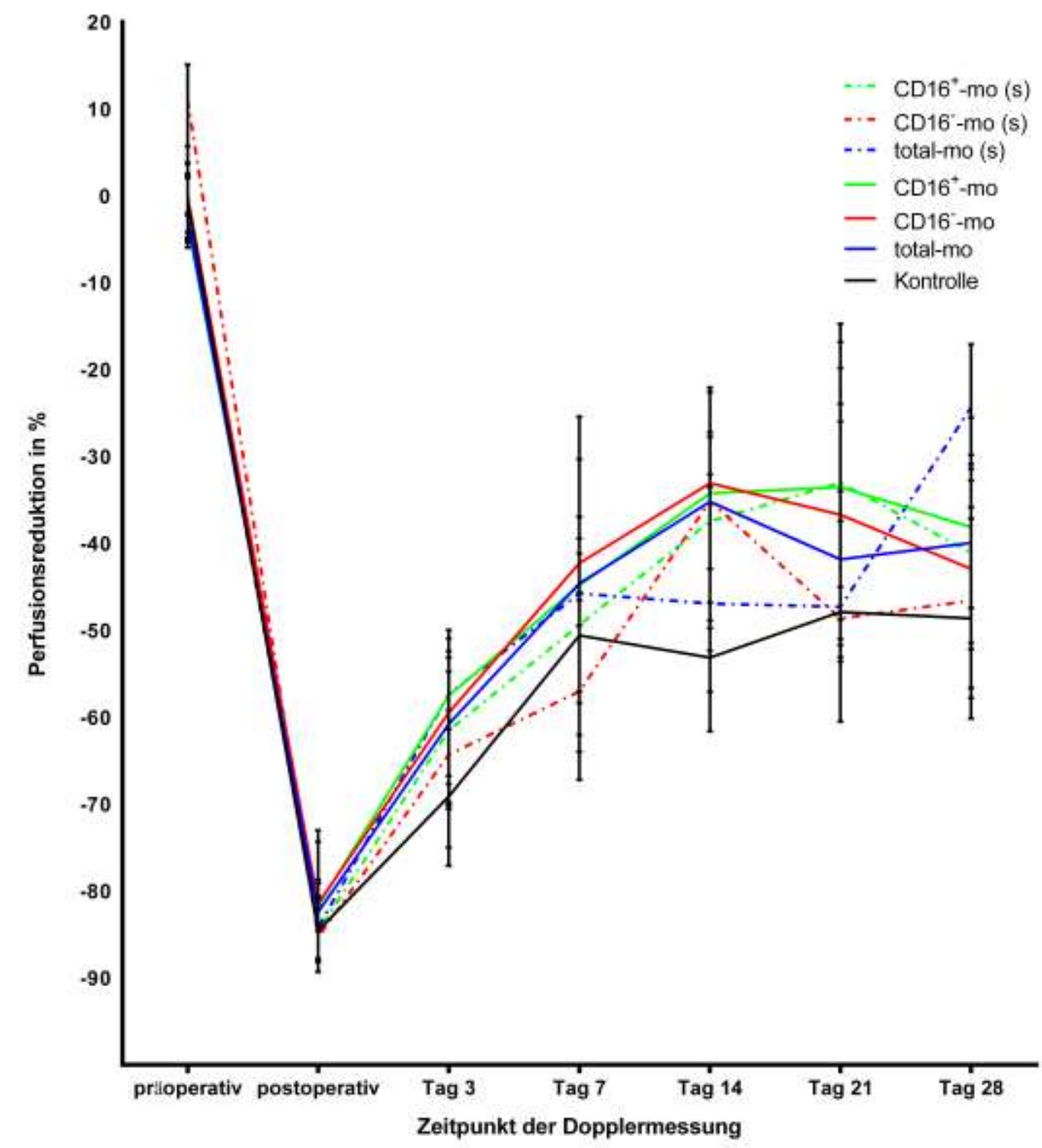

Abbildung 14: Zusammenfassende Darstellung der Laser-Doppler-Perfusionsmessung aller Interventionsgruppen

CD16-mo, CD16-negative Monozyten; CD16+-mo, CD16-positive Monozyten; total-mo, Gesamtmonozyten; CD16-mo (s), Leptin-stimulierte CD16-negative Monozyten; CD16+-mo (s), Leptin-stimulierte CD16-positive Monozyten; total-mo (s), Leptin-stimulierte Gesamtmonozyten 


\subsection{Immunfluoreszenzanalysen}

\subsubsection{Ergebnisse der Untersuchungen zur Angiogenese}

Die Angiogeneseuntersuchungen wurden an der Unterschenkelmuskulatur der Mäuse durchgeführt. Hier wurde einerseits die Kapillarzahl pro $\mathrm{mm}^{2}$ bestimmt und zusätzlich noch die durchschnittliche Anzahl der Kapillaren pro Muskelfaser. Auch bei diesen Analysen wurde zur Minimierung der Störung durch endogene Effekte die Ratio der operierten Seite zur sham-operierten gebildet.

\subsubsection{Untersuchung der Gesamtkapillarzahl nach Monozytengabe}

3.4.1.1.1 Die Gesamtkapillarzahl in Abhängigkeit von der Gabe unstimulierter Monozyten

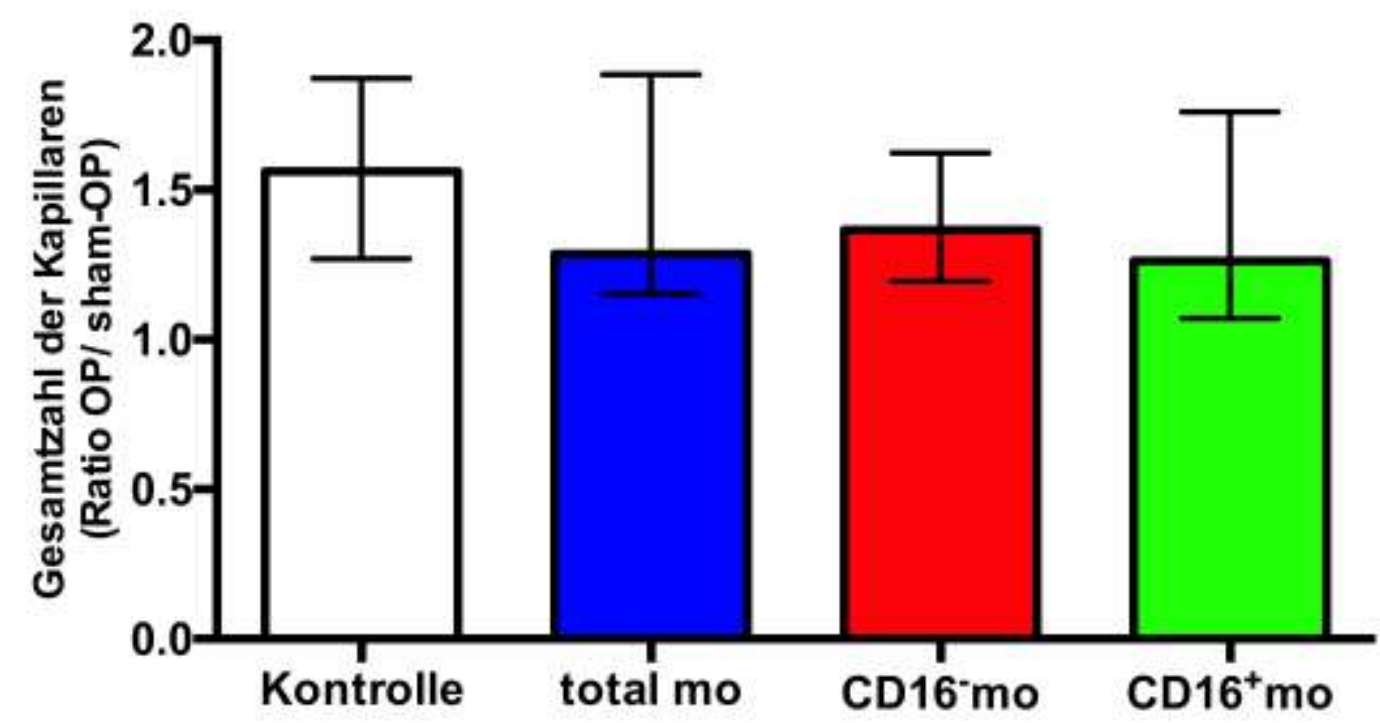

Abbildung 15: Darstellung der Verhältnisse der Gesamtkapillaren der Gruppen ohne Leptinstimulation

CD16-mo, CD16-negative Monozyten; CD16+-mo, CD16-positive Monozyten; total-mo, Gesamtmonozyten

Alle Interventionsgruppen, die mit unstimulierten Monozyten und -subpopulationen behandelt wurden, sowie auch die Kontrollgruppe hatten nach Auszählung der Gesamtkapillaren eine Ratio $>1$ (s. Abbildung 15). Somit war in dem jeweils operierten Hinterlauf durchschnittlich eine größere Anzahl an Kapillaren als im sham-operierten und somit auch eine größere Angiogeneseinduktion. Diese war mit einem Median = 1,56 (1,27; 1,87) in der Kontrollgruppe am größten. Die Ratios der Interventionsgruppen zeigten wenig Abweichungen voneinander (CD16-mo: 1,37 [1,20; 1,62]; total-mo: 1,29 [1,15; 1,89]; CD16 ${ }^{+}$-mo: $\left.1,26[1,07 ; 1,76]\right)$ und waren nach entsprechender statistischer Analyse 
untereinander sowie auch im Vergleich zur Kontrollgruppe nicht signifikant unterschiedlich.

3.4.1.1.2 Untersuchungen zur Kapillarzahl nach Gabe Leptin-stimulierter Monozyten

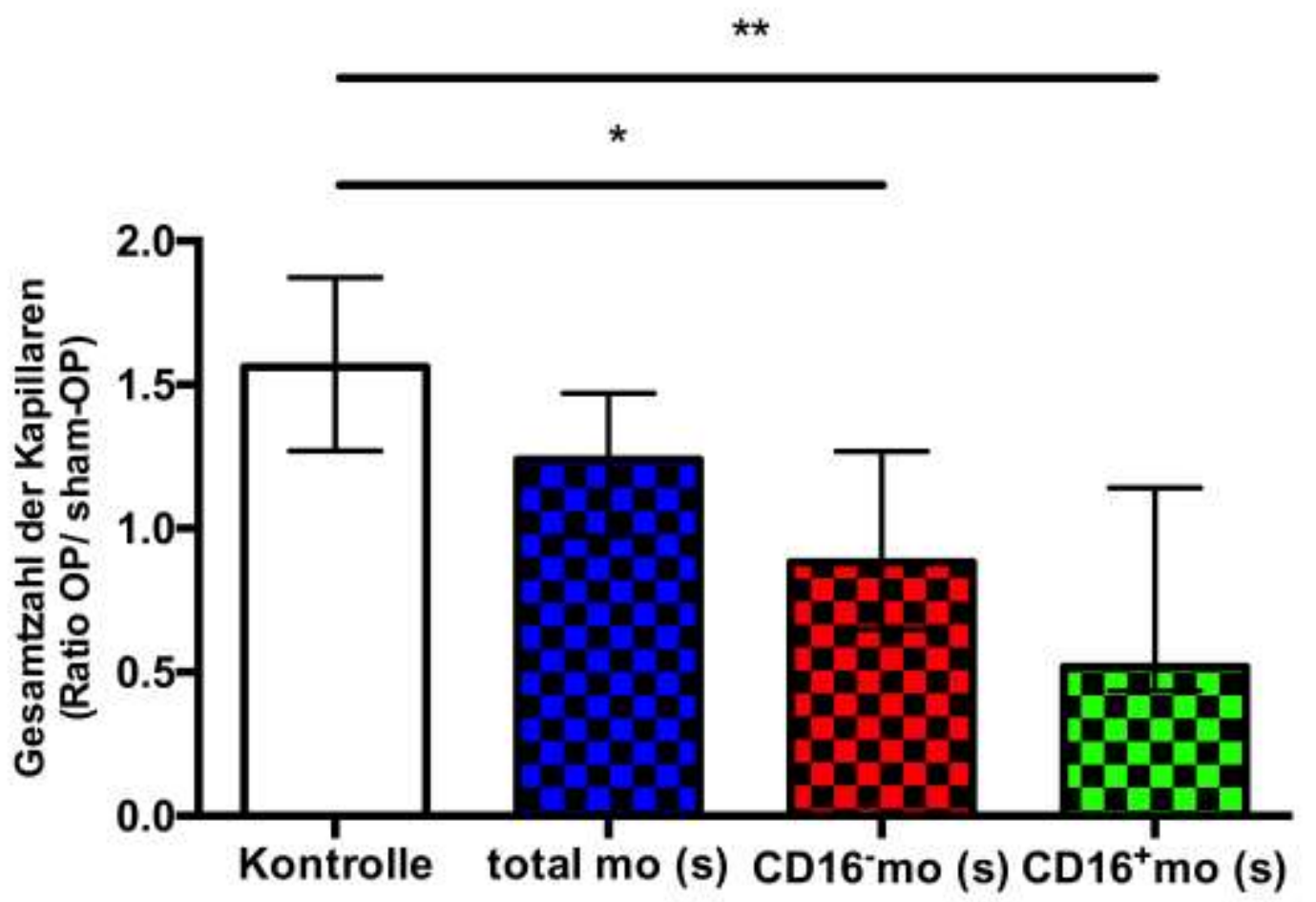
Abbildung 16: Darstellung der Verhältnisse der Gesamtkapillaren der Gruppen nach
Leptinstimulation

$\left(*=\mathrm{p}<0,05 ;{ }^{* *}=\mathrm{p}<0,01\right) ;$ CD16-mo (s), Leptin-stimulierte CD16-negative Monozyten; CD16 ${ }^{+}$-mo (s), Leptin-stimulierte CD16-positive Monozyten; total-mo (s), Leptin-stimulierte Gesamtmonozyten

Im Gegensatz zu den Interventionsgruppen unstimulierter Monozyten entwickelten die mit Leptin-stimulierten Monozyten therapierten Interventionsgruppen deutlich weniger Angiogenese im operierten Hinterlauf nach Induktion der Ischämie. Diese war mit einer Ratio $<1$ im operierten Bein teilweise sogar deutlich niedriger als im sham-operierten $\left(\mathrm{CD}_{16}{ }^{+}\right.$-mo [s]: Median $\left.=0,52[0,43 ; 1,14]\right)$. Die Anzahl der neu gebildeten Kapillaren in der CD16-mo (s)-Interventionsgruppe war nur leicht vermindert im Vergleich zur Gegenseite (Median = 0,88; $[0,65 ; 1,27])$. Nur die Gruppe der stimulierten total-mo wies bei einem Median von 1,24 $(0,97 ; 1,47)$ im operierten Hinterlauf mehr Kapillaren als im sham-operierten auf, was sich in den statistischen Untersuchungen nicht als signifikant unterschiedlich im Vergleich zur Kontrollgruppe herausstellte. Signifikante Unterschiede zeigten jedoch die Vergleiche der Gruppen der beiden stimulierten Subpopulationen im Vergleich zur Kontrollgruppe. Dies ist grafisch in Abbildung 16 veranschaulicht. 


\subsection{Unterschiede in Abhängigkeit der Leptin-Stimulation}

Wie o. g. zeigten die Gruppen der mit Leptin-stimulierten Monozyten eine deutlich geringere Kapillarisierung des operierten Hinterlaufes als die Interventionsgruppen der mit nicht-stimulierten Monozyten behandelten Tiere. Signifikante Unterschiede zwischen den Monozyten und ihren Untergruppen in Abhängigkeit von der Stimulation mit Leptin zeigten sich hier jedoch nicht.

3.4.1.2 Untersuchung der Vaskularisierung einzelner Myofibrillen

3.4.1.2.1 Kapillardichte nach Gabe unstimulierter Monozyten

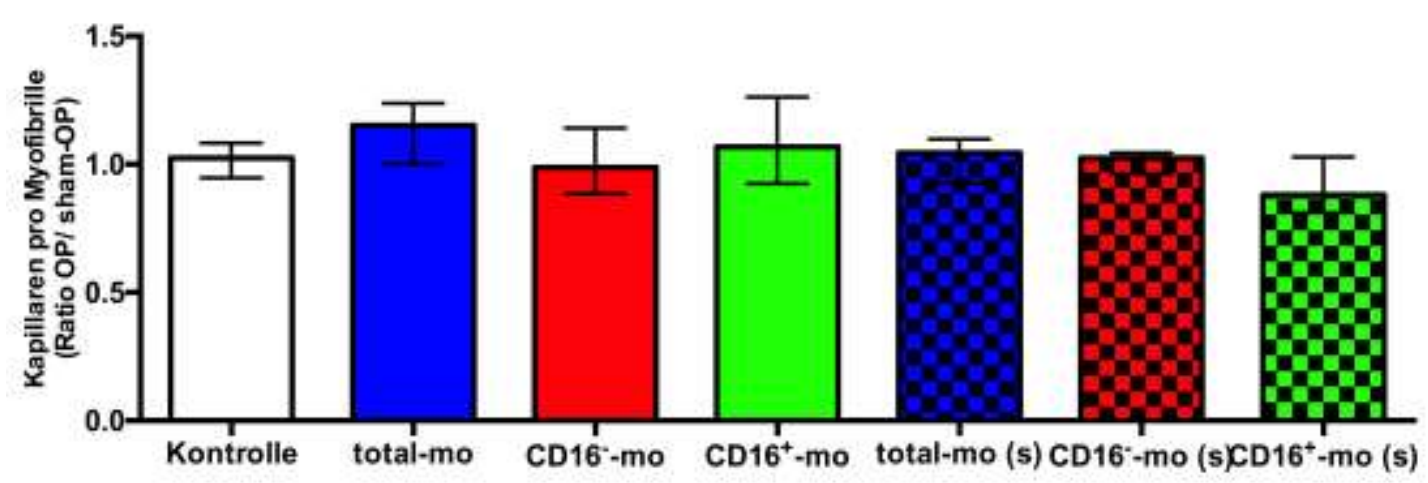

Abbildung 17: Gesamtübersicht der Verhältnisse der Vaskularisierung einzelner Myofibrillen aller Interventionsgruppen

CD16-mo, CD16-negative Monozyten; CD16+-mo, CD16-positive Monozyten; total-mo, Gesamtmonozyten; CD16-mo (s), Leptin-stimulierte CD16-negative Monozyten; CD16+-mo (s), Leptinstimulierte CD16-positive Monozyten; total-mo (s), Leptin-stimulierte Gesamtmonozyten

Bezüglich der Bestimmung der Kapillardichte bezogen auf eine Muskelfaser zeigte sich in allen Interventionsgruppen kein signifikanter Seitenunterschied. Eine grafische Übersicht zeigt Abbildung 17. 
3.4.1.3 Auswertungen der kapillären Durchschnittsfläche

\subsection{Auswirkung der Gabe unstimulierter Monozyten}

Die kapilläre Durchschnittsfläche in der Kontrollgruppe zeigte sich im Wesentlichen gleich für die operierte sowie auch die sham-operierte Seite (Median $=1 ;[0,86 ; 1,59])$. Die Tiere der nicht-stimulierten Interventionsgruppen, zeigten hier rein optisch eine leicht vergrößerte kapilläre Durchschnittsfläche der operierten Seite im Vergleich zur shamoperierten Seite (total-mo = 1,13 [0,78; 1,32]; CD16-mo = 1,16 [0,99; 1,62]; CD16 ${ }^{+}-\mathrm{mo}=$ $1,15[1,00 ; 1,33])$. Signifikante Unterschiede bestanden hier jedoch nicht (s. Abbildung 18).

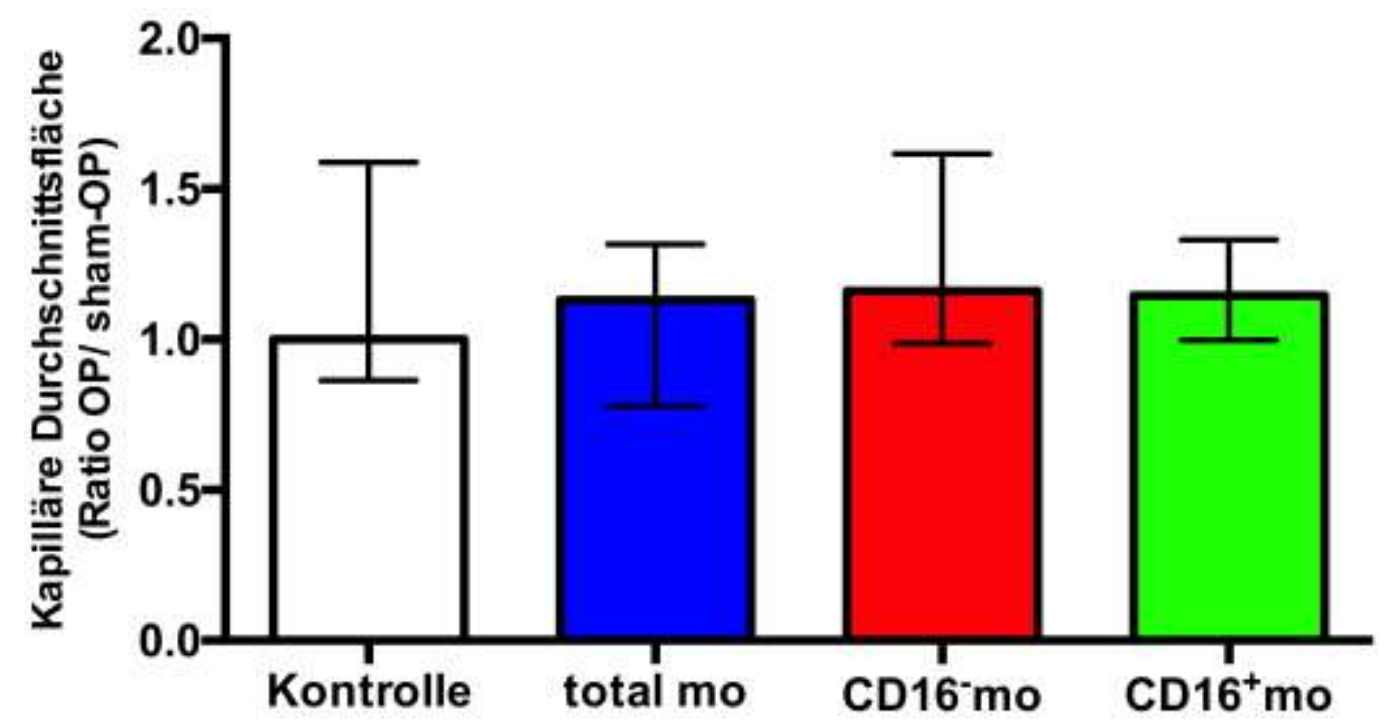

Abbildung 18: Darstellung der Verhältnisse der kapillären Durchschnittsfläche der Gruppen ohne Leptinstimulation

CD16-mo, CD16-negative Monozyten; CD16+-mo, CD16-positive Monozyten; total-mo, Gesamtmonozyten

\subsection{Kapilläre Durchschnittsfläche nach Gabe stimulierter Monozyten}

Im Vergleich zur Kontrollgruppe waren bei der total-mo (s)-Gruppe (Median = 1,18 [1,01; 1,33]), sowie auch in den stimulierten Monozytensubpopulationsgruppen (CD16-mo [s]; Median $=1,09 \quad[0,88 ; 1,39]$ und $\left.\mathrm{CD} 16^{+}-\mathrm{mo}[\mathrm{s}] ; 0,66 \quad[0,59 ; 0,79]\right)$ keine signifikanten Unterschiede zu verzeichnen. Die weitere Datenanalyse zeigte eine statistisch signifikante Verminderung ( $\mathrm{p}<0,05$; s. Abbildung 19) der kapillären Querschnittsfläche der operierten Seite nach Gabe von $\mathrm{CD}_{16}{ }^{+}$-mo (s) verglichen mit der kapillären Querschnittsfläche nach Gabe der total-mo (s). 


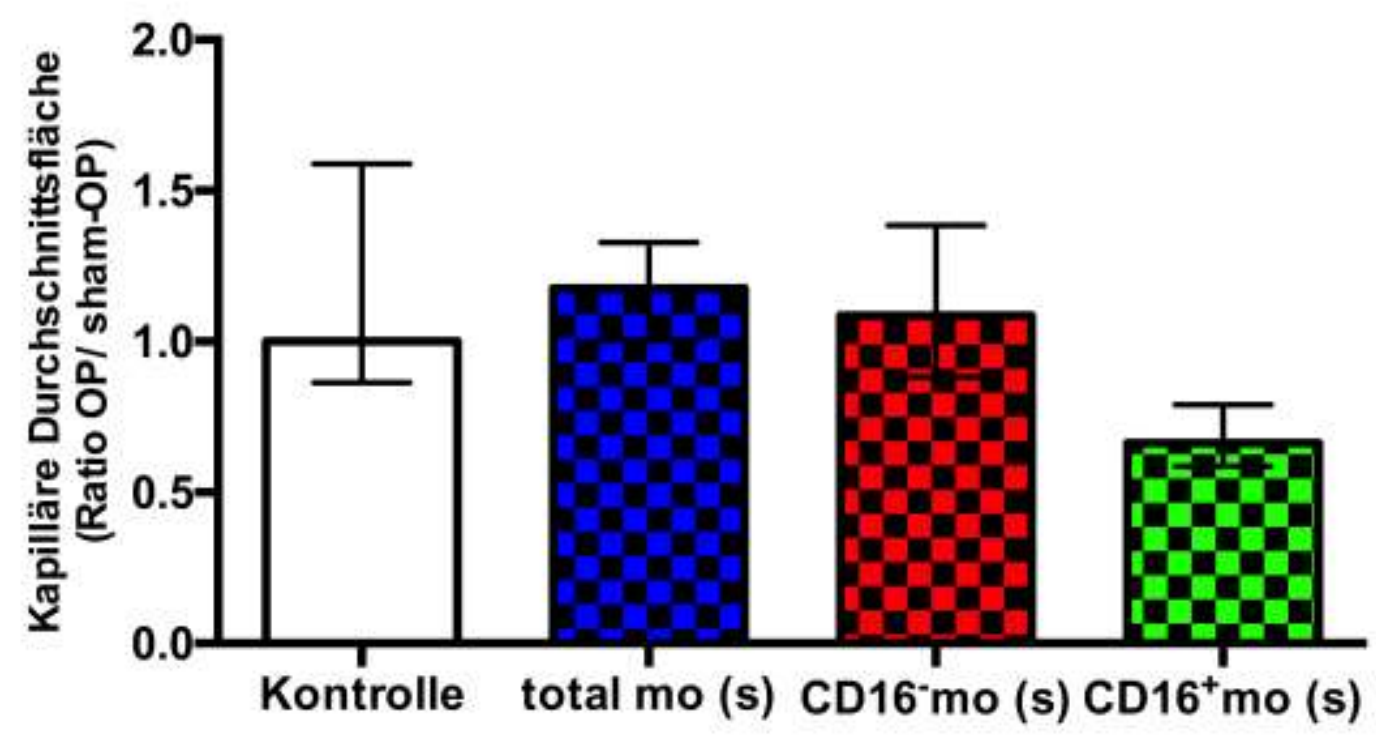

Abbildung 19: Darstellung der Verhältnisse der kapillären Durchschnittsfläche der Gruppen mit Leptinstimulation

$\left(^{*}=\mathrm{p}<0,05\right)$; CD16-mo (s), Leptin-stimulierte CD16-negative Monozyten; CD16 ${ }^{+}$-mo (s), Leptin-stimulierte CD16-positive Monozyten; total-mo (s), Leptin-stimulierte Gesamtmonozyten

\subsubsection{Untersuchungen zur Arteriogenese}

Auch in den Untersuchungen zur Arteriogenese wurden drei verschiedene Parameter in die Analyse einbezogen. Hierbei wurde zunächst die Gesamtzahl der Arteriolen pro Bildausschnitt untersucht und zusätzlich die Gesamtfläche der glatten Gefäßmuskulatur (SMA) bestimmt. Um die durchschnittliche Fläche pro Arteriolen zu ermitteln, wurde nun noch die Gesamtfläche des Bildausschnitts durch die Anzahl der Arteriolen im Bildausschnitt dividiert. Um auch hier endogene Effekte zu minimieren, wurde auch bei diesen Untersuchungen jeweils das Verhältnis (Ratio) zwischen operierter und shamoperierter Seite gebildet. 
3.4.2.1 Veränderungen der Gesamtzahl der Arteriolen

3.4.2.1.1 Die Arteriolenzahl nach Gabe unstimulierter Monozyten

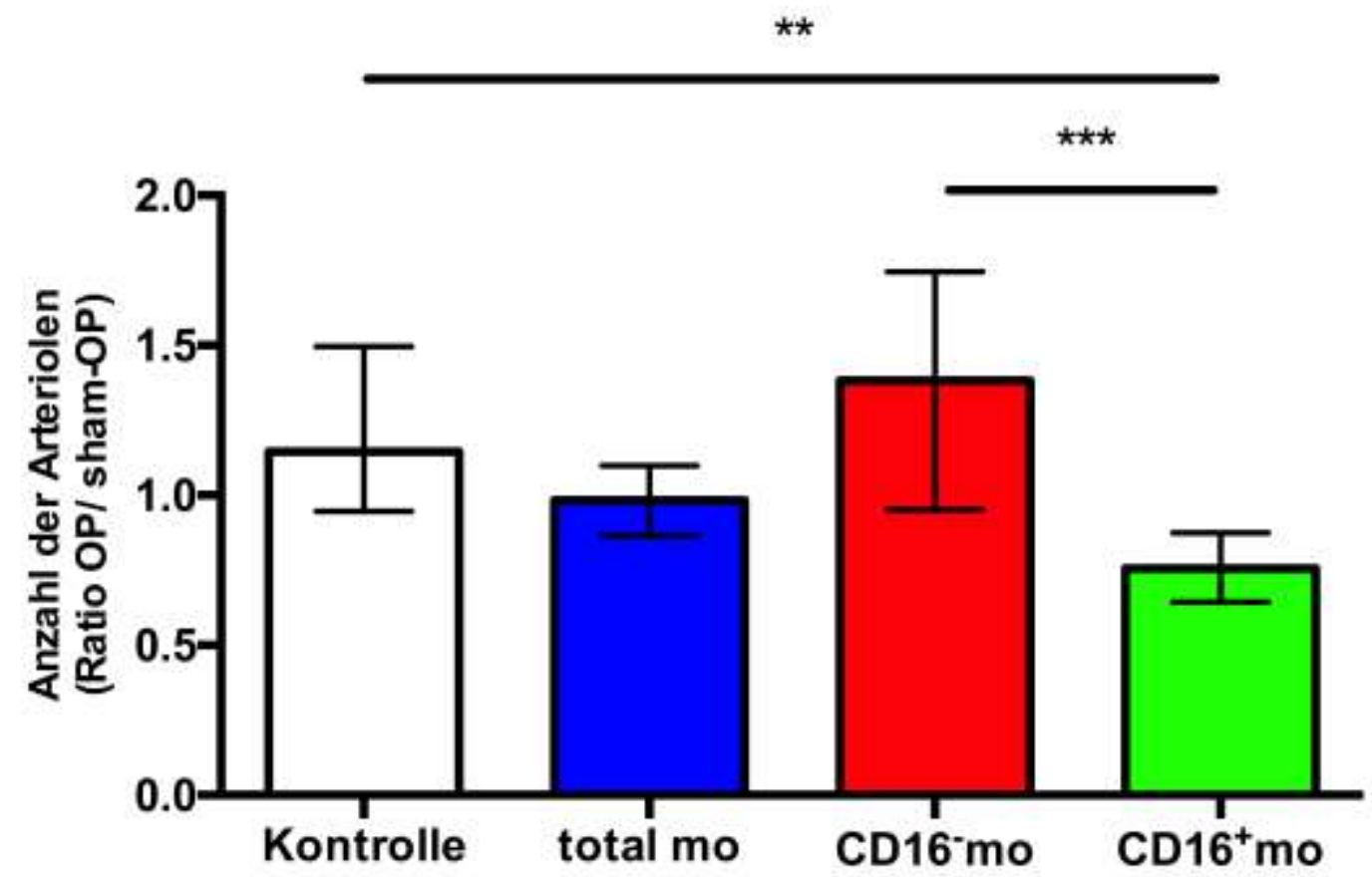

Abbildung 20: Darstellung der Verhältnisse der Arteriolenzahl der Gruppen nach Gabe unstimulierter Monozyten

(** $\left.^{*} \mathrm{p}<0,01 ; * * *=\mathrm{p}<0,001\right) ;$ CD16-mo, CD16-negative Monozyten; CD16+-mo, CD16-positive Monozyten; total-mo, Gesamtmonozyten

Die Ratio der Gesamtzahl der Arteriolen der total-mo war mit einem Median von 0,98 $(0,87 ; 1,10)$ im operierten Hinterlauf in etwa gleich zum sham-operierten Hinterlauf. Im Gegensatz hierzu war in der Gruppe mit CD16-mo (Median $=1,38 \quad[0,95 ; 1,75]$ ) behandelter Tiere die Anzahl der Arteriolen auf der operieren Seite deutlich erhöht, jedoch statistisch nicht signifikant unterschiedlich zur total-mo-Fraktion. Relevante und somit signifikante Unterschiede ergaben sich hier nur im Vergleich zur Gruppe der CD16 ${ }^{+}$-mo (p $<0,001)$, die mit einer Ratio von $0,76(0,64 ; 0,87)$ im Median auf der operierten Seite deutlich weniger Arteriolen zeigten als auf der sham-operierten Seite. Entsprechend war hier ebenfalls ein signifikanter Unterschied zur Kontrollgruppe $(p<0,01)$ darzustellen, welche mit einem Median von 1,15 (0,95; 1,50), ähnlich der CD16-mo-Gruppe, im operierten Hinterlauf eine höhere Arteriolenzahl zeigt als im sham-operierten (s. Abbildung 20). 
3.4.2.1.2 Anzahl der Arteriolen in Abhängigkeit der Gabe Leptin-stimulierter Monozyten

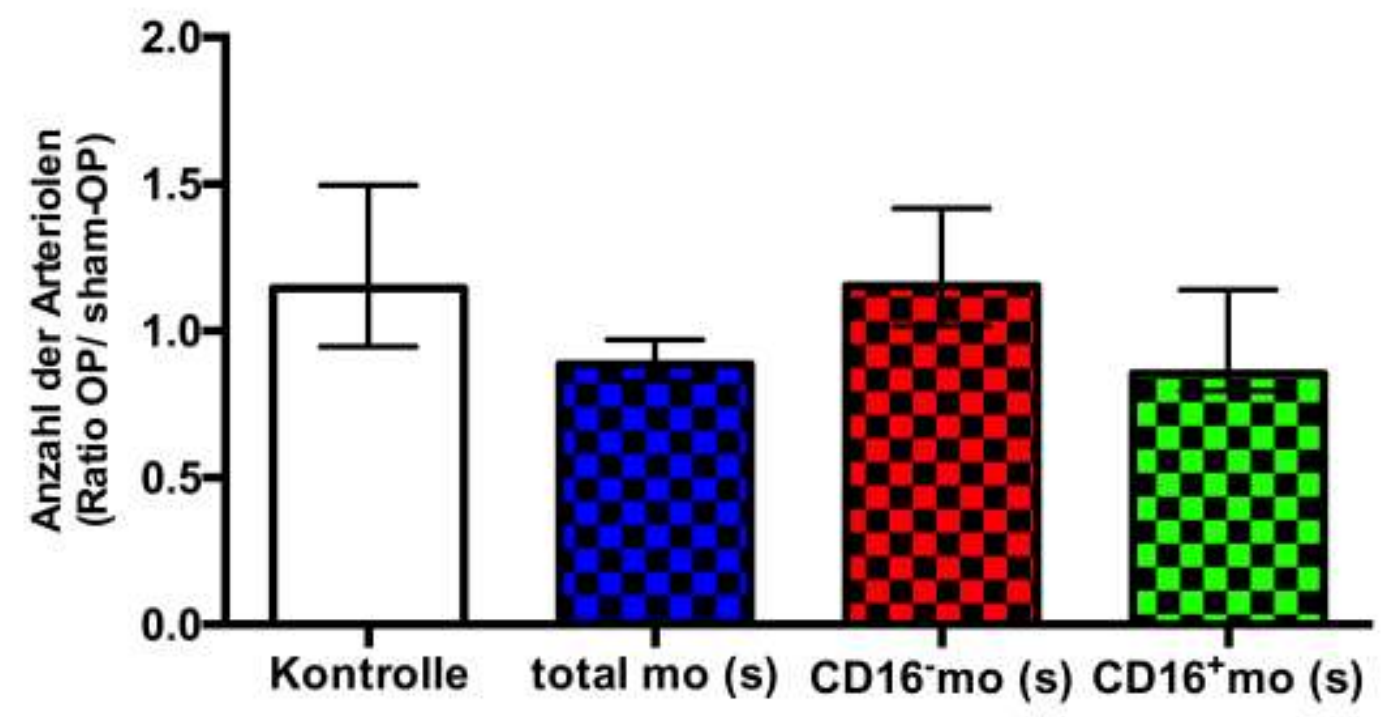

Abbildung 21: Darstellung der Verhältnisse der Arteriolenzahl der Gruppen nach Gabe Leptin-stimulierter Monozyten

CD16-mo (s), Leptin-stimulierte CD16-negative Monozyten; CD16+-mo (s), Leptin-stimulierte CD16positive Monozyten; total-mo (s), Leptin-stimulierte Gesamtmonozyten

Nach Gabe Leptin-stimulierter Monozyten und ihrer Subpopulationen war das Verhältnis zwischen Anzahl der Arteriolen im operierten Hinterlauf verglichen mit dem shamoperierten Hinterlauf nicht signifikant unterschiedlich (s. Abbildung 21).

\subsection{Leptin-abhängige Unterschiede}

Statistisch signifikante Unterschiede zwischen den Monozyten und ihren Untergruppen in Abhängigkeit von der Leptin-Stimulation zeigten sich bei der Untersuchung der Arteriolenanzahl nicht. 
3.4.2.2 Bestimmung der Gesamtquerschnittsfläche der glatten Gefäßmuskulatur

3.4.2.2.1 Die Fläche der Gefäßmuskulatur nach Gabe unstimulierter Monozyten

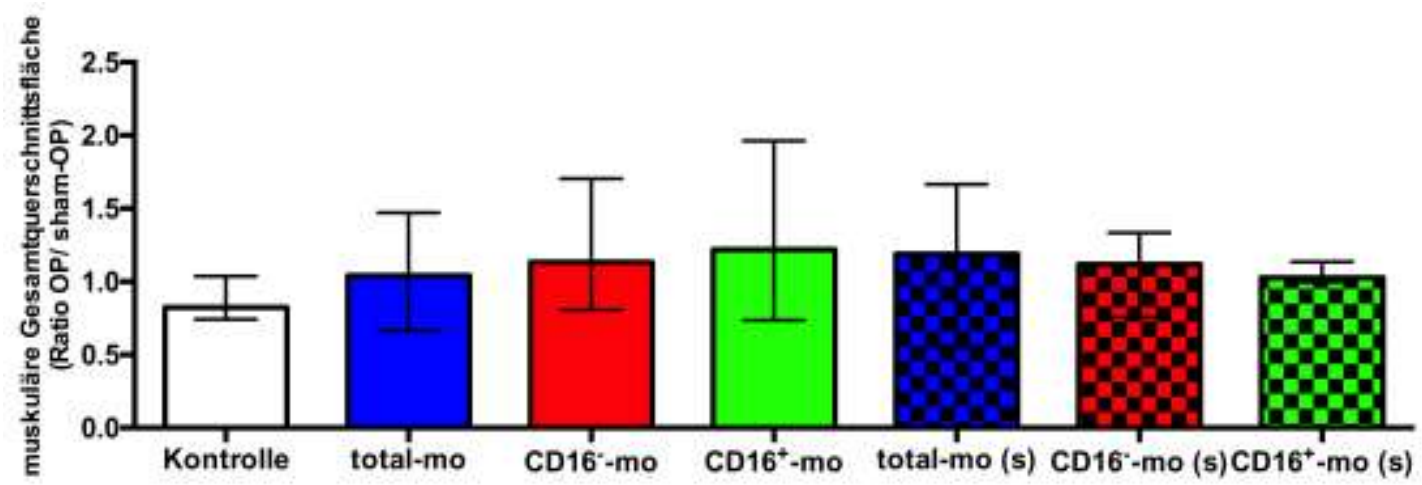

Abbildung 22: Gesamtübersicht der Verhältnisse der muskulären Gesamtquerschnittsfläche aller Interventionsgruppen

CD16-mo, CD16-negative Monozyten; CD16+-mo, CD16-positive Monozyten; total-mo, Gesamtmonozyten; CD16-mo (s), Leptin-stimulierte CD16-negative Monozyten; CD16+-mo (s), Leptinstimulierte CD16-positive Monozyten; total-mo (s), Leptin-stimulierte Gesamtmonozyten

Die Untersuchung der Fläche der glatten Gefäßmuskulatur zeigte im Wesentlichen nur in der Kontrollgruppe eine im operierten Hinterlauf verminderte Fläche im Vergleich zur sham-operierten Seite (Median $=0,82[0,74 ; 1,08]$ ). Alle anderen Interventionsgruppen zeigten entweder ein ausgeglichenes Verhältnis (total-mo, CD16 ${ }^{+}$-mo [s]) oder hatten im operierten Hinterlauf eine höhere Querschnittsfläche aufzuzeigen, als auf der Gegenseite (CD16-mo, total-mo [s], CD16-mo [s]), dies teilweise bis zu mehr als 20\% (CD16 ${ }^{+}$-mo; Median $=1,22[0,74 ; 2,00])$. Allerdings war eine statisch signifikante Differenz hier nicht zu messen (s. Abbildung 22).

\subsubsection{Ergebnisse der Querschnittsfläche der glatten Gefäßmuskulatur pro Arteriole}

3.4.2.3.1 Der Gefäßmuskulaturquerschnitt pro Arteriole nach Gabe unstimulierter Monozyten

Die histologische Untersuchung der Muskeln der Hinterläufe zeigte nach Gabe von CD16+-mo im operierten Hinterlauf eine im Median um 75\% erhöhte muskuläre Querschnittfläche pro Arteriole im Vergleich zum sham-operierten Hinterlauf (Ratio 1,75 $[1,03 ; 2,30])$. Dies war im Vergleich zur Kontrollgruppe (Median $=0,76[0,61 ; 0,90]$ ) statistisch signifikant unterschiedlich $(\mathrm{p}<0,05)$. Die Interventionsgruppen der Tiere mit total-mo sowie der CD16-mo wiesen keine statistisch signifikanten Ergebnisse auf (s. Abbildung 23). 


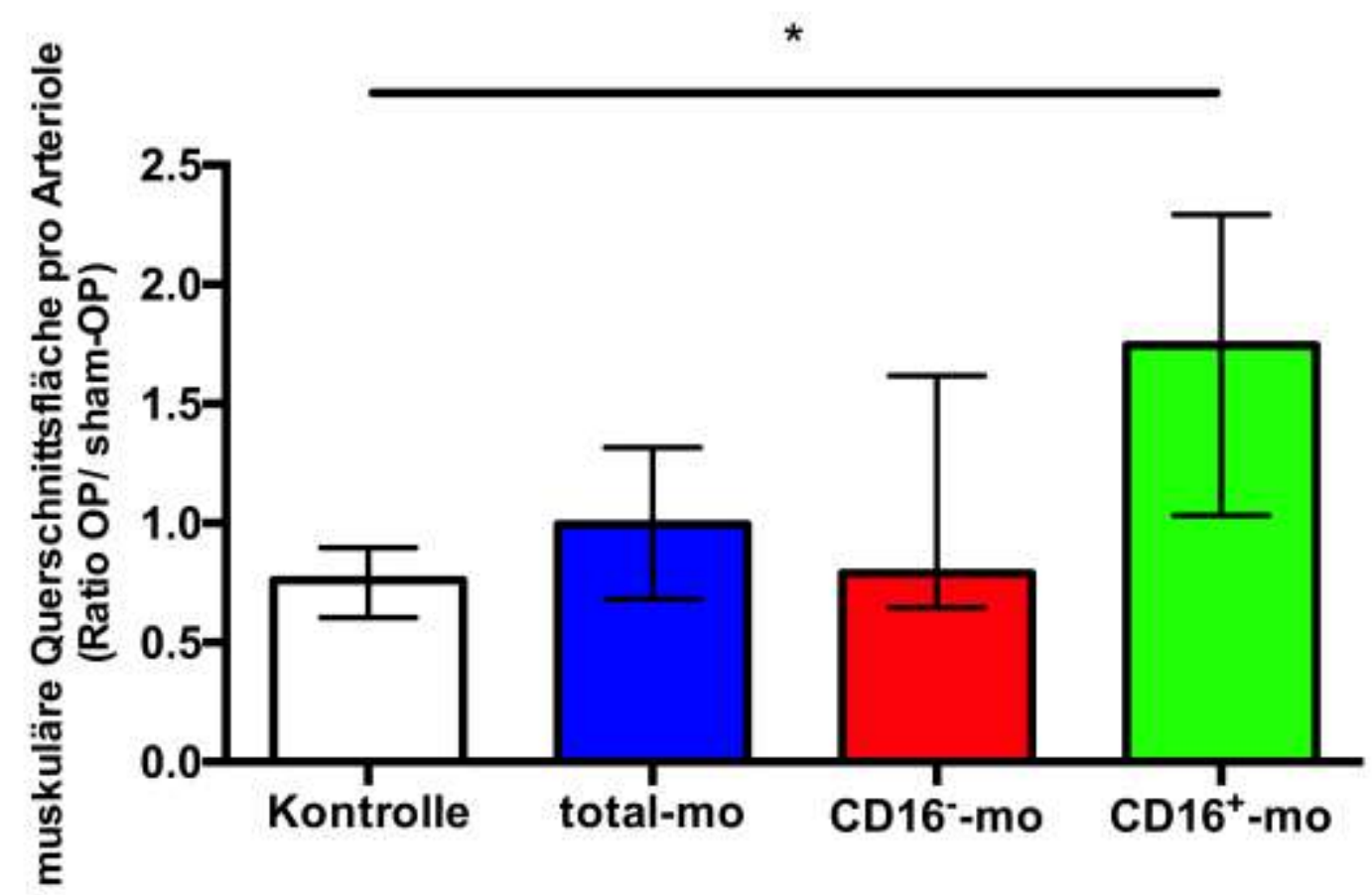

Abbildung 23: Darstellung der Verhältnisse der muskulären Querschnittsfläche pro Arteriole der Gruppen nach Gabe unstimulierter Monozyten

$\left(^{*}=\mathrm{p}<0,05\right)$; CD16--mo, CD16-negative Monozyten; CD16+-mo, CD16-positive Monozyten; total-mo, Gesamtmonozyten

3.4.2.3.2 Der Gefäßmuskulaturquerschnitt pro Arteriole in Abhängigkeit von mit Leptinstimulierten Monozyten

Die größte Zunahme im Querschnitt der Gefäßmuskulatur auf der operierten Seite ließ sich in der Gruppe der stimulierten total-mo (Median = 1,41 [0,69; 1,79]) darstellen. Eine eher nur leicht erhöhte muskuläre Querschnittsfläche pro Arteriole (Median = 1,16 [0,90; 1,23]) war in der Gruppe der $\mathrm{CD}_{16}{ }^{+}$-mo (s) zu registrieren, wohingegen die Gruppe der CD16-mo (s) einen minimal verminderten muskulären Querschnitt im Vergleich zur shamoperierten Seite (Median $=0,93[0,63 ; 1,24]$ ) zeigte (s. Abbildung 24). Signifikante Unterschiede waren hier in der statistischen Untersuchung nicht festzustellen. 


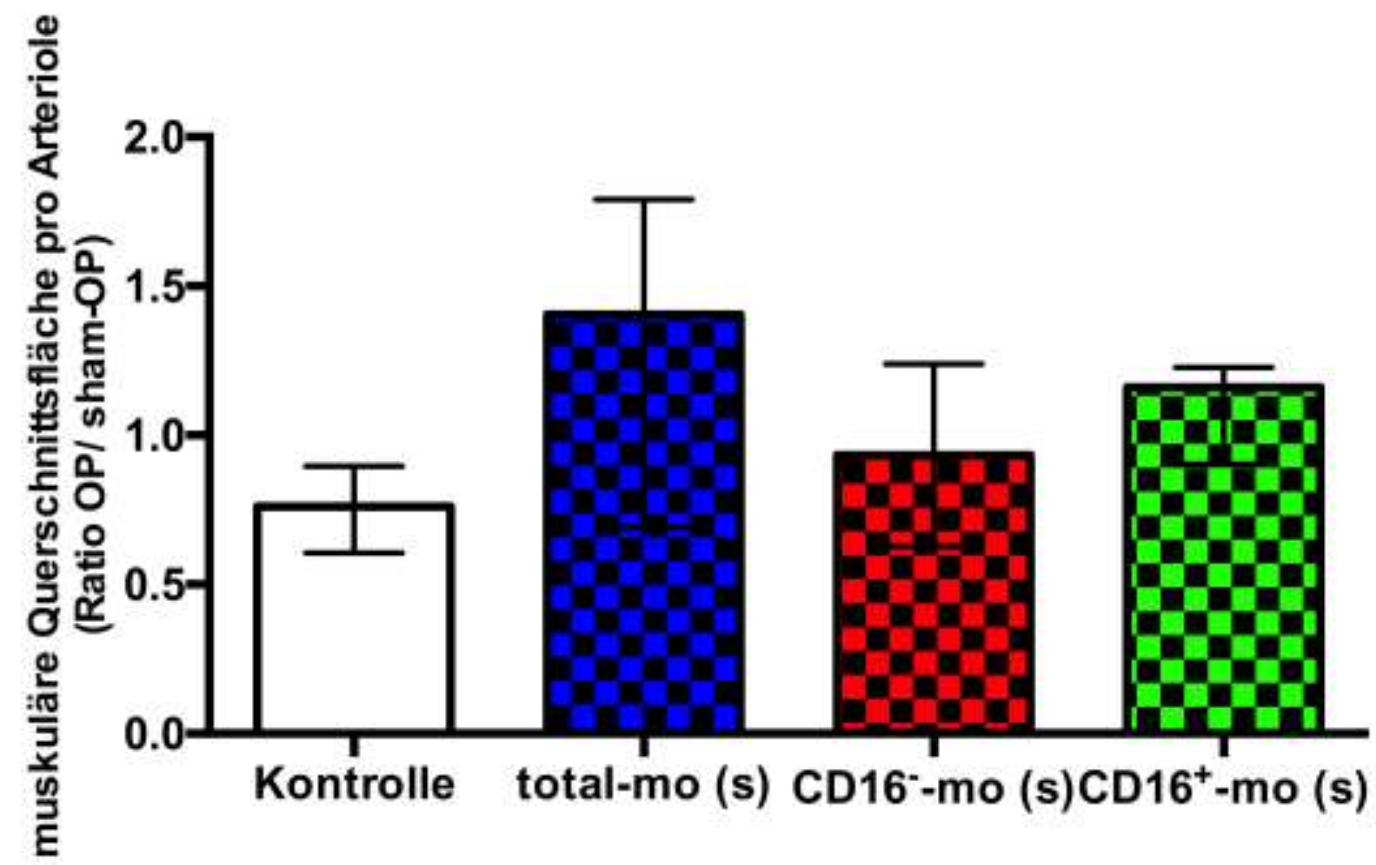

Abbildung 24: Darstellung der Verhältnisse der muskulären Querschnittsfläche pro Arteriole der Gruppen nach Gabe Leptin-stimulierter Monozyten

CD16-mo (s), Leptin-stimulierte CD16-negative Monozyten; CD16+-mo (s), Leptin-stimulierte CD16positive Monozyten; total-mo (s), Leptin-stimulierte Gesamtmonozyten

3.4.2.3.3 Unterschiede zwischen den Populationen in Abhängigkeit von der LeptinStimulation

Die Leptin-Stimulation führte statistisch $\mathrm{zu}$ keinen Unterschieden zwischen den Interventionsgruppen der jeweiligen Subpopulationen und der total-mo-Population. 


\section{Diskussion}

In der vorliegenden Arbeit wurde der Zusammenhang der Blutgefäßbildung unter ischämischen Bedingungen in Abhängigkeit von humanen Monozyten und ihren Subpopulationen in einem Mausmodell untersucht. Hierbei wurde zunächst in einer Doppleruntersuchung gezeigt, dass sich die Durchblutung über einen Zeitraum von 28 Tagen nach Zugabe von total-mo und ihren Untergruppen zunächst leicht, jedoch nicht signifikant verbessert. Nachfolgend wurden diese Tiere getötet und die entsprechenden Muskelgruppen für angiogenese- und arteriogenesetypische Areale nach drei unterschiedlichen histologischen Gesichtspunkten untersucht. Die Gabe von Monozyten und ihren Subpopulationen hatte keinen positiven Effekt auf die Angiogenese.

Statistisch signifikante Unterschiede in der Arteriogenese waren nach Gabe nichtstimulierter Monozytensubpopulationen nachweisbar. Entsprechend war hier das Verhältnis der muskulären Querschnittsfläche nach Gabe von CD16 ${ }^{+}$-mo signifikant erhöht im Vergleich zur Kontrollgruppe. Eine Leptinstimulation der Monozyten und ihrer Untergruppen hatte keinen positiven Effekt auf die Angiogeneseuntersuchungen.

\subsection{Monozyten und ihre Bedeutung in der Gefäßneubildung}

Erste Untersuchungen zu Neovaskularisation und Reperfusion nach Ischämie haben u. a. Cochain et al. durchgeführt und konnten beispielsweise zeigen, dass es im murinen Hinterlaufischämiemodell nach Substitution von Ly6C ${ }^{\text {high }}$-Monozyten zu einem signifikant verbesserten Blutfluss kommt (Cochain et al. 2010). Das ischämische Gewebe zeigte hierbei in den ersten Tagen nach Ligatur der $A$. fem. deutlich erhöhte messengerRibonucleinsäurespiegel (mRNA) von Chemokinen, die sowohl die klassischen Ly6C $\mathrm{C}^{\text {high }}$ - als auch die Ly6C ${ }^{\text {low }}$-Monozyten rekrutieren. Dies war jedoch auf Proteinebene initial (1.-3. Tag) nur für Chemokine-(C-C motif)-Ligand 2 (CCL2) erhöht. Diesem kommt als MCP-1 eine bedeutende Rolle in der Monozytenrekrutierung aus dem Knochenmark sowie bei der Monozyteneinwanderung in ischämisches Gewebe zu, da die Migration durch CCL2 stimuliert wird (Rhodes et al. 1997).

Ähnliche Berichte über eine verbesserte Reperfusion im Hinterlaufischämiemodell nach intravenöser Gabe zusätzlicher Mausmonozyten beschreiben auch Capoccia et al. bereits 2008 (Capoccia et al. 2008). Sie stellten fest, dass bei Applikation 24 h nach Ischämie die absolute Zahl eingewanderter Monozyten (also endogener und auch applizierter Monozyten) in das ischämische Gewebe bis zu 5-fach erhöht ist, obwohl die absolute Menge sich im Blut befindlicher Monozyten lediglich um ca. 10\% gesteigert wird. Des Weiteren zeigten sie, dass die Menge der endogenen Monozyten im ischämischen Gewebe hundertfach höher war im Vergleich zu den extern zugeführten. Zusätzlich war auch die Reperfusion nach Hinterlaufischämie in diesen Tieren signifikant verbessert. Die daraufhin 
gemessenen MCP-1-Konzentrationen in den ischämischen Hinterläufen der Tiere, welche mit exogenen Monozyten behandelt wurden, war hier ebenfalls signifikant erhöht, sodass geschlussfolgert wurde, dass es nach Gabe exogener Monozyten nach akuter Ischämie zu einer zügigen Einwanderung dieser Monozyten in ischämisches Gebiet kommt und diese durch Sekretion von MCP-1 die Migration endogener, inflammatorischer Monozyten begünstigt. Die direkte Einwanderung von Monozyten in den ischämischen Hinterlauf wurde in der vorliegenden Arbeit nicht untersucht. Es muss jedoch davon ausgegangen werden, dass die eigene Immunantwort der verwendeten Mäuse (nu/nu) nicht mit der in Capoccias Untersuchungen verwendeten Tiere (C57 Black 6 [C57Bl6]) verglichen werden kann, denn dort wurden zum einen vollständig immunkompetente Tiere und zum anderen keine Monozyten unterschiedlicher Spezies verwendet. Dieser Punkt könnte hier als Erklärung für die fast fehlenden positiven Effekte nach Applikation humaner Monozyten herangezogen werden.

\subsection{Die Bedeutung der Gabe humaner Monozyten in der Reperfusion}

Wie anhand der Reperfusionsdaten (Kap. 3.3) gezeigt wurde, konnte durch die Gabe von Monozyten keine signifikante Verbesserung der Reperfusion erreicht werden. Auffällig war jedoch, dass alle Interventionsgruppen eine leichte, nicht-signifikante Perfusionsverbesserung gegenüber der Kontrollgruppe aufwiesen. Dies lässt sich möglicherweise mit einer Erweiterung der zuvor gefassten Monozytenklassifikation erklären, denn die von Passlick et al. beschriebenen CD16 ${ }^{+}$- und CD16-Subpopulationen (Passlick et al. 1989) wurden von Frederic Geissmann nach näherer Klassifikation der murinen Monozytenäquivalente (Geissmann et al. 2003) ebenfalls funktionell besser beschrieben (Geissmann et al. 2010). Entsprechend wurde auf Basis dieser Erkenntnisse eine neue Nomenklatur erarbeitet. Diese berücksichtigte u. a. verschiedenste Arbeiten über die Expression von Oberflächenmolekülen (Grage-Griebenow et al. 2001b) oder die Produktion von Zytokinen (Zawada et al. 2011) der Monozyten, sodass hieraus eine dritte Monozytensubpopulation $\left(\mathrm{CD} 14^{++} \mathrm{CD} 16^{+}\right)$resultierte. Diese sogenannten intermediären Monozyten zeigten in diversen Arbeiten das höchste angiogene Potenzial (Zawada et al. 2011). Entsprechend konnte z. B. eine 1,5-fach erhöhte Expression des für TNF- $\alpha$-induced protein 2 (TNFAIP2)-codierenden Gens dargestellt werden, welche wiederum in Untersuchungen an Tumormaterial von nasopharyngealen Karzinomen mit der Überexpression des entsprechenden Proteins und somit in Zusammenhang vermehrter Angiogenese steht (Chen et al. 2011). Zusätzlich wurde diese Subpopulation bereits 2005 als Tie2-expressing monocytes (TEMs) beschrieben (De Palma et al. 2005) und 2007 gezeigt, dass sie in maligne entartetem Gewebe in signifikant erhöhter Zahl vorkommen (Venneri et al. 2007). In weiterführenden Untersuchungen zeigten sich TEMs jeweils in unmittelbarer Umgebung stark vaskularisierter Tumorareale, sowie auch in nicht-malignen Hypervaskularisierungszonen, sodass diesbezüglich von einem Recruitment von TEMs in 
Areale ausgegangen werden sollte, welche erhöhten Bedarf an Gefäßen haben und diese dort am ehesten parakrin die Angiogenese beeinflussen (Favre et al. 2013). Stimulus für die Monozyteneinwanderung war hier Ang2 (Barton et al. 2005; Felcht et al. 2012; Thurston 2003).

Nach Zusammentragen dieser Erkenntnisse zeigt nunmehr die als klassische Monozyten bezeichnete Subpopulation eine hohe Expression von CD14, jedoch keine CD16Expression $\left(\mathrm{CD} 14^{++} \mathrm{CD} 16\right)$. Intermediäre Monozyten exprimieren CD14 ebenfalls in hoher Dichte und zeigen eine schwache CD16-Expression $\left(\mathrm{CD} 14^{++} \mathrm{CD} 16^{+}\right)$. Die nicht klassischen Monozyten verhalten sich in der CD14-Expression schwächer als die anderen beiden Subpopulationen, haben jedoch eine deutlich höhere Expression von CD16 $\left(C_{14}^{+}\right.$CD16 $^{++}$(Ziegler-Heitbrock et al. 2010; Ziegler-Heitbrock und Hofer 2013). Aus technischen Gründen konnte jedoch in der vorliegenden Arbeit innerhalb der CD16Positivität nicht differenziert werden, sodass durch die durchgeführte Monozytenisolation die Gruppe der intermediären Monozyten nicht separat erfasst werden konnte. Hierdurch könnten die o. g. proangiogenen Effekte dieser Subpopulation mehr oder minder in jeder Interventionsgruppe vertreten sein und somit durch die entsprechend geringe Gesamtmenge an Zellen nivelliert werden. Die einzelnen Auswirkungen auf die Angio- und Arteriogenese werden in den folgenden Kapiteln separat diskutiert.

\subsection{Die Rolle von humanen Monozyten in der Arteriogenese}

Die Analyse der in dieser Arbeit erhobenen histologischen Ergebnisse zeigt zunächst, dass die Gabe nicht stimulierter Monozyten einen Einfluss auf die Gesamtarteriolenzahl sowie auch teilweise auf die Stärke der Arteriolenwand im ischämischen Hinterlauf besitzt. Interessanterweise sind hier nur Unterschiede bei den Monozytensubpopulationen darzustellen, wobei die $\mathrm{CD}^{-} 6^{-}$-mo die Arteriolenanzahl im ischämischen Hinterlauf steigerten und die $\mathrm{CD} 16^{+}$-mo diese verminderte (s. Kap. 3.4.2.1.1). Im Gegensatz zur signifikanten Verminderung der absoluten Arteriolenanzahl zeigte sich die durchschnittliche Dicke der Arteriolenwand nach Gabe von CD16 ${ }^{+}$-mo deutlich erhöht im Vergleich zur Kontroll- und den anderen Interventionsgruppen. Dies erklärt sich möglicherweise durch die nähere funktionelle Betrachtung der Subpopulationen auf Rezeptor-/Zytokinebene, denn hier wurde bereits 2011 bei CD16 ${ }^{+}$-mo ein schlechteres Migrationspotenzial gegenüber VEGF im Vergleich zu CD16-mo nachgewiesen (Czepluch et al. 2011). Dies ist am ehesten bedingt durch die niedrigere Expression von VEGFR-1 in CD16 ${ }^{+}$-mo gegenüber CD16-mo (Czepluch et al. 2011; Czepluch und Waltenberger 2006). Eine zusätzliche Rolle spielt hier jedoch möglicherweise auch das unterschiedliche CD31Expressionmuster der Monozytensubpopulationen. Dieses Platelet-endothelial-cell-adhesionmolecule-1 (PECAM-1/CD31) spielt eine wichtige Rolle in der Leukozytendiapedese und ist unabkömmlich für eine transendotheliale Migration von Monozyten (Muller et al. 1993). Besonders CD16 ${ }^{+}$-mo exprimieren CD31 sehr stark auf ihrer Zelloberfläche und haben 
somit die Möglichkeit, das Endothel zu durchwandern (Ancuta et al. 2009). Die nun im Vergleich zu CD16-mo deutlich verringerte Expression von VEGFR-1 erschwert die folgende Migration der $\mathrm{CD} 16^{+}$-mo durch die Muscularis in das umliegende Gewebe. Somit beschränkt sich die Wirkung der durch die $\mathrm{CD}_{16}{ }^{+}$-mo ausgeschütteten Zytokine eher auf die Arteriolenwand, sodass die eigentlichen extravaskulären Prozesse (TNF- $\alpha$-, IL-1 $\beta$ Ausschüttung) nun intramural stattfinden und die entsprechende Hypertrophie dieser vielleicht am ehesten als funktionelle Reaktion auf die vermehrte intramuskuläre Zytokinausschüttung gesehen werden kann.

Interessanterweise sind die o. g. Effekte lediglich in den Versuchsgruppen der Subpopulationen zu verzeichnen und nicht nach Gabe der total-mo nachzuweisen. Obwohl in dieser Population die CD16-mo überwiegen, sind auch hier keine Tendenzen der Effekte in Richtung dieser Untersuchungsgruppe nachweisbar, sodass unter Umständen davon ausgegangen werden könnte, dass diese jeweiligen Effekte der CD16 ${ }^{+}$-mo und CD16-mo sich gegenseitig aufheben. Der Anteil der $\mathrm{CD} 16^{+}$-mo an der total-mo-Fraktion beträgt ca. $10 \%$ und ist somit in absoluten Zahlen (30.000 Zellen) deutlich geringer als in der CD16 ${ }^{+}$ mo-Fraktion (300.000 Zellen). Entsprechend besteht hier die Möglichkeit, dass nach Gabe der total-mo die absolute Zellzahl der $\mathrm{CD} 16^{+}$-mo ggf. für die o. g. Beobachtungen nicht ausreichend ist im Vergleich zur isolierten Gabe dieser Zellen. Dies müsste in weiterführenden Untersuchungen geklärt werden.

Vergleicht man die histologischen Daten zur Arteriogenese der nicht-stimulierten Interventionsgruppen mit den histologischen Daten zur Arteriogenese der stimulierten Interventionsgruppen, zeigt sich hier für die total-mo und total-mo (s) und auch für die klassischen Monozyten (CD16-mo und CD16-mo [s]) ein ähnliches grafisches Bild mit dem Unterschied, dass die jeweils stimulierten Interventionsgruppen eine verminderte Ausprägung der Effekte zeigen (s. Kap. 3.4.2). Dies gilt vor allem für die Darstellung der Gesamtarteriolenzahl und die Arteriolenwanddicke. Beim Vergleich der Graphen in beiden histologischen Auswertungen der nicht-klassischen Monozyten $\left(\mathrm{CD} 16^{+}\right.$-mo und $\mathrm{CD} 16^{+}$mo [s]), ist dies nicht zu beobachten. Wie bereits oben dargestellt, zeigen vor allem CD16 ${ }^{+}$ mo durch ihre CD31-Expression ein hohes Potenzial für die Leukodiapedese. Entsprechend würde man in Erwartung einer Aktivierung durch Leptin, analog zu CACs (Heida et al. 2010), eine vermehrte Diapedese und o. g. Deutung folgend, eine noch dickere Arteriolenwand erwarten. Entsprechend sollte dann auch die Arteriolenzahl weiter vermindert sein. Entgegen den Erwartungen zeigt sich dies in den vorliegenden Ergebnissen nicht. Entsprechend wirkt, dieser Interpretation weiter folgend, in o. g. histologischen Untersuchungen die Stimulation mit Leptin eher abschwächend auf die Funktion der $\mathrm{CD}_{16}{ }^{+}$-mo. Ein Grund hierfür ist aus den in dieser Arbeit durchgeführten Untersuchungen nicht ersichtlich. 


\subsection{Humane Monozyten und ihre Auswirkung auf die Angiogenese}

Während sich die Applikation unstimulierter Monozytensubpopulationen nur auf die Arteriogenese auswirkte, waren nach Hinzugabe Leptin-stimulierter Monozytensubpopulationen lediglich Effekte bei der Angiogenese zu verzeichnen, ohne Einfluss auf die Arteriogenese zu nehmen. Sehr deutlich äußerte sich dies z. B. in der Verminderung der Gesamtkapillarzahl. Hierbei war der Unterschied zur Kontrollgruppe bei den CD16-mo (s) sehr stark ausgeprägt, zeigte jedoch die ausgeprägteste Verminderung nach Gabe der CD16 ${ }^{+}$-mo (s). Des Weiteren haben die Untersuchungen zur Querschnittsfläche pro Arteriole gezeigt, dass auch diese nach Gabe von $\mathrm{CD}_{16}{ }^{+}$-mo (s) signifikant verringert ist, vor allem in Gegenüberstellung zum Kollektiv der total-mo (s). Auch wenn hier keine direkten signifikanten Unterschiede zur Kontrollgruppe bestehen, so lässt sich trotz allem die Vermutung äußern, dass die zusätzliche Gabe Leptin-stimulierter CD16 ${ }^{+}$-mo entweder das weitere Vorhandensein einer größeren Anzahl von Kapillaren im Endstromgebiet nicht weiter nötig erscheinen lässt oder sogar in einem gewissen Maße zu einer Schädigung und nachfolgendem Untergang von Kapillaren führt, ohne die anderen umgebenden Strukturen histologisch oder weitestgehend funktionell zu beeinträchtigen. Ob sich dieser Effekt nur auf die Endstrombahn bezieht oder aber auch in durch Arteriolen vaskularisiertem Gebiet $\mathrm{zu}$ verzeichnen ist, wurde in vorliegender Arbeit nicht untersucht. Trotz allem ist hier unklar, warum bei annähernd gleicher Perfusion die Anzahl der Kapillaren stark abnimmt, obwohl die Anzahl, die muskuläre Querschittsfläche und auch die Gesamtfläche der Arteriolen keine Unterschiede aufweisen. Hierzu gibt die nähere Betrachtung der Leptinwirkung möglicherweise Aufschluss.

Die Wirkung von Leptin ist rezeptorvermittelt. Dieser ObR bewirkt insbesondere in Monozyten die Ausschüttung von TNF- $\alpha$ (Santos-Alvarez et al. 1999). Dem Zytokin TNF$\alpha$ wiederum kommt eine große Bedeutung im humanen Immunsystem zu. Es wirkt z. B. in neutrophilen Granulozyten migrationsfördernd und erhöht die Phagozytoseaktivität in Makrophagen. Weiterhin ist es unabkömmlich bei der Reparatur nach Endothelverletzung (Krasinski et al. 2001). Zusätzlich zeigten schon mehrere Arbeiten, dass TNF- $\alpha$ auch in der Angiogenese eine gewichtige Rolle zu Teil wird und diese durch TNF- $\alpha$ sogar stimuliert werden kann (Fajardo et al. 1992; Leibovich et al. 1987). Interessanterweise zeigten Fajardo et al. eine Abhängigkeit der Angiogenese von der TNF- $\alpha$-Konzentration, sodass diese bei niedriger TNF- $\alpha$-Konzentration stimuliert und bei entsprechend hoher Konzentration wiederum inhibiert wurde. Weitere Arbeiten deuteten jedoch daraufhin, dass das Ausmaß der Arteriogenese zum einen von der Art des jeweilig stimulierten TNF- $\alpha$-Rezeptors, zum anderen jedoch auch von dem Modus der TNF- $\alpha$-Ausschüttung abhängig ist (Sainson et al. 2008). Hier konnte z. B. gezeigt werden, dass die Proliferation von ECs durch eine pulsatile Ausschüttung von TNF- $\alpha$ angeregt wird und hierdurch Kapillaren im Angiogenese-Assay zur Aussprossung vorbereitet werden. Interessanterweise zeigte sich bei einer kontinuierlich hohen TNF- $\alpha$-Konzentration eher ein gegenteiliger Effekt. Die 
Konzentrationen des entstehenden TNF- $\alpha$ wurden in der vorliegenden Arbeit nicht gemessen, weshalb zu der Art der TNF- $\alpha$-Ausschüttung hier keine Stellung bezogen werden kann. Wie bereits in Kap. 1.3.2 beschrieben, sind $\mathrm{CD} 16^{+}$-mo eher durch eine Expression proinflammatorischer Zytokine wie TNF- $\alpha$ gekennzeichnet. Die Bildung von TNF- $\alpha$ kann durch eine hohe Leptinkonzentration induziert und dies somit vermehrt ausgeschüttet werden, was auf Zytokin- und auch mRNA-Ebene belegt werden konnte (Zarkesh-Esfahani et al. 2001). Die Ausschüttung von TNF- $\alpha$ ist hierbei jedoch linear abhängig von der Leptin-Konzentration und kann durch Hinzugabe von Lipopolysaccharid potenziert werden (Fernandez-Riejos et al. 2010; Sanchez-Margalet et al. 2003; SantosAlvarez et al. 1999). Die Messungen in vorliegender Arbeit (verminderte Gesamtkapillarzahl nach Gabe Leptin-stimulierter Monozytensubpopulationen, s. Kap. 3.4.1.1.2) können in vorliegender Konstellation möglicherweise eine in-vivo-Bestätigung der Aussage von Sainson et. al. aus dem Jahr 2008 sein, auch wenn hier die einmalige TNF- $\alpha$ Konzentrationserhöhung und somit die Funktionseinschränkung von ECs durch eine Erhöhung der Leptin-Konzentration hervorgerufen wurde.

Interessanterweise ist TNF- $\alpha$ nicht nur in der Angiogenese von großer Bedeutung, sondern spielt auch in der Arteriogenese eine wichtige Rolle (Hoefer et al. 2002). Hier waren ebenfalls in einem Hinterlaufischämiemodell bei TNF- $\alpha$-defizienten-, sowie auch TNF- $\alpha$ Rezeptor-defizienten-Mäusen eine verminderte Reperfusion und auch eine verminderte Ausbildung von Arteriolen im Vergleich zu Wildtyp- und Nackt-Mäusen detektiert worden. Folgt man an dieser Stelle der Aussage von Zawada et al., dass das angiogene Potenzial vor allem in den intermediären Monozyten beheimatet ist und dies hier vordringlich anhand der Überexpression von TNFAIP2 vermittelt wird (Zawada et al. 2011), so wäre bei isolierter Betrachtung der intermediären Monozyten eine vermehrte Reperfusion dieser Interventionsgruppe vor allem im distalen Hinterlauf zu erwarten. In entsprechenden histologischen Untersuchungen dieser Hinterläufe müsste jedoch in diesem Fall die absolute Kapillarzahl deutlich erhöht sein. Dies müsste jedoch in einer erneuten laborexperimentellen Untersuchung separat erforscht werden.

\subsection{Limitationen der Arbeit}

In vorliegender Arbeit wurde der Effekt humaner Monozyten und ihrer Subpopulationen auf die Gefäßneubildung in Mäusen untersucht. Eine entsprechende Immunantwort und somit Abstoßungsreaktion wurde durch die Verwendung von T-Zell-negativen Nacktmäusen verhindert. Dennoch ist die Annahme, dass humane Monozyten gegen murine Zytokine, die nach erfolgter Operation der Hinterlaufischämie ausgeschüttet wurden, ähnlich gut migrieren wie gegen humane Zytokine nicht eindeutig belegt. Verdeutlicht wird dies vor dem Hintergrund, dass ähnliche Experimente mit murinen Monozyten, welche in Mäuse transplantiert wurden, sehr eindeutige Ergebnisse bezüglich der Reperfusion und Angiogenese zeigten (Capoccia et al. 2008; Cochain et al. 2010). 
In vorliegendem Experiment wurden 1 $10^{6}$ Monozyten zusätzlich zu den endogenen Monozyten appliziert. Dies ist die Zahl an Monozyten, welche als Mindestmenge rekrutiert werden muss, um in einem ischämischen Gebiet Angiogenese zu induzieren (Capoccia et al. 2008; Capoccia et al. 2006). Viele vorhergehende Studien haben jedoch auch endogene Rekrutierungsorte (v. a. die Milz) für Monozyten beschrieben (Leuschner et al. 2012; Swirski et al. 2009), sodass hier bei einer Gesamtmenge von mindestens $10^{7}$ endogenen Monozyten ein Verhältnis von humanen zu murinen Monozyten von $<1: 10$ besteht. Selbst unter der Voraussetzung, dass in unserem Modell humane und murine Monozyten ein gleiches Migrationsverhalten gegenüber den ausgeschütteten Zytokinen zeigen, sind die Aussagen zur Angio- und Arteriogenese in vorliegenden Experimenten nur deutlich eingeschränkt mit der direkten Wirkung humaner Monozyten in der Ischämie in Beziehung zu setzen.

Die Leptinwirkung in vivo ist abhängig vom Gesamtkörperfettanteil des Menschen. Dies wurde in verschiedenen Fastenversuchen mit adipösen und schlanken Probanden untersucht (Sinha et al. 1996). Hier wurde herausgefunden, dass vor allem bei schlanken Personen Leptin zu $98 \%$ in gebundener Form an den löslichen Leptinrezeptor (sObR) vorliegt. Die Kopplung an den sObR verhindert z. B. ein Überschreiten von Leptin über die Blut-Hirn-Schranke, sodass hier die zentralnervösen Wirkungen (z. B. Vermittlung von Hungergefühl) nicht vermittelt werden können. In der Folge wird aber auch mit steigendem Körperfettanteil die Leptinkonzentration $\mathrm{zu}$ Gunsten des freien Leptins verschoben. Somit haben Übergewichtige und Adipöse grundsätzlich eine höhere freie Leptinkonzentration im Blut als schlanke Personen. Entsprechend sind auch in so einem Fall Monozyten höheren freien Leptinkonzentrationen ausgesetzt. Da Übergewicht und Adipositas vor allem in unserer Gesellschaft immer weiter verbreitet ist (Mitchell et al. 2011), ist die Rekrutierung von Probanden mit einem BMI $<23 \mathrm{~kg} / \mathrm{m}^{2}$ sehr langwierig und aufgrund technischer und zeitlicher Zusammenhänge nicht immer möglich. Entsprechend wurde hier auf Probanden mit einem BMI von 18,5 - $30 \mathrm{~kg} / \mathrm{m}^{2}$ zurückgegriffen (s. Kap. 2.3.1). Dies bedeutet natürlich gleichzeitig, dass die isolierten Zellen aus Probanden mit höherem BMI und somit auch höherem Körperfettanteil in vivo bereits einer erhöhten freien Leptinkonzentration ausgesetzt sind und hierdurch ggf. die physiologische Reaktion auf eine plötzlich erhöhte Leptinkonzentration verfälscht werden könnte.

Des Weiteren zeigten die hier vorliegenden durchflusszytometrischen Untersuchungen, dass die Expression des ObR auf den Monozytensubpopulationen sehr unterschiedlich ausgeprägt ist (CD16- mo 60\%; CD16 - mo 20\%; s. Kap. 3.2.2). Entsprechend sind die Monozyten in den Interventionsgruppen nach Leptinstimulation eher als heterogene Gruppe anzusehen, da das verabreichte Leptin natürlich nur auf die Monozyten wirken kann, welche auch den jeweiligen Rezeptor besitzen. Diesbezüglich sind o. g. Ergebnisse vor allem der Interventionsgruppen nach Leptinstimulation (insbesondere die Gruppe der CD16 ${ }^{+}$-mo [s]) bezüglich der Leptinwirkung entsprechend kritisch zu beurteilen. Gegebenenfalls können hier weitere Untersuchungen zur Expression und auch Funktion 
des ObR auf Monozyten zu einer differenzierteren Betrachtung der Leptinwirkung auf Monozyten und das angiogene Potenzial von Leptin beitragen.

Aufgrund technischer Limitierungen konnten im experimentellen Teil der vorliegenden Arbeit die intermediären und nicht-klassischen Monozyten nicht separat voneinander Untersucht werden. Hinsichtlich des angiogenen Potenzials vor allem der intermediären Monozyten (Zawada et al. 2011) sind die Ergebnisse zur angiogenen Potenz der in dieser Arbeit als CD16 ${ }^{+}$-bezeichneten Monozyten $\left(\mathrm{CD} 16^{+}\right.$-mo) mit eingeschränkter Aussagekraft zu sehen.

Die dargestellten Ergebnisse zeigen vor allem in den Untersuchungen zur Laser-DopplerMessung eine relativ große Schwankungsbreite. Eventuell hätte hier durch eine Vergrößerung der Interventionsgruppen $(n>10)$ eine größere Datenmenge generiert werden und so eventuell eine Verringerung des Einflusses endogener Störfaktoren wie Blutdruck der Tiere oder Umgebungswärme erreicht werden können. In einer ähnlichen Arbeit wurden so vor allem in Laser-Doppler-Messungen bei $n=14$ signifikante Ergebnisse nach Hinterlaufischämie und Gabe muriner Zellen erzielt (Lopez-Holgado et al. 2009). Des Weiteren würde hierdurch ein eventueller Einfluss anatomischer Varianten einzelner Tiere ebenfalls deutlich minimiert.

\subsection{Ausblick}

Die Ergebnisse der vorliegenden Untersuchungen zeigen, dass speziell die Gabe von CD16 ${ }^{+}$-mo die Arteriolenwand vergrößert, obwohl sich diese Untersuchungen nicht in einer Perfusionsverbesserung in der Laser-Doppler-Perfusionsmessung niederschlagen. Im Gegensatz hierzu weisen bereits durchgeführte in-vitro-Versuche darauf hin, dass vermutlich eher die Interaktion beider Monozytensubpopulation das maximale angiogenetische Potenzial entfalten. Dies zeigten u. a. auch außerhalb dieser Doktorarbeit durchgeführte, HUVECs-basierte Spheroid-Angiogenese-Assays, bei denen nach Hinzugabe eines mit total-mo, CD16-mo und CD16 ${ }^{+}$-mo konditionierten Mediums die Anzahl ausgebildeter endothelialer Sprouts ermittelt wurden (Czepluch et al. 2014). Ob nun tatsächlich das Zusammenspiel der unterschiedlichen Monozytensubpopulationen in der eingesetzten total-mo-Fraktion, oder doch die o. g. intermediäre Monozytensubpopulation für die genannten Effekte verantwortlich sind, bleibt Gegenstand fortwährender laborexperimenteller Untersuchungen. Zusätzlich sind natürlich die entsprechenden molekularbiologischen und biochemischen Mechanismen der Monozyten-induzierten Angio- und Arteriogenese aufzuschlüsseln. 


\section{Zusammenfassung}

Kardiovaskuläre Ereignisse sind die Haupttodesursache in der westlichen Welt. Monozyten und ihre Subpopulationen spielen dabei eine bedeutende Rolle für Regenerationsprozesse nach akuten ischämischen Ereignissen. In vorliegender Dissertationsschrift wurde der Zusammenhang humaner Monozyten und ihrer CD16 ${ }^{+}$- und CD16-Subpopulation auf die Entstehung neuer (Angiogenese) und Vergrößerung bereits vorhandener Blutgefäße (Arteriogenese) auf ischämische Zustände untersucht. Hierfür wurde ein bereits etabliertes murines Hinterlaufischämiemodell verwendet und den Mäusen am folgenden Tag zuvor isolierte humane Monozyten bzw. ihre Subpopulation intrakardial appliziert. Darauffolgend wurde die Reperfusion über 28 Tage beobachtet, nach der letzten Messung die Tiere getötet und ihre Hinterlaufmuskeln zur histologischen Untersuchung eingebettet. Hierbei wurden die Anzahl der Arteriolen und Kapillaren, die muskuläre und kapilläre Gesamtquerschnittsfläche, die Querschnittsfläche pro Arteriole sowie die Anzahl an Kapillaren pro Myofibrille mittels Immunfluoreszenz evaluiert. Da aus vorherigen Arbeiten bereits Daten vorliegen, dass das Proteohormon Leptin einen proangiogenen Effekt aufweist, wurde entsprechend die gleiche Versuchsreihe nochmals mit Monozyten durchgeführt, welche zuvor für $30 \mathrm{~min}$ mit Leptin stimuliert worden waren.

Die Reperfusionsanalysen mittels Laser-Dopplermessung ergaben keine signifikanten Unterschiede zwischen den verschieden Interventionsgruppen. Die Immunfluoreszenzanalysen zeigten in den Angiogeneseauswertungen überraschenderweise, dass die Gruppen der Leptin-stimulierten Subpopulationen einen negativen Effekt auf die Anzahl der Kapillaren haben ( $\mathrm{p}<0,05$ Kontrolle vs. CD16-mo [s]; p<0,01 Kontrolle vs. CD16 ${ }^{+}$ mo [s]). Auch die kapilläre Gesamtdurchschnittsfläche war hierdurch beeinflusst $(p<0,05$ Kontrolle vs. CD16 ${ }^{+}$-mo [s]). Die Arteriogeneseuntersuchungen hingegen zeigten nur einen Effekt bei unstimulierten Monozyten. Hier war vor allem die Anzahl der Arteriolen nach Gabe von CD16 ${ }^{+}$-mo signifikant erniedrigt ( $\mathrm{p}<0,01$ vs. Kontrollgruppe; $\mathrm{p}<0,001$ vs. CD16-mo). Entgegengesetzt hierzu war die muskuläre Querschnittsfläche in dieser Gruppe (kompensatorisch) deutlich vergrößert ( $\mathrm{p}<0,05$ vs. Kontrollgruppe), sodass hiermit ggf. das numerische Defizit ausgeglichen werden kann.

Die in vorliegender Arbeit angeführten Beobachtungen sind größtenteils in Einklang zu bringen mit etablierten Daten zur Arterio- und Angiogenese. Hierbei scheint die Funktion der $\mathrm{CD}_{16}{ }^{+}$-mo eine positive Auswirkung auf die Arteriogenese zu haben, wobei dieser Effekt durch eine Leptinstimulation nicht verstärkt werden kann. Die anderen untersuchten Monozyten und -subpopulationen haben keinen Effekt auf die Verbesserung der Arterio- und Angiogenese. Die zellulären Mechanismen, vor allem auch im Bereich der Monozytensubpopulationen, sollten hierbei weiter untersucht und wissenschaftlichen Studien zugeführt werden. 


\title{
6 Anhang
}

\author{
Abteilung Kardiologie und Pneumologie \\ Direktor: Professor Dr. med. Gerd Hasenfuß
}

Kardiologie u. Pneumologie · Robert-Koch-Str. $40 \cdot 37099$ Göttingen

Ansprechpartnerin:

Dr. med. Frauke Czepluch

Tel: 0551/39-12575

Fax: 0551/39-14131

Email: f.czepluch@med.uni-goettingen.de

www.herzzentrum-goettingen.de

\section{Aufklärungsbogen}

\author{
„Funktionelle Bedeutung humaner Monozytensubpopulation \\ für das Gefäßwachstum“" \\ (Untersuchung spezialisierter weißer Blutkörperchen, die am \\ Gefäßwachstum maßgeblich beteiligt sind)
}

Liebe Probandin, Lieber Proband,

wir möchten Sie einladen, freiwillig an einer wissenschaftlichen Studie der Abteilung Kardiologie und Pneumologie der Universitätsmedizin Göttingen teilzunehmen.

Wir führen eine klinisch-experimentelle Studie durch, bei der wir spezialisierte weiße Blutkörperchen untersuchen möchten, die maßgeblich an Umbauprozessen am Herz und an den Gefäßen beteiligt sind. Insbesondere sind wir hier an einer Untergruppe der weißen Blutkörperchen (Monozyten) interessiert. Im Rahmen der Studie möchten wir die Fähigkeit dieser Zellen untersuchen, am Gefäßwachstum mitzuwirken. Hierzu sollen mit den Zellen verschiedene Experimente durchgeführt werden, in denen die direkte und indirekte Beteiligung der Zellen am Gefäßwachstum analysiert wird. In dem dargelegten Forschungsprojekt erhoffen wir uns neue Erkenntnisse über die unterschiedliche Bedeutung von Monozytenuntergruppen für das Gefäßwachstum. Diese Erkenntnisse sollen uns helfen, die genaue Rolle der einzelnen Monozytenuntergruppen im HerzKreislauf-System besser zu verstehen.

Die Durchführung der Studie ist mit einem minimalen Aufwand für Sie verbunden. Im Rahmen Ihrer heutigen Blutspende werden für die Erstellung von Blutkonserven (Erythrozytenkonzentraten) und Frischplasmaprodukten weiße Blutkörperchen aus dem Blut herausgefiltert. Dieser Zellrest („Buffy Coat“) macht nur einen geringen Anteil lhrer Blutspende aus (ca. 10\% des Gesamtvolumens), ist ein Nebenprodukt und wird normalerweise nicht weiter verwendet. Im Rahmen dieser Studie sollen die Monozyten weiter isoliert werden. Die Fähigkeit der Monozyten, am Gefäßwachstum mitzuwirken, soll im Anschluss analysiert werden. Darüber hinaus möchten wir Sie bitten, einen Fragebogen auszufüllen. 
Bei einer Studienteilnahme entstehen für Sie keine zusätzlichen gesundheitlichen Risiken, da die Blutabnahme innerhalb der Blutspende erfolgt und nur die nicht benötigten Reste der Blutspende verwendet werden.

Sie haben das Recht, Ihre Teilnahme an der Studie jederzeit und ohne Angabe von Gründen zu widerrufen. Dies hat keine Auswirkungen auf Ihre jetzige und zukünftige Behandlung an der Universitätsmedizin Göttingen. Bei Widerruf der Studienteilnahme werden Ihre Blutproben vernichtet und Ihre Daten gelöscht werden.

Im Rahmen dieser Studie sollen Daten über Ihre Vorerkrankungen erhoben werden. Die erfassten Daten werden pseudonymisiert. Pseudonymisierung bedeutet Verschlüsselung von Daten/Proben ohne Namensnennung, d. h. nur mit Nummern codiert. Die Zuordnung der Daten oder Proben zu einer Person ist nur möglich, wenn hierfür der Schlüssel eingesetzt wird, mit dem die Daten pseudonymisiert wurden. Die personenbezogenen Daten/Proben werden unter besonderen Schutzvorkehrungen getrennt von den pseudonymisierten Daten aufbewahrt. Eine Entschlüsselung ist nur durch die verantwortlichen Studienärzte möglich. Dritte erhalten keinen Einblick in die Originalunterlagen. Die Speicherung der Daten erfolgt auf unbestimmte Zeit. Die Daten werden nicht an Dritte weitergegeben und Sie haben die Möglichkeit, die Löschung Ihrer Daten zu verlangen.

Die Behandlung und Diagnose vorliegender Erkrankungen wird durch die Teilnahme an der Studie nicht beeinflusst. Für die an der Studie teilnehmenden Probanden besteht kein Risiko und auch kein unmittelbarer Nutzen.

Mit herzlichem Dank.

Dr. Frauke Czepluch

Projektleiterin/Prüfärztin 


\author{
Abteilung Kardiologie und Pneumologie \\ Direktor: Professor Dr. med. Gerd Hasenfuß \\ Kardiologie u. Pneumologie $\cdot$ Robert-Koch-Str. $40 \cdot 37099$ Göttingen \\ Ansprechpartnerin: \\ Dr. med. Frauke Czepluch \\ Tel: $0551 / 39-12575$ \\ Fax: 0551/39-14131 \\ Email: f.czepluch@med.uni-goettingen.de \\ www.herzzentrum-goettingen.de
}

\title{
Einwilligungserklärung
}

\section{„Funktionelle Bedeutung humaner Monozytensubpopulation für das Gefäßwachstum“}

Ich, wurde von meinem Arzt/Ärztin

über Wesen, Bedeutung und Tragweite der Studie mit dem o.g. Titel aufgeklärt. Ich habe den Aufklärungstext gelesen und verstanden. Ich hatte die Möglichkeit, Fragen zu stellen, und habe die Antworten verstanden und akzeptiere sie. Mir sind die Risiken, die mir durch Studienteilnahme entstehen, bewusst. Die Behandlung und Diagnose vorliegender Erkrankungen wird durch die Teilnahme an der Studie nicht beeinflusst.

Ich hatte ausreichend Zeit, mich zur Teilnahme an dieser Studie zu entscheiden und weiß, dass die Teilnahme an dieser Studie freiwillig ist. Ich weiß, dass ich jederzeit und ohne Angaben von Gründen diese Zustimmung widerrufen kann, ohne dass sich dieser Entschluss nachteilig auf die spätere Behandlung durch meinen Arzt auswirken wird.

Mir ist bekannt, dass meine persönlichen Daten in verschlüsselter Form (pseudonymisiert, mit Codenummer, die nicht der Person zuzuordnen ist) gespeichert werden. Mit meinem Einverständnis zur Teilnahme an der Studie erkläre ich gleichzeitig, dass ich mit der im Rahmen dieser Studie erfolgenden Datenerhebung, pseudonymisierten Datennutzung und Speicherung einverstanden bin.

Ich habe eine Kopie der Probandeninformation und dieser Einwilligungserklärung erhalten. Ich erkläre hiermit meine freiwillige Teilnahme an dieser Studie.

Ort und Datum

Unterschrift des/r Proband/in

Ort und Datum

Unterschrift des/r aufklärenden Arztes/Ärztin 


\section{Fragebogen}

Pseudonymierungscode: (wird vom Arzt ausgefüllt)

\section{Bitte ankreuzen:}

Rauchen Sie aktuell ? Ja

Nein $\square$

Leiden Sie aktuell an einer Erkältung/Infekt? Ja $\square \quad$ Nein

Leiden Sie an einer Allergie oder Autoimmunerkrankung? Ja

Nein

Wenn ja, welche ?

Leiden Sie an einer rheumatischen Erkrankung?

Ja $\square \quad$ Nein

Wenn ja, welche ?

Leiden Sie an einer Tumorerkrankung? Ja $\square \quad$ Nein

Wenn ja, welche?

Hatten Sie schon einmal einen Herzinfarkt/Schlaganfall Ja $\square$

Nein $\square$

Haben Sie hohen Blutdruck oder werden deshalb behandelt?.Ja $\square$

Nein $\square$

Leiden Sie an der Blutzuckerkrankheit (Diabetes mellitus)?...Ja $\quad \square$

Nein

Welche Medikamente nehmen Sie regelmäßig ein (bitte auch Anti-Babypille und Kopfschmerztabletten angeben)? 


\section{Literaturverzeichnis}

Allen SJ, Crown SE Handel TM (2007): "Chemokine: receptor structure, interactions, and antagonism." Annu Rev Immunol 25: 787-820.

Alshaker H, Sacco K, Alfraidi A, Muhammad A, Winkler M Pchejetski D (2015): "Leptin signalling, obesity and prostate cancer: molecular and clinical perspective on the old dilemma." Oncotarget $\underline{6}(34):$ 35556-35563.

Ancuta P, Rao R, Moses A, Mehle A, Shaw SK, Luscinskas FW Gabuzda D (2003): "Fractalkine preferentially mediates arrest and migration of CD16+ monocytes." J Exp Med 197(12): 1701-1707.

Ancuta P, Liu KY, Misra V, Wacleche VS, Gosselin A, Zhou X Gabuzda D (2009): "Transcriptional profiling reveals developmental relationship and distinct biological functions of CD16+ and CD16- monocyte subsets." BMC Genomics 10: 403.

Arras M, Ito WD, Scholz D, Winkler B, Schaper J Schaper W (1998): "Monocyte activation in angiogenesis and collateral growth in the rabbit hindlimb." J Clin Invest 101(1): 40-50.

Barton WA, Tzvetkova D Nikolov DB (2005): "Structure of the angiopoietin-2 receptor binding domain and identification of surfaces involved in Tie2 recognition." Structure 13(5): 825-832.

Baumann H, Morella KK, White DW, Dembski M, Bailon PS, Kim H, Lai CF Tartaglia LA (1996): "The full-length leptin receptor has signaling capabilities of interleukin 6-type cytokine receptors." Proc Natl Acad Sci U S A 933(16): 8374-8378.

Belge KU, Dayyani F, Horelt A, Siedlar M, Frankenberger M, Frankenberger B, Espevik T Ziegler-Heitbrock L (2002): "The proinflammatory CD14+CD16+DR++ monocytes are a major source of TNF." J Immunol 168(7): 3536-3542.

Bergmann CE, Hoefer IE, Meder B, Roth H, van Royen N, Breit SM, Jost MM, Aharinejad S, Hartmann S Buschmann IR (2006): "Arteriogenesis depends on circulating monocytes and macrophage accumulation and is severely depressed in op/op mice."

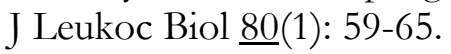

Bouloumie A, Drexler HC, Lafontan M Busse R (1998): "Leptin, the product of Ob gene, promotes angiogenesis." Circ Res $\underline{83}(10):$ 1059-1066.

Capoccia BJ, Shepherd RM Link DC (2006): "G-CSF and AMD3100 mobilize monocytes into the blood that stimulate angiogenesis in vivo through a paracrine mechanism." Blood 108(7): 2438-2445.

Capoccia BJ, Gregory AD Link DC (2008): "Recruitment of the inflammatory subset of monocytes to sites of ischemia induces angiogenesis in a monocyte chemoattractant protein-1-dependent fashion." J Leukoc Biol 84(3): 760-768.

Chen LC, Chen CC, Liang Y, Tsang NM, Chang YS Hsueh C (2011): "A novel role for TNFAIP2: its correlation with invasion and metastasis in nasopharyngeal carcinoma." Mod Pathol 24(2): 175-184.

Cochain C, Rodero MP, Vilar J, Recalde A, Richart AL, Loinard C, Zouggari Y, Guerin C, Duriez M, Combadiere B, et al. (2010): "Regulation of monocyte subset systemic levels by distinct chemokine receptors controls post-ischaemic neovascularization." Cardiovasc Res 88(1): 186-195. 
Cowan DB Langille BL (1996): "Cellular and molecular biology of vascular remodeling." Curr Opin Lipidol Z(2): 94-100.

Czepluch FS Waltenberger J (2006): "Monocyte responsiveness towards different arteriogenic stimuli: a functional comparison of various chemoattractants and their combinations." Thromb Haemost $\underline{96}(6):$ 857-858.

Czepluch FS, Bergler A Waltenberger J (2007): "Hypercholesterolaemia impairs monocyte function in CAD patients." J Intern Med 261(2): 201-204.

Czepluch FS, Olieslagers S, van Hulten R, Voo SA Waltenberger J (2011): "VEGF-Ainduced chemotaxis of CD16+ monocytes is decreased secondary to lower VEGFR1 expression." Atherosclerosis 215(2): 331-338.

Czepluch FS, Bernhardt M, Kuschicke H, Gogiraju R, Schroeter MR, Riggert J, Hasenfuss G Schäfer K (2014): "In vitro and in vivo effects of human monocytes and their subsets on new vessel formation." Microcirculation 21(2): 148-158.

De Palma M, Venneri MA, Galli R, Sergi Sergi L, Politi LS, Sampaolesi M Naldini L (2005): "Tie2 identifies a hematopoietic lineage of proangiogenic monocytes required for tumor vessel formation and a mesenchymal population of pericyte progenitors." Cancer Cell $\underline{8}(3):$ 211-226.

Deutsche Herzstiftung e. V. [Hrsg.] (2015). Deutscher Herzbericht 2014. Frankfurt am Main.

Djonov V Makanya AN (2005). New insights into intussusceptive angiogenesis. Exs: 17-33.

Epelman S, Liu PP Mann DL (2015): "Role of innate and adaptive immune mechanisms in cardiac injury and repair." Nat Rev Immunol 15(2): 117-129.

Fajardo LF, Kwan HH, Kowalski J, Prionas SD Allison AC (1992): "Dual role of tumor necrosis factor-alpha in angiogenesis." Am J Pathol 140(3): 539-544.

Favre J, Terborg N Horrevoets AJ (2013): "The diverse identity of angiogenic monocytes." Eur J Clin Invest 43(1): 100-107.

Felcht M, Luck R, Schering A, Seidel P, Srivastava K, Hu J, Bartol A, Kienast Y, Vettel C, Loos EK, et al. (2012): "Angiopoietin-2 differentially regulates angiogenesis through TIE2 and integrin signaling." J Clin Invest 122(6): 1991-2005.

Fernandez-Riejos P, Najib S, Santos-Alvarez J, Martin-Romero C, Perez-Perez A, GonzalezYanes C Sanchez-Margalet V (2010): "Role of leptin in the activation of immune cells." Mediators Inflamm 2010: 568343.

Ferrara N (1995): "The role of vascular endothelial growth factor in pathological angiogenesis." Breast Cancer Res Treat $\underline{36}(2): 127-137$.

Galie PA, Nguyen DH, Choi CK, Cohen DM, Janmey PA Chen CS (2014): "Fluid shear stress threshold regulates angiogenic sprouting." Proc Natl Acad Sci U S A 111(22): 7968-7973.

Ge H, Huang L, Pourbahrami T Li C (2002): "Generation of soluble leptin receptor by ectodomain shedding of membrane-spanning receptors in vitro and in vivo." J Biol Chem 277(48): 45898-45903.

Geissmann F, Jung S Littman DR (2003): "Blood monocytes consist of two principal subsets with distinct migratory properties." Immunity $\underline{19}$ (1): 71-82.

Geissmann F, Manz MG, Jung S, Sieweke MH, Merad M Ley K (2010): "Development of monocytes, macrophages, and dendritic cells." Science 327(5966): 656-661. 
Gordon S Taylor PR (2005): "Monocyte and macrophage heterogeneity." Nat Rev Immunol 5(12): 953-964.

Gößwald A, Schienkiewitz A, Nowossadeck E Busch MA (2013): "Prävalenz von Herzinfarkt und koronarer Herzkrankheit bei Erwachsenen im Alter von 40 bis 79 Jahren in Deutschland: Ergebnisse der Studie zur Gesundheit Erwachsener in Deutschland (DEGS1)." Bundesgesundheitsblatt Gesundheitsforschung Gesundheitsschutz 므(5-6): 650-655.

Grage-Griebenow E, Flad HD Ernst M (2001a): "Heterogeneity of human peripheral blood

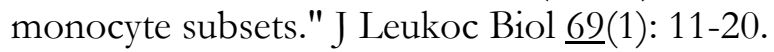

Grage-Griebenow E, Zawatzky R, Kahlert H, Brade L, Flad H Ernst M (2001b): "Identification of a novel dendritic cell-like subset of CD64(+) / CD16(+) blood monocytes." Eur J Immunol 31(1): 48-56.

Hanahan D (1997): "Signaling vascular morphogenesis and maintenance." Science 277(5322): 48-50.

Heida NM, Leifheit-Nestler M, Schroeter MR, Müller JP, Cheng IF, Henkel S, Limbourg A, Limbourg FP, Alves F, Quigley JP, et al. (2010): "Leptin enhances the potency of circulating angiogenic cells via src kinase and integrin (alpha)vbeta5: implications for angiogenesis in human obesity." Arterioscler Thromb Vasc Biol 30(2): 200-206.

Hoefer IE, van Royen N, Rectenwald JE, Bray EJ, Abouhamze Z, Moldawer LL, Voskuil M, Piek JJ, Buschmann IR Ozaki CK (2002): "Direct evidence for tumor necrosis factoralpha signaling in arteriogenesis." Circulation 105(14): 1639-1641.

https://www.perimed-instruments.com/de/Laser-Doppler-Imaging (2016).

Hudlicka O, Brown M Egginton S (1992): "Angiogenesis in skeletal and cardiac muscle." Physiol Rev 72(2): 369-417.

Krasinski K, Spyridopoulos I, Kearney M Losordo DW (2001): "In vivo blockade of tumor necrosis factor-alpha accelerates functional endothelial recovery after balloon angioplasty." Circulation 104(15): 1754-1756.

Kuch B, Heier M, von Scheidt W, Kling B, Hoermann A Meisinger C (2008): "20-year trends in clinical characteristics, therapy and short-term prognosis in acute myocardial infarction according to presenting electrocardiogram: the MONICA/KORA AMI Registry (1985-2004)." J Intern Med 264(3): 254-264.

Leach M, Drummond M Doig A (2013). Practical Flow Cytometry in Haematology Diagnosis. Oxford, John Wiley \& Sons.

Leibovich SJ, Polverini PJ, Shepard HM, Wiseman DM, Shively V Nuseir N (1987): "Macrophage-induced angiogenesis is mediated by tumour necrosis factor-alpha." Nature 329(6140): 630-632.

Leuschner F, Rauch PJ, Ueno T, Gorbatov R, Marinelli B, Lee WW, Dutta P, Wei Y, Robbins C, Iwamoto Y, et al. (2012): "Rapid monocyte kinetics in acute myocardial infarction are sustained by extramedullary monocytopoiesis." J Exp Med 209(1): 123-137.

Li MD (2011): "Leptin and beyond: an odyssey to the central control of body weight." Yale J Biol Med 84(1): 1-7.

Lim SS, Vos T, Flaxman AD, Danaei G, Shibuya K, Adair-Rohani H, Amann M, Anderson HR, Andrews KG, Aryee M, et al. (2013): "A comparative risk assessment of burden of disease and injury attributable to 67 risk factors and risk factor clusters in 21 
regions, 1990-2010: a systematic analysis for the Global Burden of Disease Study 2010." Lancet 380(9859): 2224-2260.

Limbourg A, Korff T, Napp LC, Schaper W, Drexler H Limbourg FP (2009): "Evaluation of postnatal arteriogenesis and angiogenesis in a mouse model of hind-limb ischemia." Nat Protoc 4(12): 1737-1746.

Lopez-Holgado N, Alberca M, Sanchez-Guijo FM, Villaron EM, Rivas JV, Lopez-Novoa JM, Brinon JG, Arevalo MA, Oterino E, Santamaria C, et al. (2009): "Prospective comparative analysis of the angiogenic capacity of monocytes and CD133+ cells in a murine model of hind limb ischemia." Cytotherapy 11(8): 1041-1051.

Löwel H (2006): "koronare Herzkrankheit und akuter Myokardinfarkt." Gesundheitsberichterstattung des Bundes (Heft 33).

Löwel H, Meisinger C, Heier M Hormann A (2005): "The population-based acute myocardial infarction (AMI) registry of the MONICA/KORA study region of Augsburg." Gesundheitswesen 67 Suppl 1: S31-37.

Macey MG (2007). Flow cytometry. Principles and applications. Totowa, Humana Press.

Makanya AN, Hlushchuk R Djonov VG (2009): "Intussusceptive angiogenesis and its role in vascular morphogenesis, patterning, and remodeling." Angiogenesis 12(2): 113123.

Metivier F, Marchais SJ, Guerin AP, Pannier B London GM (2000): "Pathophysiology of anaemia: focus on the heart and blood vessels." Nephrol Dial Transplant 15 Suppl 3: $14-18$.

Mitchell NS, Catenacci VA, Wyatt HR Hill JO (2011): "Obesity: overview of an epidemic." Psychiatr Clin North Am 34(4): 717-732.

Mukherjee R, Kanti Barman P, Kumar Thatoi P, Tripathy R, Kumar Das B Ravindran B (2015): "Non-Classical monocytes display inflammatory features: Validation in Sepsis and Systemic Lupus Erythematous." Sci Rep ㅁ: 13886.

Muller WA, Weigl SA, Deng X Phillips DM (1993): "PECAM-1 is required for transendothelial migration of leukocytes." J Exp Med 178(2): 449-460.

Myers MG, Jr. (2004): "Leptin receptor signaling and the regulation of mammalian physiology." Recent Prog Horm Res 59: 287-304.

Nahrendorf M, Pittet MJ Swirski FK (2010): "Monocytes: protagonists of infarct inflammation and repair after myocardial infarction." Circulation 121(22): 2437-2445.

Nahrendorf M, Swirski FK, Aikawa E, Stangenberg L, Wurdinger T, Figueiredo JL, Libby P, Weissleder R Pittet MJ (2007): "The healing myocardium sequentially mobilizes two monocyte subsets with divergent and complementary functions." J Exp Med 204(12): 3037-3047.

Palframan RT, Jung S, Cheng G, Weninger W, Luo Y, Dorf M, Littman DR, Rollins BJ, Zweerink H, Rot A, et al. (2001): "Inflammatory chemokine transport and presentation in HEV: a remote control mechanism for monocyte recruitment to lymph nodes in inflamed tissues." J Exp Med 194(9): 1361-1373.

Passlick B, Flieger D Ziegler-Heitbrock HW (1989): "Identification and characterization of a novel monocyte subpopulation in human peripheral blood." Blood 74(7): 25272534. 
Rhodes NP, Hunt JA Williams DF (1997): "Macrophage subpopulation differentiation by stimulation with biomaterials." J Biomed Mater Res 37(4): 481-488.

Risau W (1997): "Mechanisms of angiogenesis." Nature 386(6626): 671-674.

Robert-Koch-Institut [Hrsg.] (2014). Koronare Herzerkrankung. Faktenblatt zu GEDA 2012: Ergebnisse der Studie "Gesundheit in Deutschland aktuell 2012". Gesundheitsberichterstattung des Bundes. RKI, Berlin, Robert-Koch-Intitut. [zu sehen unter:

https://www.rki.de/DE/Content/Gesundheitsmonitoring/Gesundheitsberichterst attung/GBEDownloadsF/Geda2012/koronare herzerkrankung.pdf? blob=publi cationFile ]: 1-4.

Sainson RC, Johnston DA, Chu HC, Holderfield MT, Nakatsu MN, Crampton SP, Davis J, Conn E Hughes CC (2008): "TNF primes endothelial cells for angiogenic sprouting by inducing a tip cell phenotype." Blood 111(10): 4997-5007.

Sanchez-Margalet V, Martin-Romero C, Santos-Alvarez J, Goberna R, Najib S GonzalezYanes C (2003): "Role of leptin as an immunomodulator of blood mononuclear cells: mechanisms of action." Clin Exp Immunol 133(1): 11-19.

Santos-Alvarez J, Goberna R Sanchez-Margalet V (1999): "Human leptin stimulates proliferation and activation of human circulating monocytes." Cell Immunol 194(1): 6-11.

Schaper W Buschmann I (1999): "Arteriogenesis, the good and bad of it." Cardiovasc Res 43(4): 835-837.

Serbina NV, Jia T, Hohl TM Pamer EG (2008): "Monocyte-mediated defense against microbial pathogens." Annu Rev Immunol 26: 421-452.

Shyy YJ, Hsieh HJ, Usami S Chien S (1994): "Fluid shear stress induces a biphasic response of human monocyte chemotactic protein 1 gene expression in vascular endothelium." Proc Natl Acad Sci U S A 91(11): 4678-4682.

Sierra-Honigmann MR, Nath AK, Murakami C, Garcia-Cardena G, Papapetropoulos A, Sessa WC, Madge LA, Schechner JS, Schwabb MB, Polverini PJ, et al. (1998): "Biological action of leptin as an angiogenic factor." Science 281(5383): 1683-1686.

Sinha MK, Opentanova I, Ohannesian JP, Kolaczynski JW, Heiman ML, Hale J, Becker GW, Bowsher RR, Stephens TW Caro JF (1996): "Evidence of free and bound leptin in human circulation. Studies in lean and obese subjects and during short-term fasting." J Clin Invest 98(6): 1277-1282.

Stadler N, Eggermann J, Voo S, Kranz A Waltenberger J (2007): "Smoking-induced monocyte dysfunction is reversed by vitamin C supplementation in vivo." Arterioscler Thromb Vasc Biol 27(1): 120-126.

Statistisches Bundesamt (2014). Todesursachen in Deutschland 2013. Fachserie 12, Reihe 4. Wiesbaden.

Suganami E, Takagi H, Ohashi H, Suzuma K, Suzuma I, Oh H, Watanabe D, Ojima T, Suganami T, Fujio Y, et al. (2004): "Leptin stimulates ischemia-induced retinal neovascularization: possible role of vascular endothelial growth factor expressed in

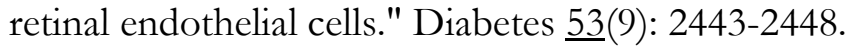

Swirski FK, Nahrendorf M, Etzrodt M, Wildgruber M, Cortez-Retamozo V, Panizzi P, Figueiredo JL, Kohler RH, Chudnovskiy A, Waterman P, et al. (2009): "Identification of splenic reservoir monocytes and their deployment to inflammatory sites." Science 325(5940): 612-616. 
Tartaglia LA (1997): "The leptin receptor." J Biol Chem 272(10): 6093-6096.

Tartaglia LA, Dembski M, Weng X, Deng N, Culpepper J, Devos R, Richards GJ, Campfield LA, Clark FT, Deeds J, et al. (1995): "Identification and expression cloning of a leptin receptor, OB-R." Cell 83 (7): 1263-1271.

Thurston G (2003): "Role of Angiopoietins and Tie receptor tyrosine kinases in angiogenesis and lymphangiogenesis." Cell Tissue Res 314(1): 61-68.

Van Rooijen N (1989): "The liposome-mediated macrophage 'suicide' technique." J Immunol Methods 124(1): 1-6.

Van Rooijen N Sanders A (1994): "Liposome mediated depletion of macrophages: mechanism of action, preparation of liposomes and applications." J Immunol Methods 174(1-2): 83-93.

Venneri MA, De Palma M, Ponzoni M, Pucci F, Scielzo C, Zonari E, Mazzieri R, Doglioni C Naldini L (2007): "Identification of proangiogenic TIE2-expressing monocytes (TEMs) in human peripheral blood and cancer." Blood 109(12): 5276-5285.

Waltenberger J, Lange J Kranz A (2000): "Vascular endothelial growth factor-A-induced chemotaxis of monocytes is attenuated in patients with diabetes mellitus: A potential predictor for the individual capacity to develop collaterals." Circulation 102(2): 185190.

Weber C, Belge KU, von Hundelshausen P, Draude G, Steppich B, Mack M, Frankenberger M, Weber KS Ziegler-Heitbrock HW (2000): "Differential chemokine receptor expression and function in human monocyte subpopulations." J Leukoc Biol 67(5): 699-704.

Wiesner G, Grimm J Bittner E (2002): "Vorausberechnung des Herzinfarktgeschehens in Deutschland." Bundesgesundheitsblatt Gesundheitsforschung Gesundheitsschutz 45(5): 438-445.

Zarkesh-Esfahani H, Pockley G, Metcalfe RA, Bidlingmaier M, Wu Z, Ajami A, Weetman AP, Strasburger CJ Ross RJ (2001): "High-dose leptin activates human leukocytes via receptor expression on monocytes." J Immunol 167(8): 4593-4599.

Zawada AM, Rogacev KS, Rotter B, Winter P, Marell RR, Fliser D Heine GH (2011): "SuperSAGE evidence for CD14++CD16+ monocytes as a third monocyte subset." Blood 118(12): e50-61.

Zhang Y, Proenca R, Maffei M, Barone M, Leopold L Friedman JM (1994): "Positional cloning of the mouse obese gene and its human homologue." Nature 372(6505): 425432.

Ziegler-Heitbrock L Hofer TP (2013): "Toward a refined definition of monocyte subsets." Front Immunol 4: 23.

Ziegler-Heitbrock L, Ancuta P, Crowe S, Dalod M, Grau V, Hart DN, Leenen PJ, Liu YJ, MacPherson G, Randolph GJ, et al. (2010): "Nomenclature of monocytes and dendritic cells in blood." Blood 116(16): e74-80. 


\section{Danksagung}

Zuallererst geht mein Dank natürlich an Frau PD Dr. med. Frauke S. Czepluch für die Bereitstellung des Themas und das gemeinschaftliche Durchführen vieler Versuche. Sie hat in ihrer Funktion als Doktormutter die Grundlage für die Bearbeitung wissenschaftlicher Fragestellungen gelegt und mich durchgehend bis zur Fertigstellung der Dissertationsschrift unterstützt.

Nachfolgend gebührt ein besonderes Dankeschön Frau Prof. Dr. med. Katrin Schäfer, in deren Arbeitsgruppe ich meine ersten laborexperimentellen Schritte vollziehen durfte und die mir fachlich und methodisch, insbesondere beim Erlernen der OP-Methode jederzeit helfend zur Seite stand. Des Weiteren wurde mir durch sie erstmalig die Möglichkeit gegeben, einem internationalen wissenschaftlichen Kongress beizuwohnen.

Weiterhin bedanken möchte ich mich bei Herrn Univ. - Prof. Dr. med. Gerd Hasenfuß, Direktor der Klinik für Kardiologie und Pneumologie der UMG sowie Vorsitzender des Herzforschungzentrums Göttingen, dass ich in seiner Klinik meine Dissertation anfertigen und die Hilfe der Mitarbeiterinnen und Mitarbeiter in Anspruch nehmen durfte.

Ein herzliches Dankeschön gilt auch unseren beiden MTAs Sarah Barke und Anika Hunold, die auch nach der Einarbeitung in die Methodik und experimentelle Arbeit immer ein „wachsames Auge“ und vor allem sehr gute Anregungen, sowie so manchen Trick und Kniff bereitstellten, mit dem ein Versuch letztlich doch funktioniert hat.

Des Weiteren gilt mein Dank meinen Mitstreitern, Frau Dr. med. Magdalena Beham, Herrn Dr. med. Hendrik Kuschicke und Herrn Dr. med. Sebastian Herzberg, die dauerhaft für ein sehr gutes zwischenmenschliches Klima in unserem Labor gesorgt und damit so manch wissenschaftlichen Misserfolg aufgefangen haben.

Zuletzt sei auch all meinen Freunden, insbesondere ist hier Herr Dr. rer. pol. Markus Plewa zu nennen, der durch seine Hilfe im Rahmen der statistischen Auswertung wesentlich zum Erfolg der Arbeit beigetragen hat. 